\title{
Reflections on design decisions of practical significance to embankment dams
}

\author{
V. F. B. DE MELLO*
}

Design decisions, implying action despite uncertainty, may face exponential risks in dam engineering and must therefore be sorted out into two categories: those controlled by the statistics of extreme-value conditions, and those amenable to treatment under statistics and probabilities of averages. Absolute priority belongs to the first group, and it is emphasized that any computations connected with them are delusions. The designer must run away from the problem by 'choice of change of statistical universe'. Important examples are full interceptor filter-drainage inclined into upstream zone, stereometric hindrance seepage filtering, and use of a grout buffer to homogenize a zone of foundations exhibiting extreme dispersions of pervious discontinuities. Within statistics of averages an optimized embankment design is proposed based on flow nets; the advantages of an internal impervious blanket are shown. The behaviour of compacted embankment materials is accepted (as demonstrated in a companion paper) as evidencing prestressing; routine stability analyses are reappraised to permit significant economies and improved probabilistic factors of safety $F$; instrumentation is associated with Bayes' theorem to quantify the observational method. Finally, it is postulated that embankment dam engineering must begin to develop Satisfaction Indices with respect to average behaviour, in substitution for intangible $F$ values with respect to catastrophe.
Les décisions concernant un projet impliquent une action en dépit d'une incertitude. En matière de barrages, elles peuvent comporter des risques exponentiels et de ce fait, doivent être classées en deux catégories: celles qui se réfèrent à des statistiques relatives à des conditions extrêmes, et celles justiciables d'un traitement par statistiques et probabilités relatives à des moyennes. Une priorité absolue doit être donnée à la première catégorie mais il est souligné que tout calcul dans ce domaine est dépourvu de signification réaliste: le concepteur doit lui tourner le dos en cherchant à résoudre le problème par un choix d'univers physique tel que le phénomène soit exclus. Des exemples importants sont fournis par l'emploi d'un filtre d'interception incliné dans la recharge amont, par l'entrave stéréométrique exercé par le filtre à la migration des grains, et par l'utilisation d'un bouchon d'injection pour rendre homogène une fondation rocheuse présentant des variations crratiques et extrêmes dans la perméabilité. Dans l'optique de statistiques relatives à des moyennes, une conception optimisée de section de digue est proposée en partant des réseaux de lignes d'écoulement; on décrit les avantages d'un tapis imperméable interne; le comportement des matériaux compactés est accepté (comme cela est montré dans un autre article) avec des évidences de précontrainte; les calculs classiques de stabilité font l'objet d'un examen critique en vue de rechercher des économies substantielles et d'aboutir à de meilleurs facteurs de sécurité probabilistiques $F$; l'emploi d'instrumentation doit profiter du théorème de Bayes en vue d'aboutir à la quantification de la méthode observationelle. Enfin, il est souhaitable que dans les barrages l'ingénieur s'efforce de développer, pour les diverses solutions, des Indices de Satisfaction concernant les conditions moyennes de comportement, au lieu de valeurs $F$ intangibles qui se rapporteraient à des cas de ruptures.

I need hardly say how honoured I am, and how grateful to the British Geotechnical Society, for having been invited to deliver the Seventeenth Rankine Lecture. The really formidable contributors to geomechanics who have hitherto occupied the position that is presently mine to fill, have established and expanded such an aura of honour and responsibility connected with the task, that I cannot but submit, with diffidence, the question: 'what could I possibly offer to the profession, through this outstanding geotechnical society to which the world owes this prestigious initiative, besides an immeasurable stream of contributions and advances?'

\footnotetext{
* Private consultant in soil mechanics.
} 
For a person whose professional call may be described as specializing in being a practising generalist of soil engineering, the initial hurdle was to settle on a subject. I felt it might be the wish of this house to hear of engineering preoccupations that deeply affect the developing areas of the world. As an engineer representing a young region requiring every technological advance for rapid development, my message could only be connected with the importance of engineering work of first-order approximations in initial decisions, most significant both in safety and in economy.

Moreover, the investments at stake and at risk in dam building are so vast, that $I$ felt compelled to use this opportunity to catalyse contributions from audience and readers, of direct importance to the very efforts in embankment dam design on which I herewith bring my proposals. I bring not theories and proofs, but reflections; and, in many instances, I bring not cold facts, but intuitions and estimates, in earnest search for idea fertility.

Within such a context I resolved to tackle the subject entitled 'Reflections on design decisions of practical significance to embankment dams', obviously within predominantly Brazilian experience.

\section{ENGINEERING PERSPECTIVE}

Field and laboratory testing ability in geomechanics has advanced very fast and far in the past twenty years. Computational ability yet faster and farther. Field instrumentation and observations have been developed and refined very considerably. The overwhelming trend has simultaneously been of concentration of the ablest talents in the analytical walks of engineering science. Finally, as if in apologetic shying away from the seductive illusions of determinism, considerable and very laudable effort has come to be devoted to statistics and probability in civil and geotechnical engineering. Thereupon, the question that arises, and is especially acute in developing regions, is: "has there been a compatible comprehension of fundamental engineering design principles, that could profit of such advances towards economic optimization of design? What basic guidelines can be formulated to permit relying on such advances for modifying precedent with due comprehension and with eagerness for economy without increased risks?'

Is the refinement in the analysis of specific problems, taken as predetermined within a preconceived structure, the dominant activity of engineering advance?

Lambe (1973) has emphasized that prediction is the very heart of the practice of civil engineering, and that one must not only predict, but make decisions and take actions on the basis of the prediction. I have tended to emphasize a different order of priorities. Engineering involves action based on decision despite uncertainty. Prediction is one necessary vehicle for adequate decision; but, most often an engineer's capacity at predicting is disparately poor regarding what will happen, and quite competent, in comparison, at predicting what will not happen; in other words, we inherently know that there are upper and lower bounds, and that we may place ourselves beyond such bounds. Moreover, the intuitive ability to estimate parameters for prediction is frequently much poorer in connection with newly formulated 'component, or analytical' parameters of a given phenomenon than in connection with the complex lumped parameter closer to the phenomenon itself, with which the survival (and therefore reasonable) intuitions of Animal and Man have been distilled from age-old experience; for instance, one may have a much better feel for whether or not a slope appears stable, than for the cohesion parameter that might justify such stability. As civil engineers, and especially geotechnical engineers, we cannot presume to simplify our problem, but must needs simplify the solution; which frequently comprises resorting to upper or lower bounds, even if for lumped parameters only roughly estimated. 
As a young boy I read a Roman historical legend with which many of you may be familiar and that must have made a deep impression on me, since a few months ago, more than forty years later, it suddenly came to mind at an impromptu lecture. During the war between Rome and Alba Longa in the seventh century $\mathrm{BC}$ in the reign of Tullus Hostilius, it was agreed by the two cities that had been in constant warring, that the settlement of the dispute would be decided on the outcome of combat between two sets of triplet brothers, the Horatii for Rome, and the Curiatii for Alba. In contest two of the Horatii were quickly killed; but the third, feigning flight, cnticed the Curiatii into pursuing him and managed to slay his wounded pursuers, one by one. The legend suddenly struck me as outlining remarkably well some fundamental principles of engineering. Firstly, one cannot fail to note the decision to obviate or minimize the waste of warring. Secondly, the lesson that if one does have to depend on extreme value statistics (dependence on triplet heroes) notwithstanding the serious consequence to the cumulative fate, one should attempt to forecast not only the 'first passage probability' but also the possible trend toward stabilization or progressive degeneration of the consequent outcome. Finally, it is in the third hero of the Horatii that we find the real engineer. Rather than face frontally the uneven odds of the statistical universe of direct combat where the problem lay, he chose to feign running away from the problem; thereby the problem was subdivided into components that were individually tackled with ease. Engineering is, indeed, the artful decision to avoid a problem, to run away from a statistical universe of unequal odds, of decomposing the problem into parts against which the odds of solution are really so immeasurably more favourable, that 'full guarantee' of outcome may well be claimed.

Engineering design and construction, implying the call for determinism within statistical variability, and embodying the inexorable discontinuity of yes-no decision within the continuum of reality, is founded on the ability to make a decision often transcending that of decision theory as such, because of the ability to act deterministically on the built structure in such a way as to make it the overriding conditioner. In short, it includes as the principal aid, prior to the specialized knowledges for treatment of a particular statistical universe, the wisdom of choice of a change of universe for a solution, based on the freedom to place oneself safely outside the less favourable universe under analysis and estimation. I take the liberty to repeat (de Mello, 1975c) 'Good design is not yet cornered, from position of affluence of ingenious (i.e. engineering) ideas, into being better calculation or better estimation of intangible risks'.

\section{CONCEPTUAL IMPLICATIONS OF STATISTICS AND PROBABILITY WITHIN DAM ENGINEERING}

The uncertainties in embankment dam design (Bird, 1961) and the role of so-called 'calculated risks' (Casagrande, 1965) in such works have been repeatedly stressed in the qualitative terms that always precede attempts at quantification. The inevitable association of such concepts of uncertainties and risks and decision, with statistics (representation of the small sample of data and events that have happened as a part of the respective universe of hypothetical amply multiplied repetitions of similar cases) and probabilities (estimation and inference, on universes that are imagined to prevail, of response to random phenomena or even to stochastic chains) and decision theory, has led to rapidly multiplied applications of such theories to quantifying risks, probabilities of failure as substitutes for factors of safety, and probable consequences of hypothetical ruin in terms of the respective computational tools. It is indispensable to examine briefly some important concepts at play behind the lure of the

\footnotetext{
${ }^{1}$ As used in Monte Carlo methods.
} 
success that unquestionable numbers always seem to imply. Within the engineering obligation to action despite uncertainty, what action principles can we recommend for the required ccrtainty on embankment dams, while we await the confirmation of the use of the theories on uncertainty?

In order to propose the design principles in terms of conceptual statistics, for more fruitful interplay between engineers and statisticians, one must begin by emphasizing the difference between statistics of averages and statistics of extreme values. Settlement of an embankment is dependent on the cumulative effect of a very large number of soil elements, and is therefore an obvious condition of applicability of averages. On the other hand, the failure of a chain in tension, at its extreme weakest section, is the classic example of the need for extreme value theory: in dams the problems of piping, and of tensile cracking, can be reasoned to be dependent on extreme value statistics and probability. So many are the problems thwarting satisfactory engineering application of extreme value theorization, as can be quickly recognized, that the most fundamental principle of humility in civil engineering design is as follows.

As a first step, use every possible means to avoid having to deal with conditions determined by the statistics and probabilities of extreme values (DP1). Such a recommendation may sound strange and even absurd, firstly because the engineer has been led to believe in successful application of extreme value theorization, and secondly because it may seem that if a phenomenon pertains to extreme value conditions, an engineer could hardly help facing it. Neither position is definitive. In particular, an engineering structure may often be engineered to exclude a phenomenon: arching a bridge is sufficient to exclude tensions; prestressing concrete is a search in the same direction; such 'total' changes of conditions destined to serve the same function, constitute what I refer to as a 'choice of change of statistical universe'.

As regards the successful theoretical application of extreme value theorization, prior to the mathematical problems one must recognize at least two conceptual problems. Firstly it must be recalled that the natural phenomena and observations connected with extreme values are ipso facto rare and difficult to confirm or deny, and are inexorably viewed through the subjcctive conditionings of some temporal theorization. Secondly, one is dependent on a predetermination of how small a sample to consider as yet significant, but random and independent; for instance, in extreme hydrological intensities, is it maximum daily (total, therefore average), or maximum hourly (and so on ... .) precipitations that must be considered? Moreover, as regards a conceptual dilemma faced at the solution end of the engineering problem, one must question: since the severest extreme value event is ever in the offing, to what extent is it sound engineering to prepare defence for a rare extreme event whose laws of recurrence (and of possible change of laws while awaiting recurrence) we do not understand, while inexorably burdening present society with heavily increased costs? Hydrological computations may be used for an example, since we are conditioned to accept that within that field civil engineering is well enough served by extreme value statistics. Upon closer analysis we realize that even the hydrologist (although favoured with yearly events of the extreme population) has beaten a retreat, in considerable frustration, because of repeated catastrophic events he was unable to predict or fend against; hydrometeorological conditions have recognizedly changed with time in most basins, but, principally, our appreciation of random and non-random intervening factors has continually changed. Thus a significant change of engineering attitude was introduced, which appears to be a shameful retreat: in the words of Benjamin (1974), the engineers 'have a PMP, probable maximum precipitation, a PMF, probable maximum flood, maximum credible events and the like. Upon investigation, however, we find there are no probabilities in these events, only certainties'. The conceptual fallacy is coupled with unfortunate engineering: the inexorable consequences of increased costs of spillway works are 
STANDARD DEVIATIONS

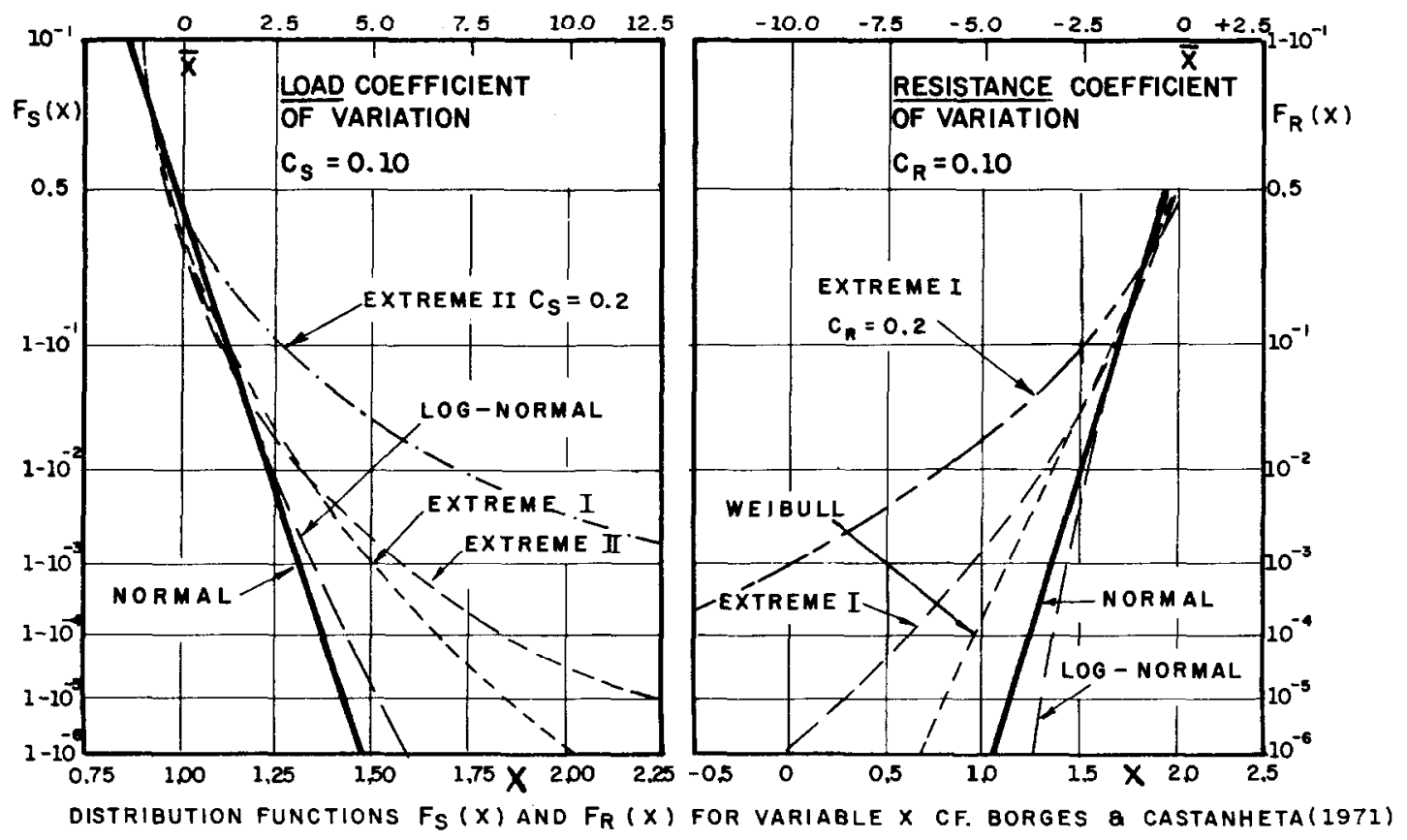

Fig. 1. Indication on great variations of computed probabilities at low risks depending on type of extreme-value distribution assumed

already a heavy burden on new dam projects, not to mention the catastrophically increased costs to downstream developments if the gates are indeed operated to release the once-never flood.

Thus, while retaining the case of hydrology as an example, as regards a feared helplessness of the engineer in obviating the risk of the extreme flood, we may point to two obvious engineering design measures: one by forcing the extreme phenomenon to average itself out automatically, and the other, by incorporating an appropriate physical change of statistical universe. Thus, one important design consideration has consistently been the reservoir floodrouting ability, with increased freeboards and surcharge as necessary; spillway adequacy should be judged with regard to the ratio of volumes of surcharge against anticipated flood. Moreover, the really ingenious and humble solution of physical defence against incalculable probabilities is to design a fuseplug spillway of minimal first cost, deferring the higher costs of the event of low probability to accompanying the event itself.

In embankment dams one cannot fail to notice that the phenomenon of piping is typically dominated by extreme value statistics, since at the exit of the seepage path (wrongly but necessarily assumed average) it is the least stable particle subjected to the most unfavourable point gradient that will be picked off first. Hydraulic engineering provides us with the neat demonstration of the engineering solutions for an analogous phenomenon, which is cavitation. Much effort was wasted on attempting to develop surfaces smoother and more resistant to erosion; the statistical universe of predicting how, when and where, erosion and cavitation would start, was inevitably fraught with frustrations. Not so, however, the prediction of when 
erosion and cavitation would not occur: one very successful step was the change of geometry of surfaces so as to guarantee positive pressures; the next step, recognizing in humility the (present) unpredictability of local pulsating negative pressures, was to supply copious aeration, changing to a different statistical universe, engineered to immeasurably greater probabilities of success. As will be further discussed in a later section, the appropriate geometry of filter-intercepts, and the resort to simplest principles of stereometric hindrance of erodible particles by void sizes of well-graded filter material are, for protection against piping failure, the two component analogies to the 'total' solution of the cavitation problem.

Although I must beg leave to exclude from present consideration the problems associated with seismic risks, it may be noted that the scientific approach has been intensely pursued of attempting to investigate the extreme value conditions under which fully saturated specimens may suddenly liquefy; meanwhile in the light of my fundamental proposition regarding extreme value conditions, a more appropriate engineering endeavour might profitably assess the advantages of driving compaction and drainage piles of crushed rock into the sandy subsoils or of injecting (and occasionally reinjecting) air into them (to flee from the problem of full saturation and pore-fluid incompressibility).

The starting problem faced in the mathematical formulation of an extreme-value case lies in the fact that a very ample number of pertinent observations would be necessary, to insinuate what the appropriate probability distribution function (PDF) might be, and such an insinuation must then be satisfactorily abstracted into the necessary mathematical formulation for extrapolation to the extreme, and checked for goodness of fit with random sets of data. Fig. 1 shows some often-quoted distributions, including for comparison those that govern data around averages (e.g. normal or Gaussian, and lognormal), and is intended to remind emphatically that at the desirable extremes of very small risk the computed probabilities vary by several orders of magnitude depending on the type of distribution assumed (Ang and Cornell, 1974). It should serve to expose how fallacious to engineering conclusions are the frequent probabilistic formulations wherein the author is forced to begin by assuming a certain extremevalue PDF. In many cases, extreme quantities and phenomena documented with sufficient data preferences have indeed been demonstrably established for one (e.g. Type I for high winds, traffic peaks, etc.) or another (e.g. Type III, or Weibull, for fatigue failure, consumer product failure, etc.) classical PDF.

Thus, on the one hand one must emphasize the need for data, and of adequate statistical digestion thereof (Lieblein, 1974); and on the other hand, wherever possible, one must devise adequate testing programmes for truly checking theories. For instance, Pretorius (1972), by analysing size effects on brittle unconfined compression failure of hundreds of rock specimens, proved that the assumed independence of links of the Weibull weakest link theory is not valid, and proposes the weakness correlation theory for a much better explanation of the dependence detected, even while admonishing 'further experiments are required to determine if this will be sufficient to account for the size effect in rock strength testing' (specimen size effects (de Mello, 1959; Parry, 1972; Chandler and Skempton, 1974)).

Recapitulating, therefore, in connection with dam and geotechnical engineering, catastrophic extreme-value situations must be avoided a priori because of the honestly precarious data, and the inability to collect test data for formulation of PDFs. What test programme might contribute towards formulation of the appropriate PDF on extreme earthquakes or on catastrophic failures of dams towards downstream? Thus it will be understood that one should accept as a prior, sine qua non design principle (DP 1, Fig. $2^{2}$ ) the concept of exclusion of extreme

${ }^{2}$ For an explanation of Fig. 2 see the Appendix. 


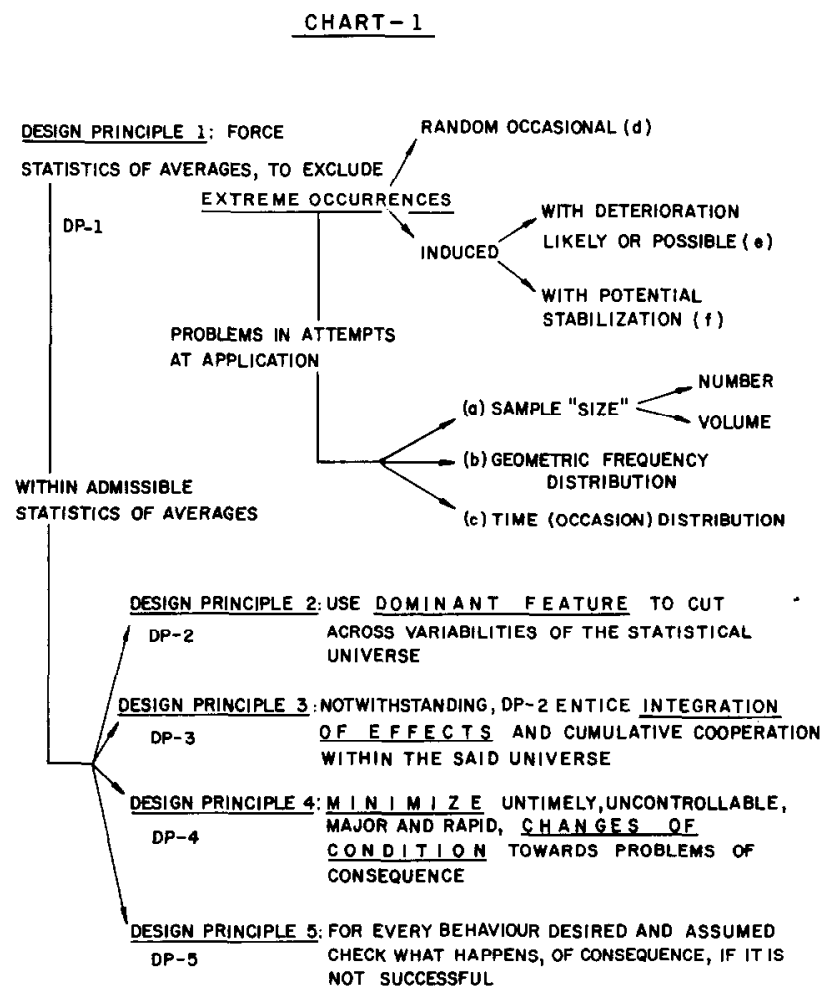

Fig. 2. Recommended checklist of design principles

value conditions by choice of change of universe, as expatiated above: only subsequently does one acquire the right to optimizations and computations within the confines of the statistics of averages. For such subsequent steps, the additional conceptual design principles 2, 3, 4 and 5 are proposed as summarized forthwith, and the designer is reminded that since design is decision, and decision is conditioned by desire (de Mello, 1975a), for prudence it is indispensable to use such suggestions as a quick checklist, much as a pilot is bound to run through his checklist on every instrument before take-off.

Design principle 2 (DP 2) may be explained by means of several common examples: the basic thought is to use a dominant overriding conditioner, so as to make the engineering behaviour essentially independent of the statistical variabilities possible. If a subsoil presents questionable conditions for footing foundations, one employs piles to cut across the 'soil pressure bulb' of concern. Rather than delve into refinements of comparing risks of failures of two alternate footing foundations, if the stakes are high, the engineering solution will be to use piling to cut across the universe of uncertainty of the upper strata: nevertheless, enginecring science is to be lauded for developing methods of analysing comparatively the two alternative footing cases. In the same light strong preference is given to a chimney filter-drainage interceptor over the full height of the dam superstructure not only for the physical exclusion of piping (extreme-value) under DP 1, but also for subsequent optimizations according to DP 2 . A cut-off (as complete as possible) across pervious foundations should be similarly viewed, as should also a blanket or trench-drainage feature for control of uplift downstream. 
Design principle 3 (DP 3) recommends not despising the cumulative contributions of the dominated universe, which is a principle of prudence, homogenization, and economy: in the case of piling, preference for pile types that foster frictional resistance, even if principal reliance is on point resistance-variabilities of pile lengths and bearing capacities will be attenuated: in the case of pervious foundations, lengthening the seepage path to the utmost, as long as it does not interfere with another factor that may become conditioning and more important. Preference for a single well-graded filter transition in comparison with a succession of uniform filters may be viewed in a similar light. Finally, in a sense, compaction should be recognized as an engineering measure ably 'invented' to homogenize and to pretest within certain limits of effectiveness.

Design principle 4 (DP 4) incorporates the well-recognized concepts of preloading or prestressing and of the observational method (Peck, 1969) as important design considerations. Quite naturally one finds the proportion of failures increasing significantly as the ratio of incremental to existing stress increases, and as the time rates of such changes become higher; moreover, the final rate of development of the failure, and the consequences thereof, are much more serious when the loading is a so-called soft load (remains practically unchanged, or even aggravates, as deformations accentuate) in comparison with a hard load (readjusts downwards due to the very deformations generated). Thus a very useful design expedient favours as high a prestressing as necessary, under slow controlled conditions, to stresses to be reached under future uncontrolled critical conditions. For instance, if reservoir filling is anticipated to be rapid and poorly controlled ${ }^{3}$ and as the principal agent of instability is pore pressure, it is advantageous to permit development of construction period pore pressures to high levels, equivalent to prestressing. Pore pressure loading due to a full reservoir is a serious soft loading in comparison with construction period or rapid drawdown pore pressures.

Design principle 5(DP 5) finally reminds engineers that most frequently it is on the adequacy of the hypotheses, and not on refinements of computations, that the safety and satisfactory performance of a dam are critically dependent. Every design decision and, especially, every design computation, presupposes some functional hypotheses: as soon as one has made the presumed routine (average) hypothesis, one must consider how the desired behaviour would change if the parameters were to vary about the average as much as they are statistically wont to, or even as much as they might under conditions of very low probability.

What happens to the assumed flow net and to pore pressures, if the filter-drainage system proves insufficient or clogs? What can be done to the foundation treatment if a grout 'curtain' proves insufficiently impervious? What stress-strain indications must be feared if shear deformations develop higher than expected? For every behaviour desired and assumed, that may possibly be widely different within proven statistical variablity, is there an automatic solution 'built-in', or is there an open door to complementary measures of design-as-you-go, if instrumented observations are useful, and there is adequate time and control of events?

Although such concepts appear intuitive it has been felt necessary to emphasize them because 'experienced' dam engineers (the ones who usually impose the physical model and choice of universe) may be unfavourably affected by subjective interpretations of 'precedent' while the younger geotechnicians and statisticians may be led to disproportionate enthusiasm with computational refinements though centred on poorly engineered models. The fact is that despite an extensive literature survey, no references were located specifically covering the necessary points of caution. One first looks at typical dam cross-sections used over the past

\footnotetext{
${ }^{3}$ Examples of common causes include: no bottom outlet, ungated spillway and with sill close to maximum reservoir level, filling during rainy season, etc.
} 
30 years, and these will show that, historically, precedent is automatically associated with geometric similitude, and symmetry, which is quite comprehensible because of the importance of visual perceptions in the acquisition of experience.

Figure 3 exemplifies the fact that a very important typical cross-section, repeatedly used for dams of widely different heights, has essentially adopted and retained geometric similitude and symmetry. Incidentally, the geotechnicians who express great concern over transverse settlements for a dam cross-section on soil foundations at abutments, generally fail to appreciate how very many of the data are available on major settlements which have been satisfactorily experienced by the upper parts of dams on their own underlying section. However, needless to emphasize, no geotechnical behaviour is linear and obviously as the height increases, the trends of conditioning behaviour change appreciably. More important, however, is the aberration of symmetry. One simple look at a dam, with water impounded, should be sufficient to shock one into realizing that there cannot be anything symmetrical. Further, as dam heights have been increased and the river valleys downstream have been increasingly developed, one moment of thought to the risk values at stake in a downstream (DS) full reservoir failure in comparison with upstream (US) rapid drawdown failure, should serve to show that the cases are absolutely disproportionate; therefore it cannot possibly be a question of comparing a hypothetical $F$ of 1.2 to US, as against an $F$ of 1.5 to DS. The DS failure must be made virtually impossible, in the same way as it is impossible to fail an arched span in tension. The US and DS zones of a dam are different and complementary notwithstanding the growth through a phase of infancy of undifferentiated apparent behaviour that could generate confusions of similarity and symmetry.

In closure of these introductory remarks it is emphasized that many different practices of design cross-section, and of construction, have been successful in survival of individual cases. What might be concluded therefrom, through presumed statistics, depends on the eyes of the viewer. We must accept that optimization should definitely favour some trends in comparison with others. Some solutions may be reasoned to contain within them the seed of significantly higher likelihood of failure, and yet may have been guarded from such an extreme event by variabilities within probability (or by God's infinite bounty). One wants to survive best in the most economical manner. One wants to survive despite risk of considerable difference of conditions from case to case.

\section{DESIGN DECISION OF TOP PRIORITY: EMBANKMENT DRAINAGE FEATURE AGAINST CATASTROPHIC RISKS TO DOWNSTREAM}

Considering the risks involved, the extent of time during which there is exposition to such risks, the appurtenant conditions of lack of control of the main agent of failure, and the uninvestigated changes of properties and behaviour of soils with time, it is obvious that the most fundamental design feature on which decision between alternates must be optimized is the system of internal drainage for control of the seepage forces generated by a full reservoir.

It would be beyond the scope of any paper to cover any reasonable proportion of the combinations of problems that may arise in the design of a given dam. This is particularly so as regards foundation conditions. Therefore foundation problems (although recognized to be often the principal conditioner in embankment engineering) will not be broached except with regard to exemplifying important principles on upper and lower bounds. It is contended that first-order choices of fundamental importance may be found vindicated on the basis of even the simplest physical models it is possible to visualize, while subsequent refinements dictated by more 'realistic' physico-mathematical models may prove to introduce no more than secondorder revisions in the earlier basic decisions. More knowledgeable readers will therefore bear 


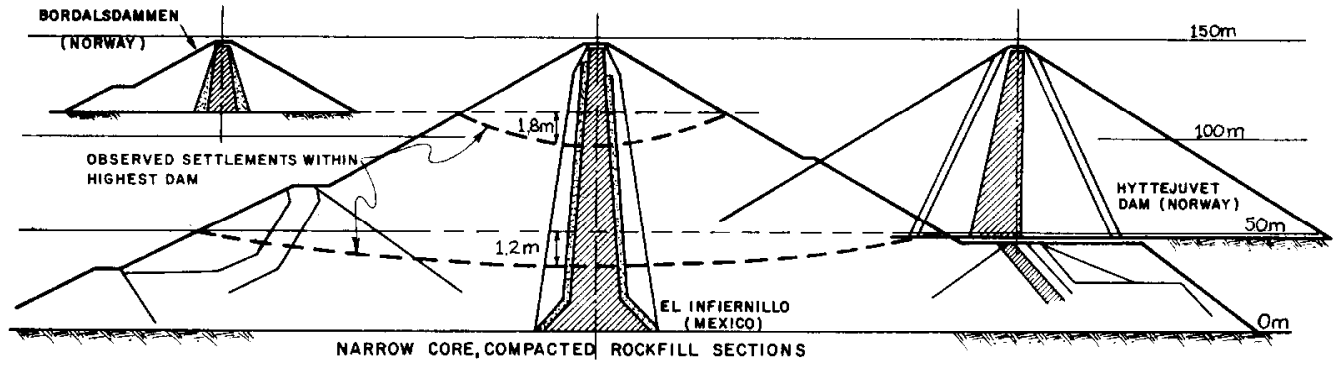

Fig. 3. Geometric similitude and symmetry prevalent in presumed precedents

with the intentional presentation starting with grossly simplified models. In fact, if the conclusions appear all too obvious, it is hoped that the obvious question be raised: how is it that so very many dams continue to be designed under definitely less favourable cross-sections, merely because similar previous cases were probabilistically spared the intervention of an extreme value condition and its inexorable consequences?

\section{Interceptor drainage and flow nets}

Firstly, it must be recognized that ever since the use of flow nets was authoritatively proposed (Casagrande, 1937) and became the widespread basis for the design of dams, it has been ipso facto assumed that the conditions of statistics of averages prevail; that is, it must be accepted that extreme value conditions had been previously excluded from the designed prototype. ${ }^{4}$ Thus before beginning to discuss comparative flow nets, one must make a cross-examination to determine the extent to which DP 1 has been satisfied in excluding extreme value conditions.

An extensive literature survey firstly failed to reveal any publications dedicated to the above mentioned prior problem of design choice of physical model (Reinius, 1961 ; Patel et al. 1964) and, secondly, would indicate no distinction between prior concern on extreme value problems of risks and consequences, and subsequent attention to optimizations amenable to computations.

Problems of flow across the dam due to full reservoir are those of mass instability generated by seepage pressures and seepage flows, both pertaining to integrated effects and averages; collaterally there are the erosive actions of piping. If a piping phenomenon belongs to the statistics of extremes and has to be excluded (by stereometric hindrance filtration, such as will be discussed in a later section, obviously it is not by a flow net and consequent interpretation that it is handled. It is indispensable to intercept any possible flow path by the filter-drainage (DP 1): It is conceptually inadmissible to accept modern designs that do not have 'full' interceptor drainage simultaneously satisfying DP 1 and DP 2.

Figure 4 summarizes conceptually the historical evolution connected with the filter-drainage feature, and attempts to emphasize that, as far as 'evolutions' have inherently relied on average information (flow nets, flows, frequency of non-unsuccessful cases, etc.) by the appropriate use of inappropriate theorization we run statistically increased risks of surprising and catastrophic failures in cases 1, 2 and 3, which do not have the interceptor chimney filter-drain. In cases

\footnotetext{
${ }^{4}$ It is interesting to note, in this connection, that much of the discussion between Lane (1935) and Casagrande really implied the simultaneous use of two distinct languages: Lane was tackling intuitively an extreme value condition of discontinuity, whereas the flow net could pertain only to the homogeneous continuum as an averaged condition, even if the altered boundary condition of the discontinuity were introduced in its extreme-value hypothesis.
} 
4 and 5 it is necessary to optimize within the upstream zone and foundation, in which the statistical universe of the presumed flow net lies, in accordance with DP 3, 4 and 5; however, the optimization must be with absolute priority to the risks of failure under extreme hypotheses towards downstream.

The improvement from case 1 to case 2 comprises the historically comprehensible insertion of the toe drain, or short exit blanket drain, at the point of the usual first failure symptom of

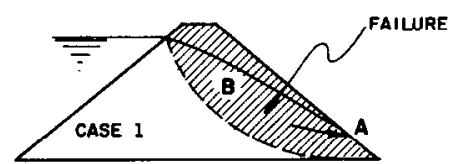

REPEATED FAILURES

EXIT A (EXTREME)

MASS B (AVERAGE)

VERY INFREOUENT

FAILURES ;

EXITS A (EXTREME)
AVERAGE

CONCLUSION

1) FLATTER DS SLOPE... LITTLE IMPROVEMENT.

2) TOE ANO BLANKET FILTER-DRAIN OF CASE 2.

FAILURES STILL BLAMED ON "UNuSUac" CONOITIONS. COMPARE CONCEPTUALLY WITH SPILWWAY DESIGN FOR AVERAGE FLOOD.

(a) CONCEPTUAL - HISTORICAL IMPROVEMENT OF CONTROL OF PORE PRESSURE CONDITIONS
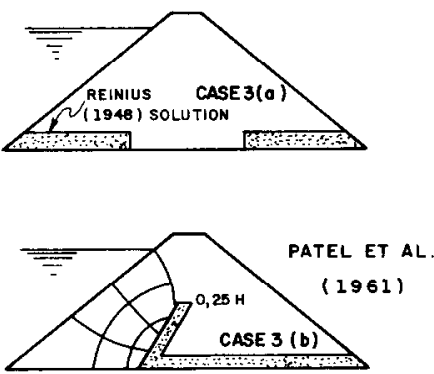

\section{OPTIMIZE FOR}

US SLOPE UNDER

RAPID DRAWDOWN

ROD, OF MUCH

LESSER

IMPORTANCE .
CONCEPTUALLY

UNACCEPTABLE

INCREASE OF

DS RISKS

COMPARED

WITH

CASE 2 .

(b) OVER-CONFIOENCE IN FLOWNETS AND DISPAOPORTIONATE ATTENTION TO US STABILITY.
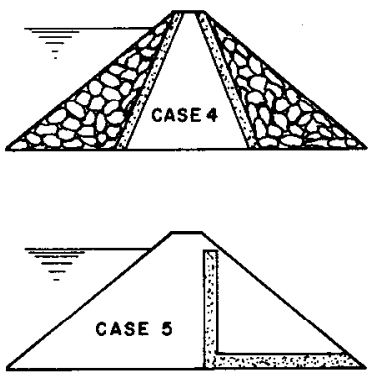

(c) ACCEPTABLE BASES FOR OPTIMIZATIONS

ONLY CASES 4 AND 5 VALID. STRONGLY REQUIRE OPTIMIZATIONS, INCLUDING FOUNDATION HYPOTHESES (PRINCIPALLY ON HIGHLY INDETERMINATE AND SIGNIFICANT SEEPAGE CONDITIONS).
VALID FOR OPTIMIZATIONS UNDER DP-2,3,4,5.

REQUIRES OPTIMIZATION AVOIDING VERTICAL ELEMENT AND NEAR SYMMETRY AS IN CASE 4.

Fig. 4. Conceptual discussion of design evolution for control of pore pressures 

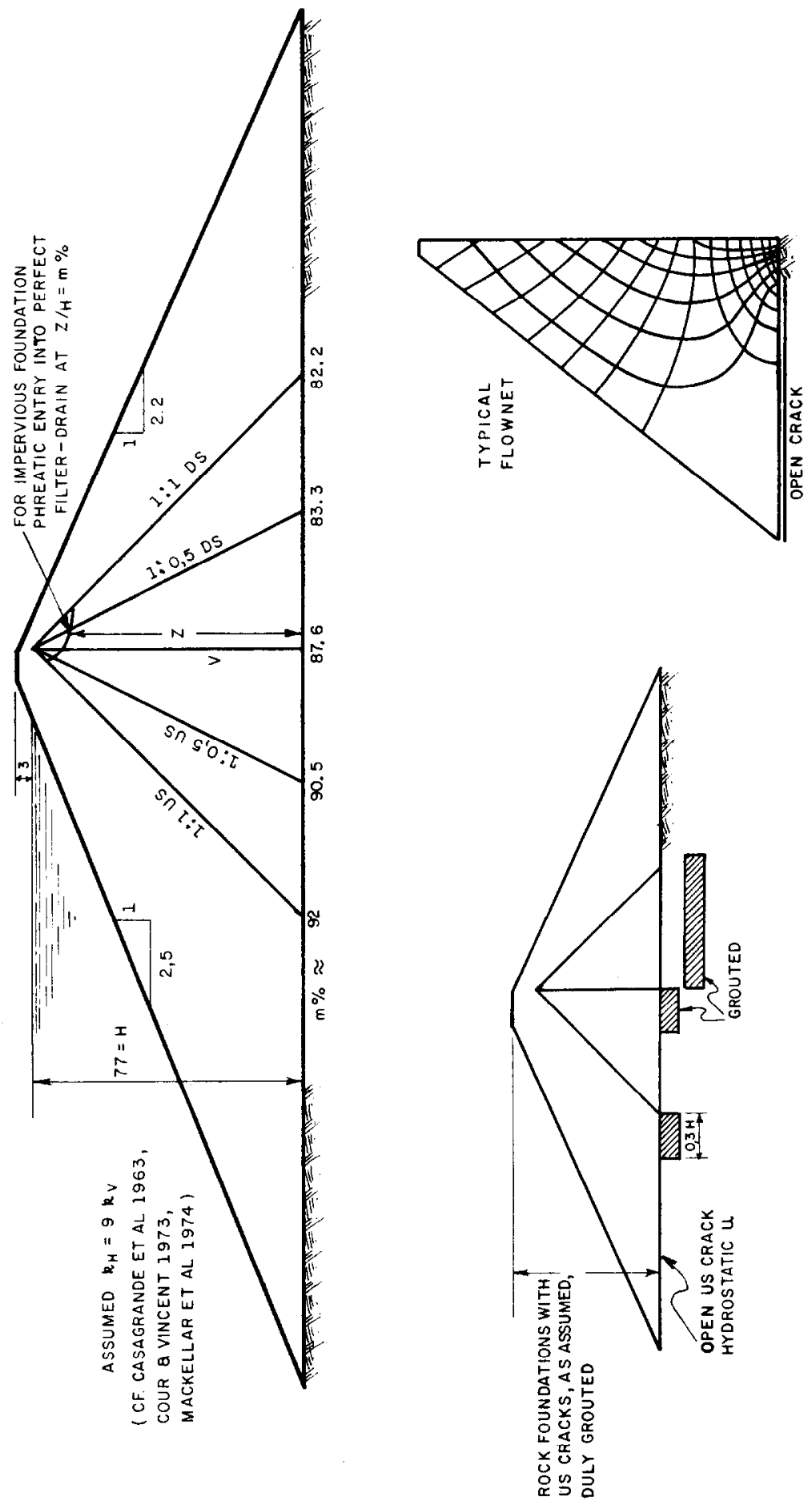

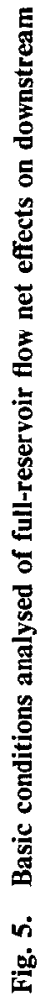


case 1 , achieving very visible success by depressing the condition $\mathrm{A}$ of case 1 . The theorization that followed, be it the classic Kozeny solution, or the many adaptations thereof to exit conditions to distant (short) inclined drains (Casagrande, 1937), are all fundamentally unacceptable, because they do not satisfy DP 1, and are a fortiori dangerous because of the created impression of a satisfactory theoretical solution (Dixon, 1967). The extreme condition of piping at exit A of case 2 is not a freak condition, but a typical extreme condition of the possible universe which the design must consider from the start. The conceptual error of blaming such infrequent failures on unusual and extraneous factors is analogous to designing a spillway for average floods and blaming occasional inexorable failures under extreme events to extraneous causes.

Case $3 \mathrm{a}$ incorporates an interesting solution (Reinius, 1948) towards imitating at the US base a drainage condition similar to case 4 for favouring the respective stability under rapid drawdown (RDD); but under DP 1 it is as unacceptable as case 2 and even more. It embodies a totally unacceptable principle of permitting the catastrophic extreme-value DS failure of much higher risk to be aggravated on behalf of an improvement of the almost inconsequential US slope stability under statistics of averages of the RDD condition. Case $3 b$ (Patel and Maheshwari, 1961) embodies the right approach towards control of flow nets in the US zone; but with over-confidence in flow nets includes serious risks to the upper part of the dam and unnecessarily stringent impervious requirements on the foundation.

Finally, case 5 is the only one that will be used in the subsequent discussions. It comprises a brilliant engineering solution of achieving out of a homogeneous compacted section, the principal desired functional zoning of a DS shell excluded from interference by a reservoir flow net. As often happens when a dominant design decision transcends a statistical universe (de Mello, 1975c) the successful solution can be directly imitated with considerable success for quite a long time without requiring any studies of optimization. However, there has been in parallel a considerably body of experience gained with narrower cores inclined to the vertical in earth-rock sections leading to conclusions that a vertical chimney should in principle be avoided, that a moderately narrow impervious zone is sufficient and more favourable in the embankment, and that inclining upstream is distinctly favourable. Concomitantly there have been continued indications that the principal factor of unfavourable seepage behaviour arises from the foundations, comprising inevitable extreme variability of hypotheses because of dam site geology. Therefore, the dominant factor in optimization of the interceptor drains is definitely not construction pore-pressures or statistics of averages controllable by many other expedients and, for the crucial full reservoir pore-pressures, not only the chimney filter across the embankment but also the foundation drainage should be judged under extreme hypotheses.

\section{Positioning of chimney filter inclined upstream}

For the desired optimization of position of the fully intercepting filter-drainage chimney, with regard to absolute exclusion of catastrophic failure, the simplest failure model it is possible to visualize would comprise the downstream sliding of a downstream wedge due to the soft load imposed by the full reservoir. When catastrophic failures are at stake one must reason that it cannot be in connection with second- or third-order approximations of computations, but must involve basic physical models subjected to working conditions (even if statistically rare) significantly different from those presumed under routines that cloak the underlying hypotheses.

For the purpose of illustration, such all-important optimization studies on the dam superstructure have been conducted for the idealized cross-section of Fig. 5, considering five alternative positions of the filter-drain chimney, and firstly using routine fiow net assumptions. The filter-drain has been considered fully efficient (phreatic boundary) as a nearly attainable 


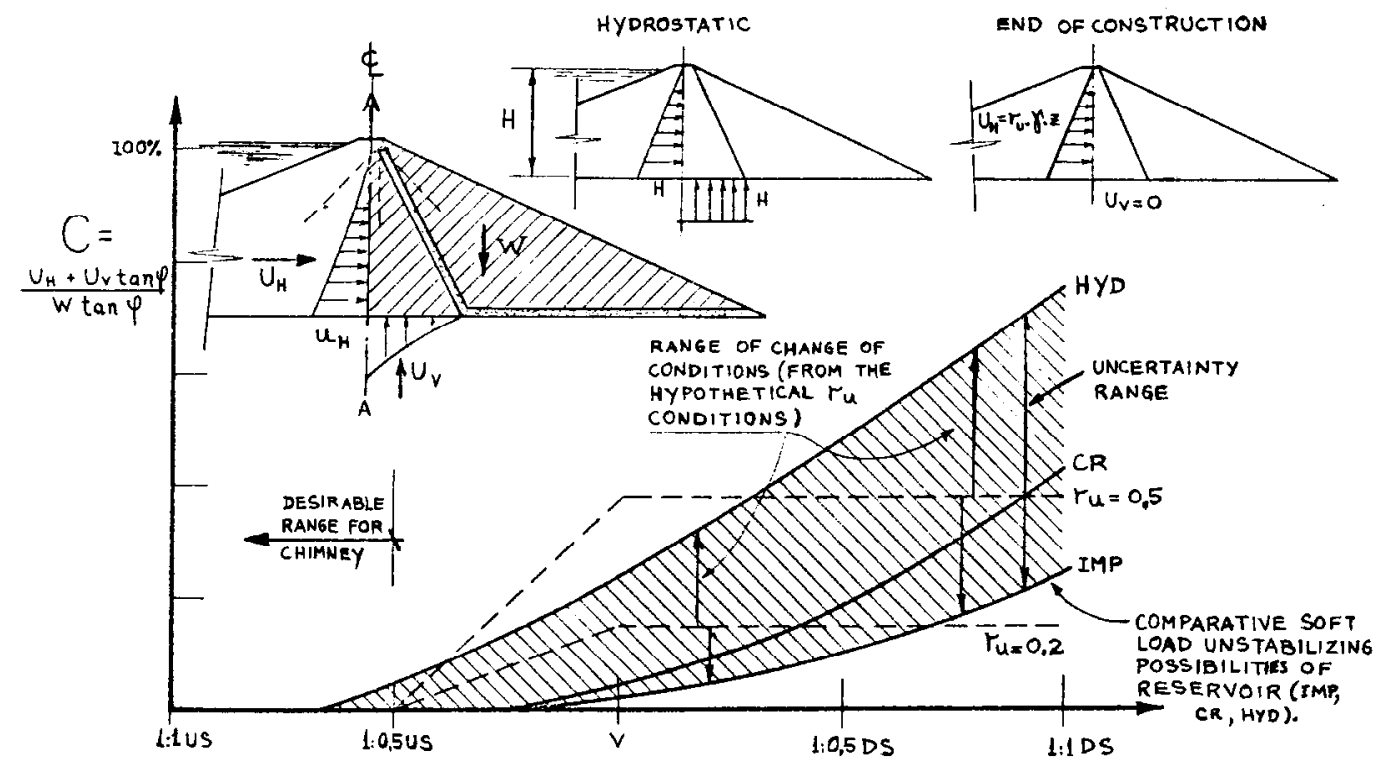

Fig. 6. Priority optimization of chimney position for DS stability

condition, though extreme and favourable. The most frequent design assumption on foundation permeability has been of total impermeability; its pore-pressures are designated $U_{\text {imp. }}$ Moreover, a frequently possible very unfavourable foundation condition can be represented in first-order approximation by an open horizontal crack under the upstream zone of the dam, as schematically indicated at the bottom of Fig. 5. In many competent rocks (e.g. sheeted granites, basalt flows, etc.) such cracks are a frequent feature, and over a significant part of the upstream foundation it is quite reasonable to anticipate that vertical effective stresses unevenly distributed may not achieve compressing such cracks into tighter closure. Obviously in a case of an open crack we must a priori DP 1 have relied on a satisfactory infilling by grouting; it has been assumed that the crack has been grouted for a minimum length of $0.3 \mathrm{H}$ upstream from the chimney-filter, and at least as far as the dam centre line for cases of the chimney-filter inclined downstream. A sample flow net is shown for the vertical V chimney: such pore-pressures are designated as $U_{\mathrm{CR}}$.

For examination of the first-order comparative merits of the different positions of chimneyfilter, one may well employ highly simplified hypotheses of stability wedges; the crude simplicity of the physical models and statics does not alter the overall conclusions on relative merits. Absolute priority must be given to minimization of destabilizing features of the reservoir soft load on the downstream wedge; moreover, a second criterion of preference may be established with regard to minimizing the change of conditions (of pore-pressures) from end-of-construction to full reservoir. The destabilizing soft load due to reservoir filling may be considered as the sum of the horizontal pore-pressure thrust $U_{\mathrm{H}}$ at the back of the wedge (Fig. 6) plus the component $U_{\mathrm{v}} \tan \phi$ with which the vertical pore-pressure thrust $U_{\mathrm{v}}$ contributes unfavourably; meanwhile, the stability of a downstream wedge of weight $W$ is related to the component $W \tan \phi$; the relative destabilizing potentiality in the different cases may be reflected through an index $C=\left(U_{\mathrm{H}}+U_{\mathrm{v}} \tan \phi\right) / W \tan \phi$. On using an index such as $C$ it must be emphasized that preference for a design section is established not only through comparisons of the indices 


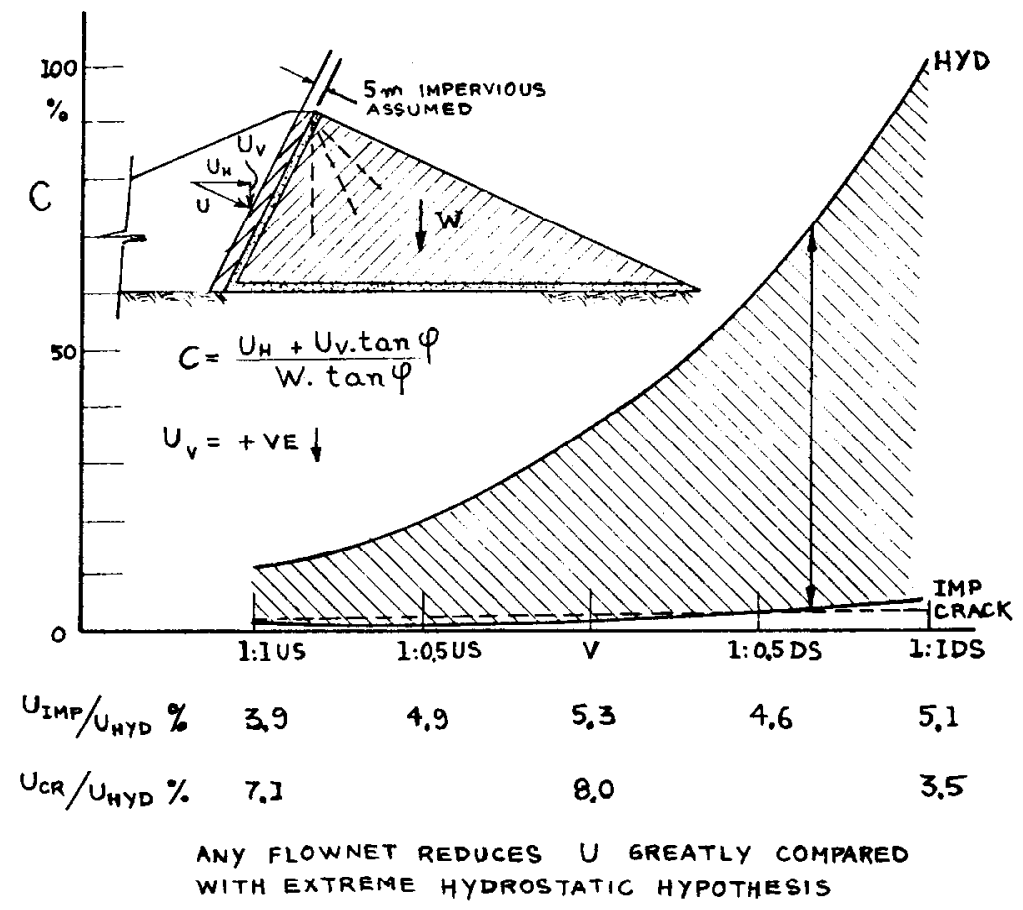

Fig. 7. Optimizations of chimney position using another simple stability model

$C$ for different chimney positions, but also on the basis of the comparison of the range of uncertainty affecting such values for the different chimney positions, depending on the variations possible in the total thrusts $U_{\mathrm{H}}$ and $U_{\mathrm{v}}$. Of course, the greater the proportional dependence of the DS stability on the reservoir pore-pressure thrusts, the greater the range of uncertainty (which would require compatibly increased $F$ values in design calculations).

Figure 6 summarizes the computed indices $C$ for hypothesized sliding wedges of vertical back AA, and specifically with AA along the centre line; the indications strongly favour inclining the chimney at least 1:0.5 US. Extended calculations with different locations for the line AA confirm such a design preference, with regard to DS stability, and certainty thereof (substantially independent of the flow net assumed).

In the graph in Fig. 6 the same simplified model is used to indicate the comparative ranges of change of conditions of pore-pressure thrusts on first reservoir filling. For purposes of illustration two hypothetical construction-period pore-pressure coefficients were used for the embankment. Once again the preference for US-inclined chimneys is strongly supported.

Since a downstream failure under full reservoir must, in design, be rendered really impossible (by choice of universe), the validity of the preference must be confirmed under as many as possible hypothetical models of anticipated failure. Just as an example the additional model of Fig. 7 may be visualized. The wedges separated by the chimney-filter and horizontalblanket drainage were assumed to be the possible sliding wedges. The upstream pore-pressure thrusts were taken along a hypothetical plane $5 \mathrm{~m}$ upstream of the chimney; the foundation uplift was excluded, in view of the purely comparative analysis. The physical model might be viewed as closely akin to the limiting case of rockfill dams (i.e. fully drained downstream masses) with upstream impervious membranes (upstream-deck dams). 


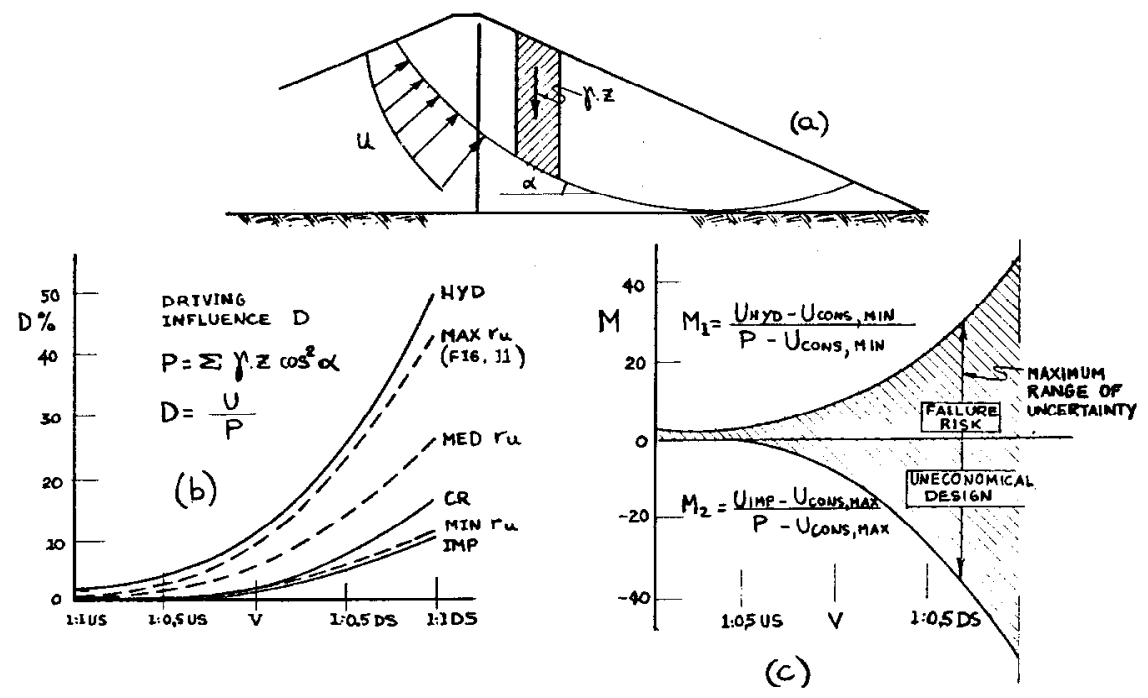

Fig. 8. Confirming optimization of chimney position by simplified sliding circle analyses

The computed indices $C$ obviously repeat the indications in favour of US-inclined wedges. Another point meriting special attention is summarized in the tabulation at the bottom vilue graph: one may not have noted, in routine uses of flow nets, how small a percentage ( 4 to $8 \%$ ) of the total hydrostatic thrust survives to be transmitted to the final $5 \mathrm{~m}$ behind the filter, no matter what flow net is employed. It is the very automatic assumption of gradual loss of head in accordance with flow nets that must be questioned first. One must recall the preoccupations of the past score of years with regard to cracking and pervious discontinuities, and further note that, especially under transient conditions of very rapid reservoir filling, the ratios of apparent impermeability tend to be accentuated, fostering membrane-type behaviour. The disproportionate uncertainties on magnitudes of the important soft load, $U_{\mathrm{imp}}$ to $U_{\mathrm{hyd}}$, impose the design choice of universe whereby the direction of such a load is the initial guarantee that its magnitude is immaterial; with interceptors inclined upstream, it is practically immaterial to downstream stability whether the interceptor is a drain or a seal.

As a final illustration reaching similar conclusions the sliding-circle model was used as indicated in Fig. 8. After the priority optimization with regard to catastrophic mass DS instability, under DP 4 further optimization on satisfactory operational behaviour of consequence (to DS) seeks to minimize the important change of conditions in moving from the wellcontrolled end of construction (EC) situation, to the full reservoir condition on first filling. Analyses were conducted on many possible failure circles; Fig. 8 concentrates attention on a single one, purposely taken relatively deep for most salient effects. As already stated, the significant driving influence subject to change is the pore-pressure thrust $U$, and, once again, the simplest indices have been formulated as defined in the figure: the driving influence index $D \%$, and the index $M \%$ of change of conditions. Construction-period pore-pressures were considered only for the US zone, because DS of the chimney many expedients are available under DP 2, DP 3 and DP 5 for controlling them at will; moreover, they suffer no change on reservoir filling, and only change favourably by dissipation with time.

The biggest change of $D$ occurs if a low end of construction pore-pressure (ECu) is followed by extreme hydrostatic reservoir loading (cracks); such as major possible change index $M_{1}$ 


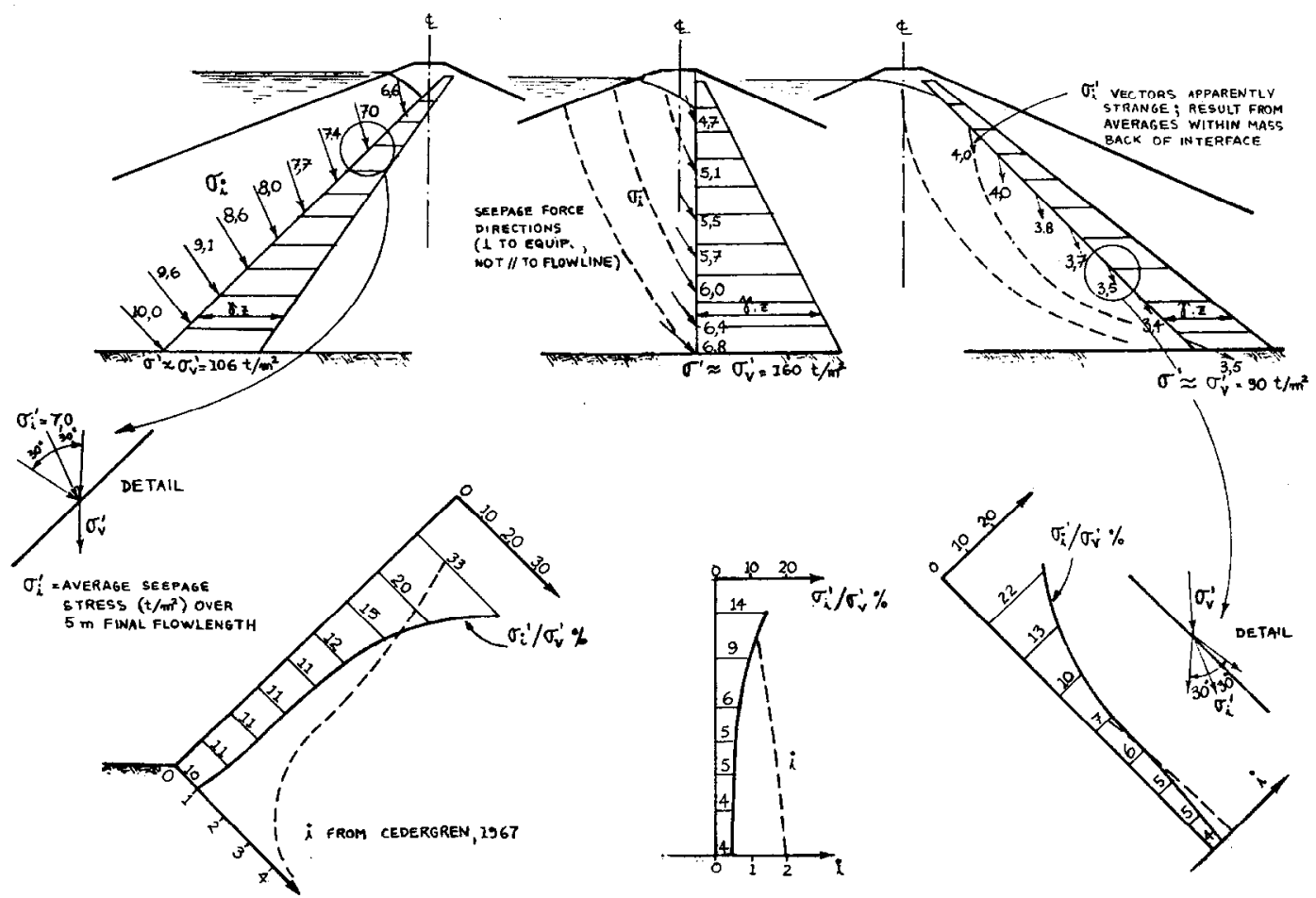

Fig. 9. Seepage exit problems (average)

reflects the worst risk of failure. At the other end lies the possible condition of change index $M_{2}$ corresponding to a high $\mathrm{EC} u$ followed by average flow net conditions $U_{1 \mathrm{mp}}$. If a design is dictated by the condition of high $\mathrm{EC} u$ (and negative value of $M_{2}$ ) an uneconomical condition prevails, because flatter slopes will have been required merely because of a transitory instability. The maximum range of uncertainty is represented by the span between the two limits of $M$. It is evident from Fig. 8(c) that the chimney interceptor should not be DS-inclined.

In a further important comparison of the relative merits of the alternate chimney positions, the second aspect of potential catastrophic failure, that associated with tendencies to piping, requires preliminary evaluation. More detailed discussion of the problem as connected with statistics of extremes will be found in a later section. At this point only the average tendencies set by seepage forces are examined. The flow net data permit average near-exciting conditions from the clay to the filter to be established, as shown for three chimney positions in Fig. 9. From the flow net data (established by finite element analyses for more careful differentiations) the magnitudes and directions of the seepage pressures on the soil mass close to the interface were determined. The seepage force per unit volume was transformed into a pressure across an arbitrary constant length of $5 \mathrm{~m}$ just behind the interface. The potential effects of such seepage vectors should depend on comparisons with the overburden effective stresses locally significant: the simplest comparison, without considering vectors and pertinent lateral overburden stresses, etc., is the mere scalar proportion $\sigma^{\prime}{ }_{1} / \sigma^{\prime}{ }_{v}$ with regard to the vertical overburden effective stresses at the filter face, as shown in the lower graphs of Fig. 9. The first-order indications of these graphs are that conditions are more unfavourable at the top than further down. Although in due fairness it must be conceded that the solutions furnished by Cedergren 
(1967) (gradients $i$ as plotted) would not seem to support the same indication, my results would suggest emphasizing that in conventionally designed embankment dam sections, with slopes and filters merely set by straight lines, the uppermost stretch may well prove to be the Heel of Achilles in a full-reservoir condition; a widening towards the crest would be desirable.

A second indication extracted from Fig. 9 is that the unfavourable changes in stress magnitudes, rotating the chimney to upstream, appear modest. The directions of such seepage stresses may be of much greater significance, in which respect the core-filter interfaces inclined upstream offer the favourable trend towards added compressive stresses and possible arching. The schematic details in Fig. 9 show the nominal directions of mean exit seepage stresses as determined, and include a presumed possibility of such directions fanning to at least $\pm 30^{\circ}$ around the central direction estimated.

Further consideration of the problem of localized seepage exit stresses is deferred to a subsequent section, with emphasis on the strongly averaging premises of the very theory behind flow ncts, and the further recognition that at the routine level of discretizations of flow nets (even with finite element analyses) not even the singular points (average) of such a theoretical formulation may be covered (Wolski et al., 1970; Reinius, 1973).

The final question regarding optimization of chimney-filter position in the superstructure concerns seepage losses (average). Fig. 10 furnishes the necessary indications; obviously a two or threefold increase in computed seepage is irrelevant, beyond the precisions of tests and computational hypotheses.

\section{PROPERTIES AND BEHAVIOUR OF COMPACTED MATERIALS}

\section{Fine-grained materials}

A vast amount of research of the past score of years has established the fundamentals of behaviour of compacted fine-grained materials, but precedent on embankment dam design and construction specifications has not been noticeably adjusted in accordance. Any interpretative model proves satisfactory as long as one works in closed-cycle interpretations/applications, within the same statistical universe; it is only when one extrapolates to conditions beyond those well represented in the experience universe, that the predictions will prove untenable if the model is physically inappropriate.

For purposes of optimizations within the chosen basic cross-section, it is necessary to reappraise, on the basis of available test and field performance data, the prevailing mental models of geotechnical behaviour associated with compacted materials. One is led to interpret that historically there was justification for the automatic application of the model of a homogeneous material of improved quality, through mental association with the classic comparisons of dense as opposed to loose sands. In consonance with such a model, such extensive and meticulous research projects as the investigation of stress-deformation and strength characteristics of compacted clays (Casagrande et al., 1960, 1962, 1963, 1964) were programmed as if all specimens belonged to a single universe of behaviour defined by a constant density; and the trend has prevailed towards interpretation of parameters $\left(c, \phi, c^{\prime}, \phi^{\prime}, E, r_{\mathrm{u}}\right)$ as constant or linearly varying. In a companion paper to be published some pertinent data have been collected from some well compacted and controlled dams, and a total of 167 undisturbed block samples tested therefrom. The paper postulates that compaction effectively represents the imparting of a 'nominal pre-consolidation pressure' that approximately homogenizes behaviours up to the corresponding overburden pressures, but is incapable of affecting significantly the intrinsic behaviours at higher pressures, within what is analogous to virgin compression ranges. 


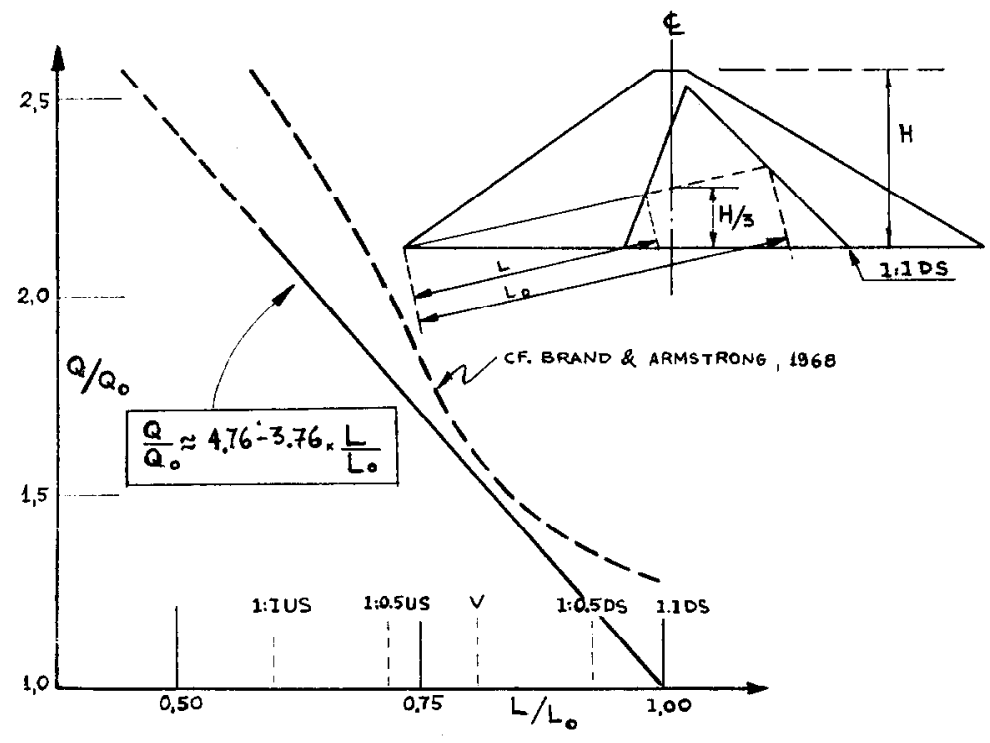

Fig. 10. Minor influence of chimney filter position on seepage losses

A summary of the results therein documented includes the following points which have been incorporated into the present discussions illustrating optimizations of design decisions around the hypothetical dam cross-section adopted. On the basis of satisfactory statistical regressions it is demonstrated that the compaction preconsolidation pressures $p_{\mathrm{c}}$ may be estimated as a function of percent compaction (PC) and maximum Proctor compaction dry densities $\gamma_{\mathrm{d} \max }\left(\mathrm{t} / \mathrm{m}^{3}\right)$. For the range of $80 \approx \mathrm{PC} \approx 105 \%$ such pressures vary approximately linearly between about 2 and $7 \mathrm{~kg} / \mathrm{cm}^{2}$, which seems well justifiable with reference to stress transmission from tyres (Freitag and Green, 1962; Freitag and Knight, 1962; Freitag et al., 1965; Hall, 1968). Field compression data from our compacted clay dams, when plotted in semilog paper in analogy to oedometer curves, also clearly exhibit the nominal preconsolidation pressure (apparently not observed by Gould, 1953). It is clear that compacted fine-grained materials must be interpreted as behaving differently within two distinct universes, that of precompression by compaction, and the virgin compression one. Moreover, it appears satisfactorily demonstrable that the field behaviour of compacted fills exhibits the interference of residual stresses due to compaction.

Within the precompressed range the drained strength equation includes a $c$ value dependent on the PC, and construction period pore-pressures have been negative or negligible in the very clayey materials (presumably in connection with so-called 'porous clays' of borrow-pit conditions comprising high percent air voids and macropores even when found wet of the standard Proctor optimum). Beyond the compaction precompression the differentiations in geotechnical parameters become accentuated. First, such widely different core matcrials of about equivalent permeabilities as that of Oroville (Gordon and Wulff, 1964) and Salto Osorio (de Mello, 1973, 1975c) exhibit compressibilities (expressed through $E$ values in reference to present routines of finite element analyses) that can be 2 to 3 times one another. This is so notwithstanding that in the very clayey residual soils of $W_{\mathrm{L}} \sim 50 \%$ the virgin compression $C_{\mathrm{c}}$ tends to be significantly lower than might be presumed by analogy with the Terzaghi-Peck correlation 

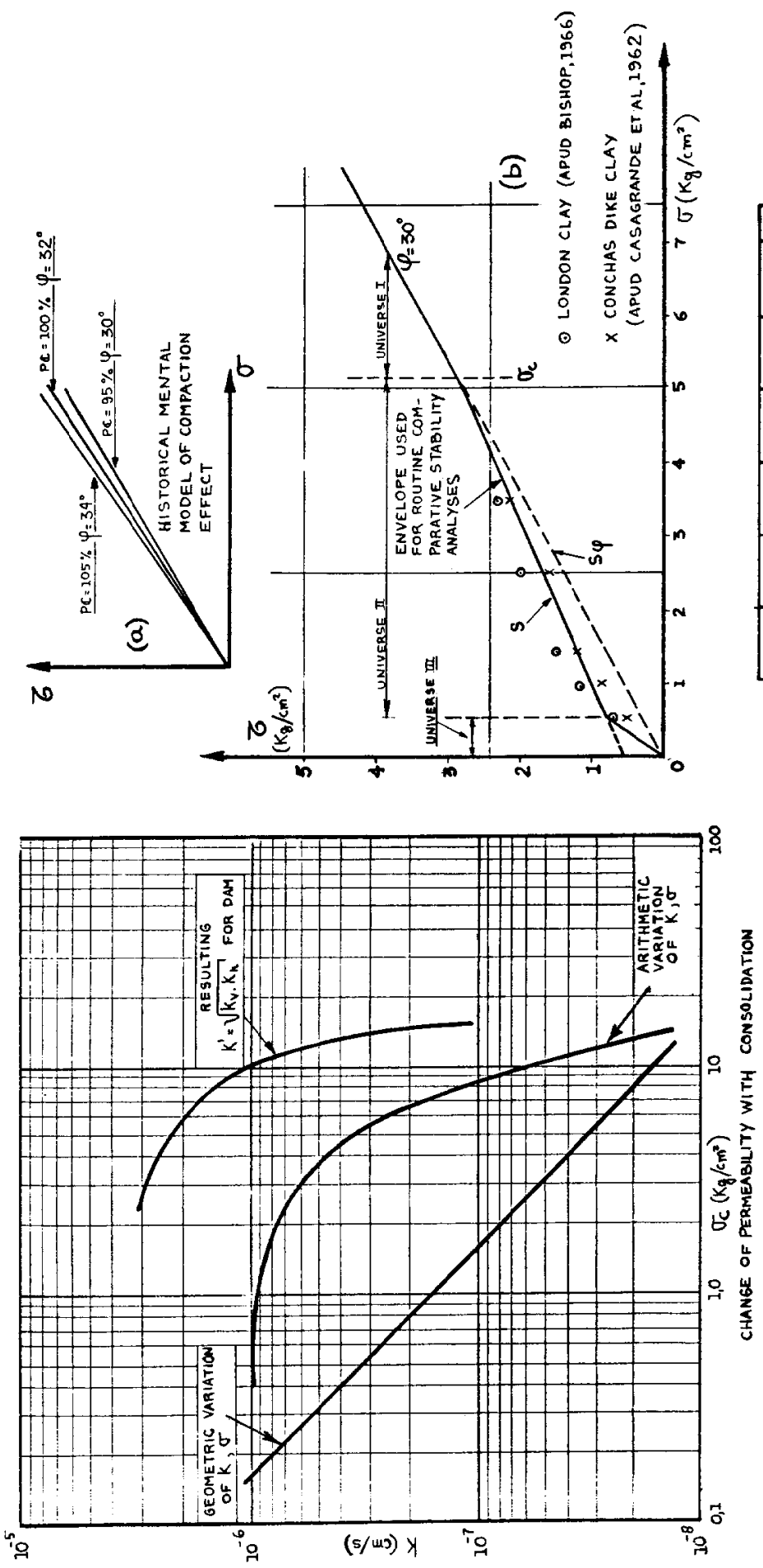

\begin{tabular}{|c|c|c|c|}
\hline & & $\odot$ & $x$ \\
\hline 웅 & $\stackrel{+}{+}$ & $\underset{\sim}{\mathscr{c}}$ & $\underset{0}{0}$ \\
\hline 옹 & $v$ & 怘 & $\stackrel{\oplus}{\nexists ~}$ \\
\hline 品 & $\underset{m}{m}$ & $\stackrel{m}{=}$ & 오 \\
\hline$\stackrel{\circ}{\sim}$ & in & $\stackrel{\circ}{:}$ & $\stackrel{\overrightarrow{6}}{\stackrel{\theta}{n}}$ \\
\hline 으 & $\stackrel{\circ}{\circ}$ & $\underset{N}{N}$ & $\underset{-10}{0}$ \\
\hline$\hat{b}^{\circ}$ & d̊ & के & के \\
\hline
\end{tabular}

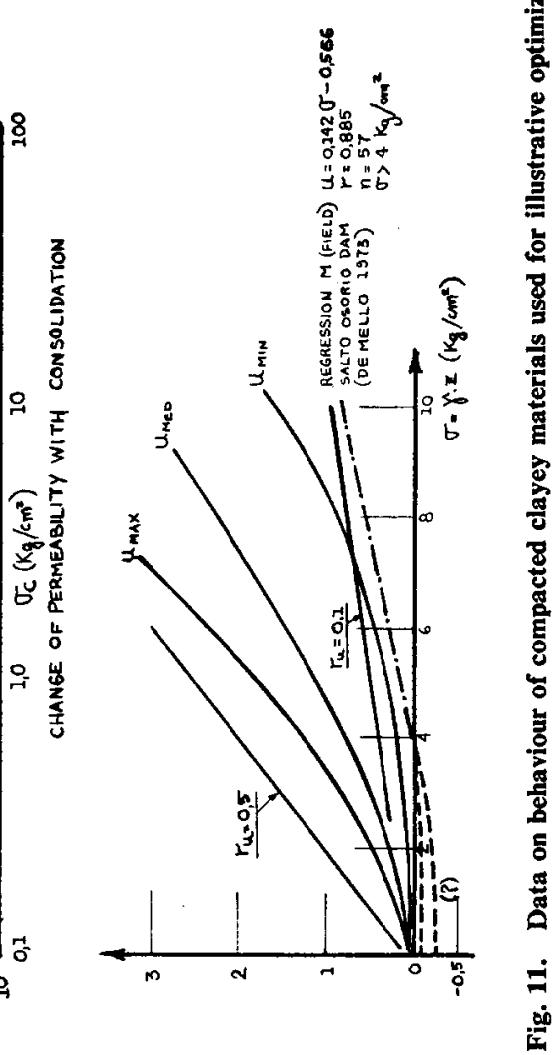




\begin{tabular}{|c|c|}
\hline ROCK TYPE & \multirow{2}{*}{ REF. } \\
\hline REGRESSION & \\
\hline EL INFIERNILLO DIORITE & \multirow{2}{*}{$\begin{array}{l}\text { MARSAL-1967, } \\
1971,1973 .\end{array}$} \\
\hline$\zeta=1.10 \sigma^{0.870}$ & \\
\hline IDEM SILIC CONGLOM & \multirow{2}{*}{$\begin{array}{l}\text { MARSAL-1971, } \\
1973 .\end{array}$} \\
\hline $6=1.27 \sigma^{0.8}$ & \\
\hline PIZANDARAN SAND + GRAVEL & \multirow{2}{*}{$\begin{array}{l}\text { MARSAL ET AL. } \\
1967\end{array}$} \\
\hline$\zeta=1.27 \sigma^{0.876}$ & \\
\hline SAN FRANCISCO BASALT & \multirow[t]{2}{*}{ MARSAL 1972} \\
\hline$\zeta=1.54 \sigma^{\circ}$ & \\
\hline $\begin{array}{l}\text { NET ZAHUALCOYOTL CONGLOM } \\
\overline{6.1 .19 \sigma^{\circ} 0.881}\end{array}$ & $\begin{array}{l}\text { GAMBOA \& } \\
\text { BENASSINI-796? }\end{array}$ \\
\hline MALPASO CONGLOMERATE & \multirow{2}{*}{ MARSAL 1973} \\
\hline$\sigma=1.59 \sigma^{0.800}$ & \\
\hline
\end{tabular}

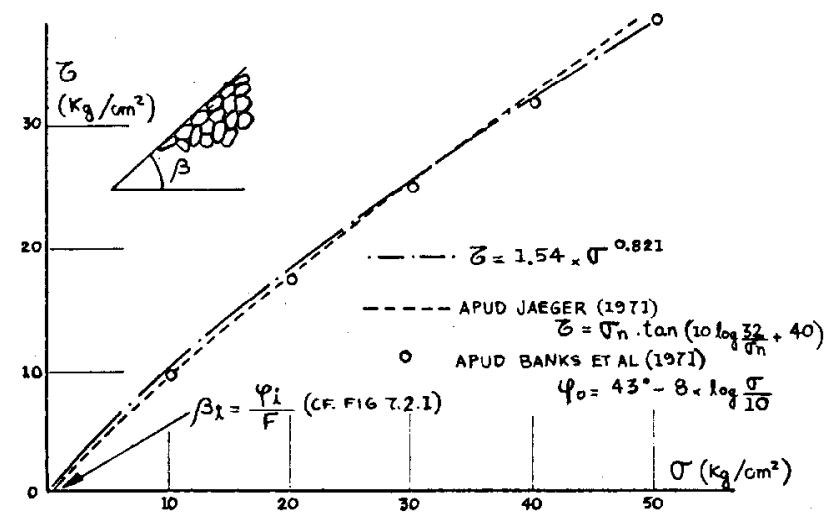

Fig. 12. Summary data on curved strength envelopes in granular materials

$C_{\mathrm{c}} \approx 0.007\left(W_{\mathrm{L}}-10\right)$, and a better statistical correlation is obtained of $C_{\mathrm{c}} \approx 0.21\left(2 \cdot 70-\gamma_{\mathrm{d} \max }\right)$ directly with the Proctor compaction maximum dry density in $t / \mathrm{m}^{3}$. Moreover, field compressions tend to be significantly lower still, than as indicated by any laboratory tests. Correspondingly, construction-period pore-pressures tend to be significantly lower than predicted by laboratory tests.

Finally, there is a very significant permeability gradient with pressure, due to consolidation, which has been recognized since the earliest days of soil mechanics. Apparently, however, the likely interference of such a factor on flow nets of dams has not been questioned or investigated, probably as a consequence of the assumed mental model of homogeneity. The minimum gradient that should be justifiably considered corresponds to somewhere between a $1 \cdot 0$ and $1.5 \mathrm{log}$ cycle decrease of permeability for one log cycle of pressure increase, and therefore has been taken as at least a 100 -fold variation of permeability from top to bottom of the idealized dam cross-section studied for optimizations and comparisons.

Figure 11 summarizes the data on drained shear strength, on construction period porepressures, and on permeability gradient with pressure, that were adopted for further illustrative optimizations.

\section{Rockflls compacted in lifts}

In the companion paper to be published on behaviour of compacted embankment materials, it is first shown that early rockfill construction with dumped rock and acceptance essentially of 'angles of repose', employed slopes generally steeper than later began to be considered necessary in compacted rockfills. Yet there is no record of instability of such slopes. Such sound evidence of field performance suggests the need of re-examination of current routines on stability of rockfill slopes and factors of safety. Moreover, as a preliminary it became necessary to reappraise the widespread mental models on the geotechnical quality, indices, and behaviour, of rockfills compacted in lifts.

Among the principal points established regarding the mental models on the nature of compacted rockfills are: the layered heterogeneity of the compacted rockfill; the differentiation between compaction compressions of the lift and subsequent compression under overburden loading of the compacted lift; correspondingly, the lack of analogy between compression observations in field compaction tests and in the construction period settlements; and the 
acceptable evidences that rockfill compaction also induces effects tantamount to precompression, somewhat similar to the nominal preconsolidation pressures in compacted clayey fills. In short, it is emphasized that compaction in rockfills arose exclusively because of concern on deformations, but its concomitant benefits on strength and stability have not been adequately capitalized.

Regarding the stability of compacted rockfill slopes, if sound foundations are assumed, the only conditioning factor is the strength envelope, which in recent years has been much investigated by large-scale triaxial tests. Since the only factor that could contribute to somewhat deeper sliding surfaces, is the curvature of the strength envelopes, a reference study was conducted to establish presently available data on the probable magnitude of such an effect. Fig. 12 summarizes the information gathered, for use in the discussion of design decisions on stability of compacted rockfill slopes.

\section{OPTIMIZED BASIC CROSS-SECTION WITH REGARD TO ALL FLOW NET CONSIDERATIONS}

Based on priority concern with risks to downstream it has been established that the filter should be inclined about 1:0.5 US as far as the embankment superstructure is concerned. Further optimization must consider other currently recognized design criteria, both of less critical slope instabilities, and of desired economies. Such further analyses were necessarily conducted, for satisfactory credence and refincment in detection of parametric differences, by flow nets from finite element analyses and by computerized stability analyses (program SSTAB based on Spencer, 1967).

\section{Homogeneous embankment on impervious rock: mass instability of US slope on rapid drawdown $(R D D)$}

In first-order approximation, on the safe side, this problem should be viewed in the light of an instantaneous change of conditions from the prior equilibrium condition of the US mass acquired under the full-reservoir flow net. The current routine assumption of a fully saturated material is also on the safe side. The data on pore-pressures $u$ from the $W_{\mathrm{L} \max }$ flow nets for the five positions of filter are summarized in Fig. 13. The nearly linear variation evidenced at any elevation furnishes a convenient basis for estimates, while the constant $u$ loci (isobars) rotate jointly with the filter. Such data are of use for computing initial conditions for consolidating soil specimens for triaxial testing under pertinent anisotropic consolidated saturated undrained (ACSU) conditions.

The analysis of RDD instability has merited considerable attention in publications, and will be further discussed in a subsequent section. For the first-order approximation sought towards optimization on the design cross-section, the following reasoning is proposed. If the soil structure were incompressible, on altering instantaneously the US face boundary condition, and assuming instantaneous transmission of pore-pressures in the incompressible fluid, one would obtain the so-called rapid drawdown (RDD) flow net (analogous to the slightly more severe flow net of persistent rainfall on a saturated embankment). The principal desired RDD flow net indications and data on such consequent stress changes are summarized in Fig. 14. It is emphasized from the start that all such simplified pore-pressure estimates require revision in consideration of pore-pressures generated by volume change tendencies, as will be discussed. Partial drawdown (PDD) flow nets (Reinius, 1948) appear more unfavourable for shallow upper circles because as drawdown increases, the flowlines in the upper zone become more vertical (consequently equipotentials tend to be horizontal and flow net porepressures tend to zero). However, considering the compacted strength envelope (Fig. 11) it does not follow that instability is greater for such shallow circles and PDD. Morgenstern 


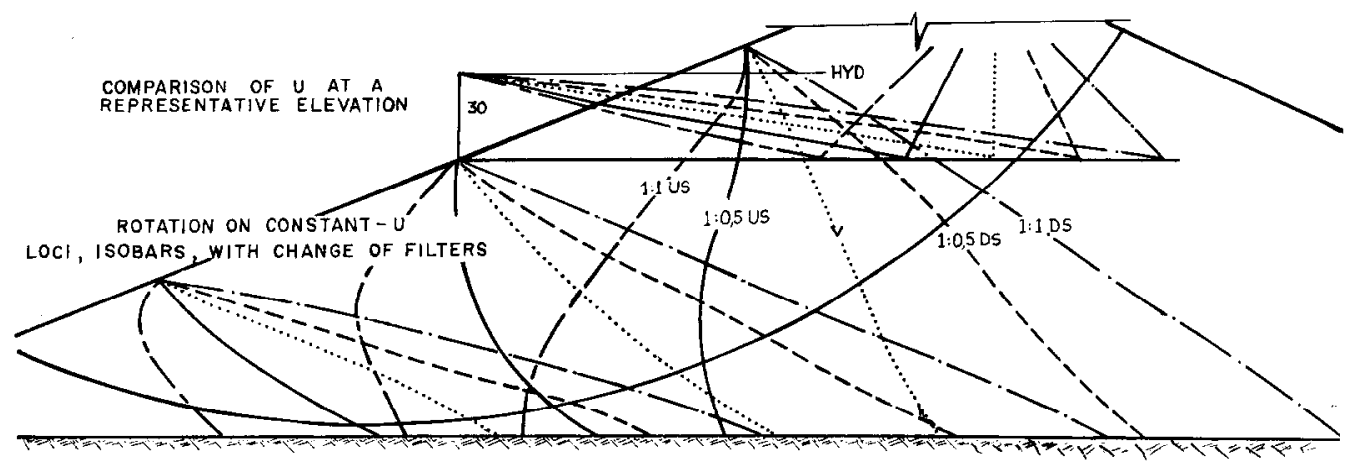

Fig. 13. Homogeneous embankment on impervious rock. Full reservoir flow net data for various positions

(1963) indicates $F$ values consistently lower for RDD than PDD by use of Bishop's hypotheses on drawdown instability. In the present study it has been decided to investigate only full drawdown (with the conservative assumption of impervious rock). For convenience Fig. 14(b) furnishes the varying position of the subvertical flow line of bifurcation of the nets (that Reinius (1948) assumed vertical and in a fixed position). At a first glance one senses that in the zone in which flow lines continue towards DS (the filter), the US slope is not subjected to unstabilizing seepage.

One would aim at minimization of the change of conditions (DP 4) for the US mass, and one recognizes that such optimization should be based on effective stresses. Consideration of anisotropies and rotations of principal planes must be relegated to later stages. Thus one should examine the change of vertical effective stress. If there is no tendency to change of effective stresses in going from flow net 1 to flow net 2, the soil structure is not subject to compressions, and is, therefore, 'virtually incompressible' in the same sense as a flow line is a virtual 'impervious boundary'. In such a case, fully saturated, the applicability of the RDD drainage flow net from the phreatic line for instant $t=0$ (conservative), is not thwarted by transient excess pore-pressures generated by soil compressions.

The optimization sought is indicated in Fig. 14(a), where the changes $\Delta \sigma^{\prime}$ are plottcd along typical planes of interest. The ideal condition sought, of $\Delta \sigma^{\prime}=0$, occurs fairly uniformly for a filter somewhere between the $V$ and 1:0.5 US positions; this is quite reminiscent of the ideal $1: 0 \cdot 5$ US suggested earlier. However, since one cannot presume to fulfil so narrow a condition as $\Delta \sigma^{\prime}=0$ obviously one would favour a small negative $\Delta \sigma^{\prime}$ because any small, occasional dilatant behaviour can only contribute to stability.

Another condition in which the applicability of the RDD flow net should not be thwarted by transient excess pore-pressure is where there is equality of compressibilities of the pore fluid in going from $u_{1}$ to $u_{2}$ and of the soil structure in going from $\sigma_{1}{ }^{\prime}$ to $\sigma^{\prime}{ }_{2}$. Such a condition could occur in considering shallow circles wherein the soil compressibility is low due to compaction precompression, while the fluid compressibility is increased due to the unsaturated condition. Fig. 15 was prepared to facilitate estimation of the $\Delta u=u_{2}-u_{1}=u_{\mathrm{RDD}}-\boldsymbol{u}_{\mathrm{wL} \max }$. In this instance the desirable condition would be of positive $\Delta u$ (compression of pore fluid) to favour stability. Although all the changes $\Delta u$ resulted negative, which is mildly unfavourable, the further US the filter moves, the smaller is this effect; this confirms favouring US-inclined chimneys. Routine indications for stability computations have automatically attributed compressibility to clayey embankments. One should not presume to know the values of the 

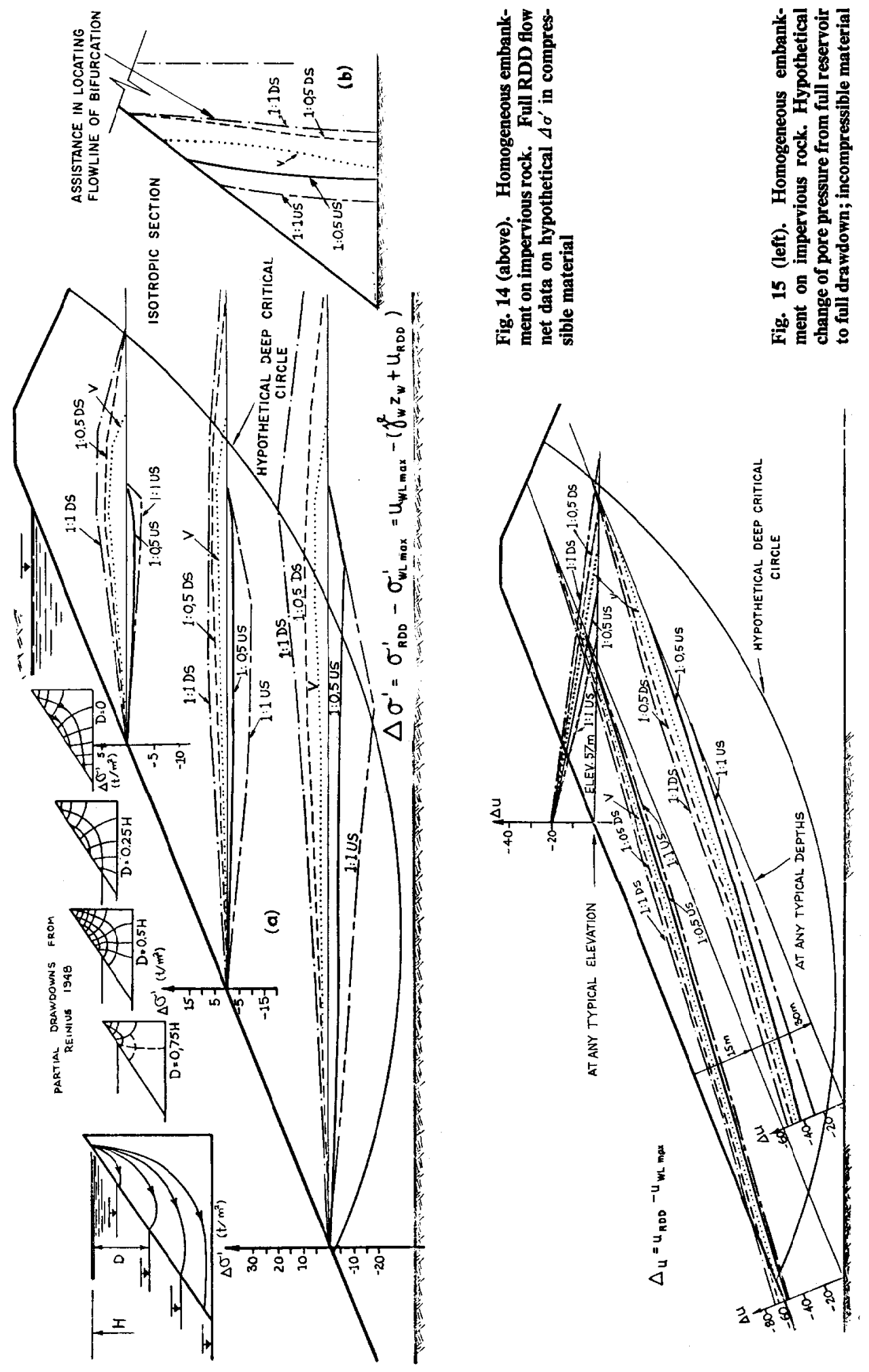
relative compressibilities of pore and fluid, since compaction specifications can alter them completely, and constitute a weapon at the disposal of the designer; conditions vary considerably from shallow depths affected by compaction precompressions, to greater depths possibly subject to virgin compression and soil closer to back-pressure saturated; and, of course, they depend on the stress changes being in the loading or unloading and reloading conditions.

As discussed earlier, an extreme, frequently possible, flow net uncertainty concerning the boundary condition of the US zone founded on bedrock corresponds to the hypothesis of an open crack close to the surface. Such an uncertainty affects not only the priority DS stability already mentioned, but also for RDD instability of the US slope. Fig. 16 indicates the relative merits of the three filter positions, 1:1 DS, V, and 1:1 US; in minimizing such uncertainty, the farthest US position is evidently best.

As has been explained, the US instability is directly related to change of conditions from initial $W_{L \max }$ flow net $u_{1}$. Fig. 16(a) indicates how different the $u_{1}$ conditions can be. The RDD flow net in the limit approaches the textbook case of vertical flow lines and horizontal equipotentials (i.e. zero $u_{2}$ pore-pressures in incompressible material). The US crack generates a significant increase in the $u_{2}-u_{1}$ in comparison with the impervious foundation, increasing the uncertainty on the US embankment behaviour. Similarly the uncertainty on DS stability transpires in the tabulation accompanying Fig. 16(b).

Obviously an US-inclined filter significantly reduces uncertainty: as the filter-drainage feature moves US, it participates more in dominating the flow net behaviour, reducing the proportion of interference of erratic foundation factors.

Embankment with permeability gradient with depth (heterogeneous): impervious foundation; full reservoir; full and partial drawdowns

Whereas dams up to about $20 \mathrm{~m}$ in height (depending on the compaction preconsolidation pressure) can rightly be treated as homogeneous, it is obvious that in significantly higher dams the properties of the material vary considerably with a 'virgin consolidation' under the overburden. The direct consequence on flow nets arises from the decrease of permeability with void ratio, but for obvious reasons the analyses had to employ the variation of permeability with pressure, for which the arithmetic variation (see Fig. 11) conveniently incorporated a compaction preconsolidation effect. The nature and magnitude of this influence was investigated for the three filter positions $1: 1 \mathrm{US}, 1: 0 \cdot 5 \mathrm{US}$, and $1: 0 \cdot 5 \mathrm{DS}$.

For the full reservoir condition the interference of the permeability gradient (embankment denominated heterogeneous (HET)) is best visualized by indication of the shift in equipotentials superposed on the routine flow net of the homogeneous (HOM) embankment; Fig. 17(a) furnishes the typical results, and can be accepted as intuitive.

The flow net is pushed upward but, expectedly, with no influence in the upper part of the dam. The corresponding interference on the RDD conditions affecting US stability appears suitably presented in the form of comparisons of isobars of the flow net pore-pressures (Fig. 17(b)).

Figure 18 presents, synthetically, some representative isobars for full reservoir affecting DS stability for the HET case as compared with the HOM, for the three filter positions. Concomitantly a coefficient of influence of the permeability heterogeneity on the DS stability circle is represented. Obviously the unfavourable influence is more modest the more the filters are inclined upstream.

According to what is demonstrated in Figs 14 and 15, the principal factors conditioning upstream instability will be considered as the changes $\Delta u$ and $\Delta \sigma^{\prime}$ in changing from $W_{\mathrm{L} \max }$ to 


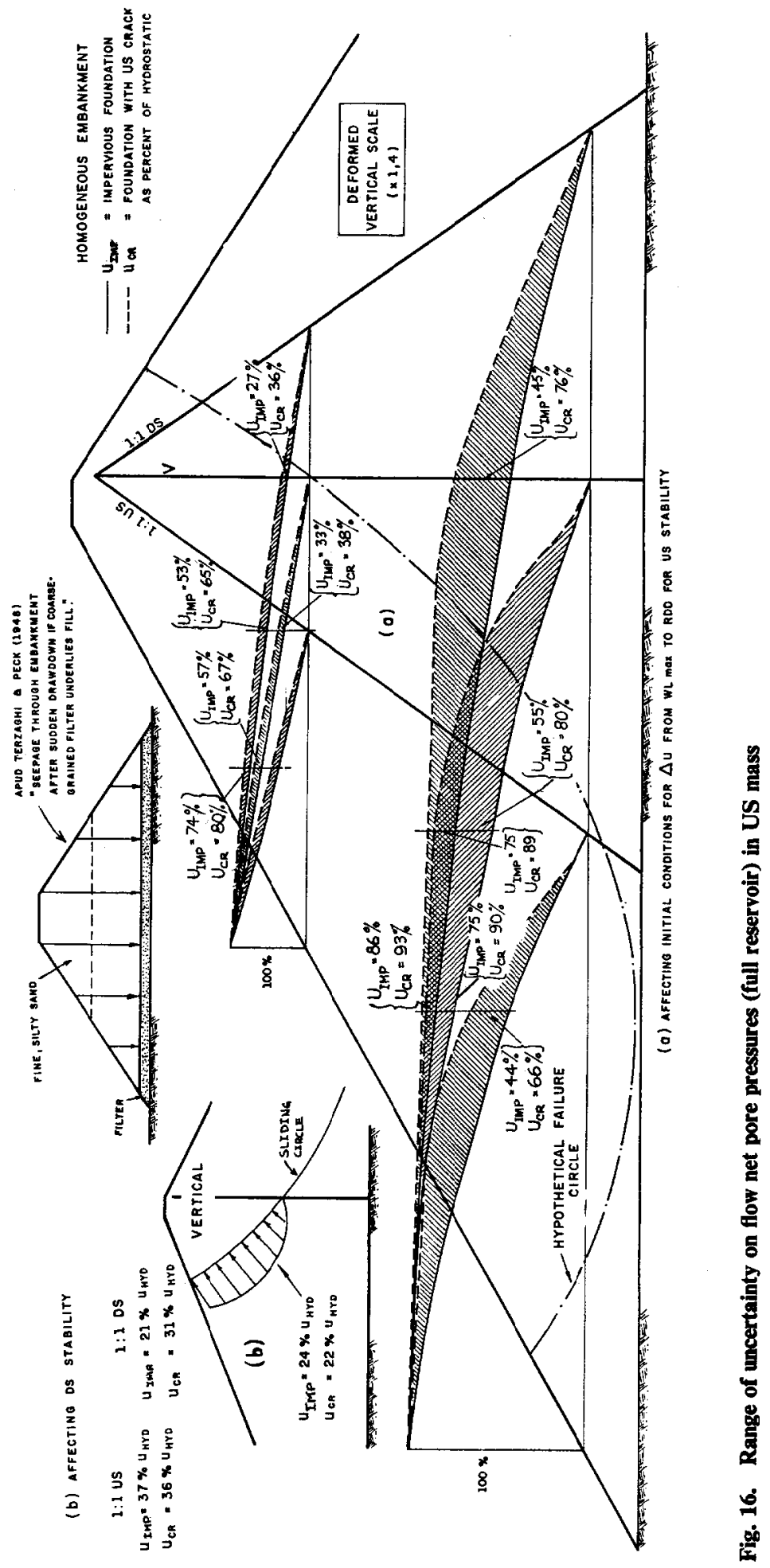




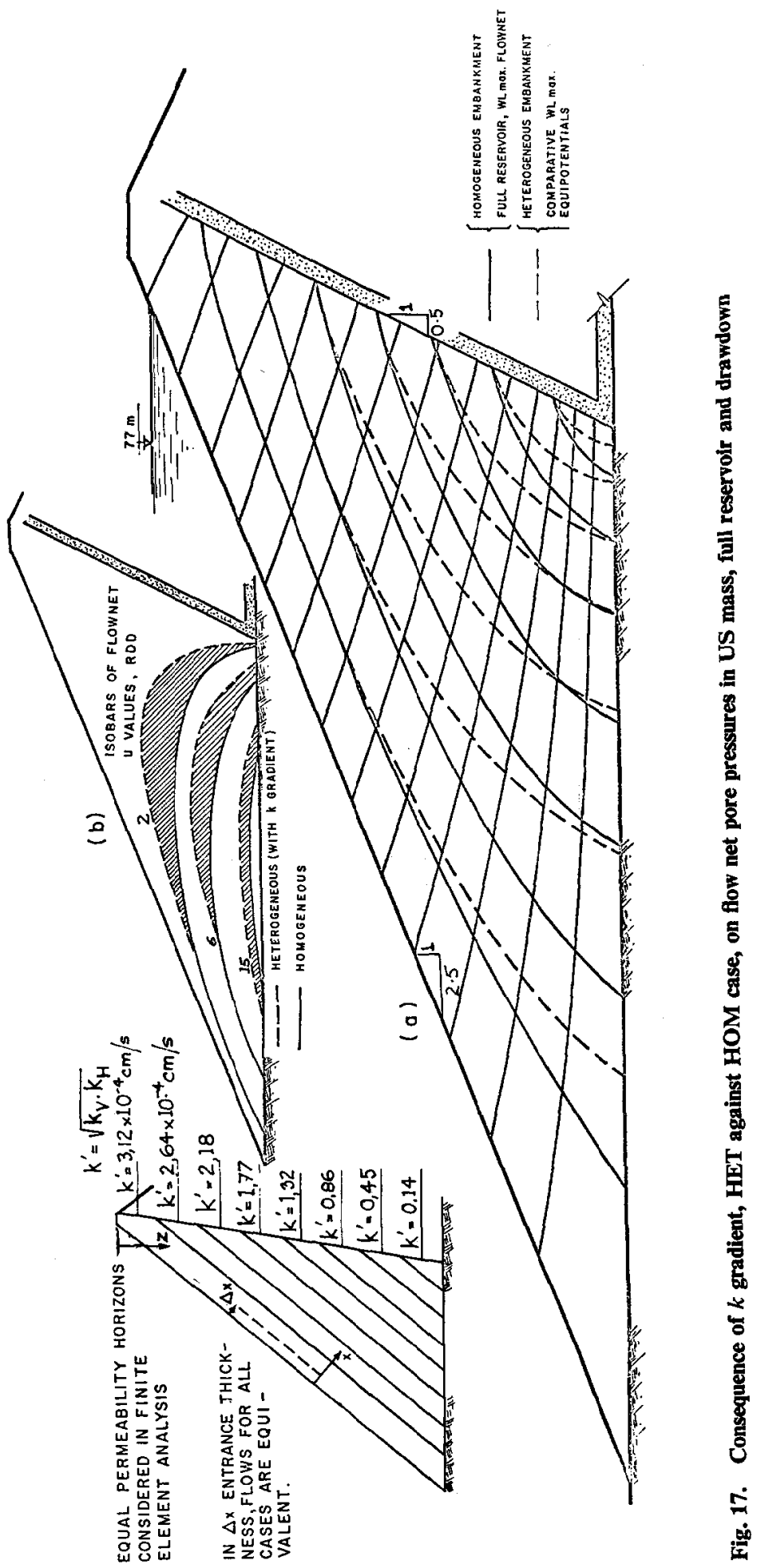




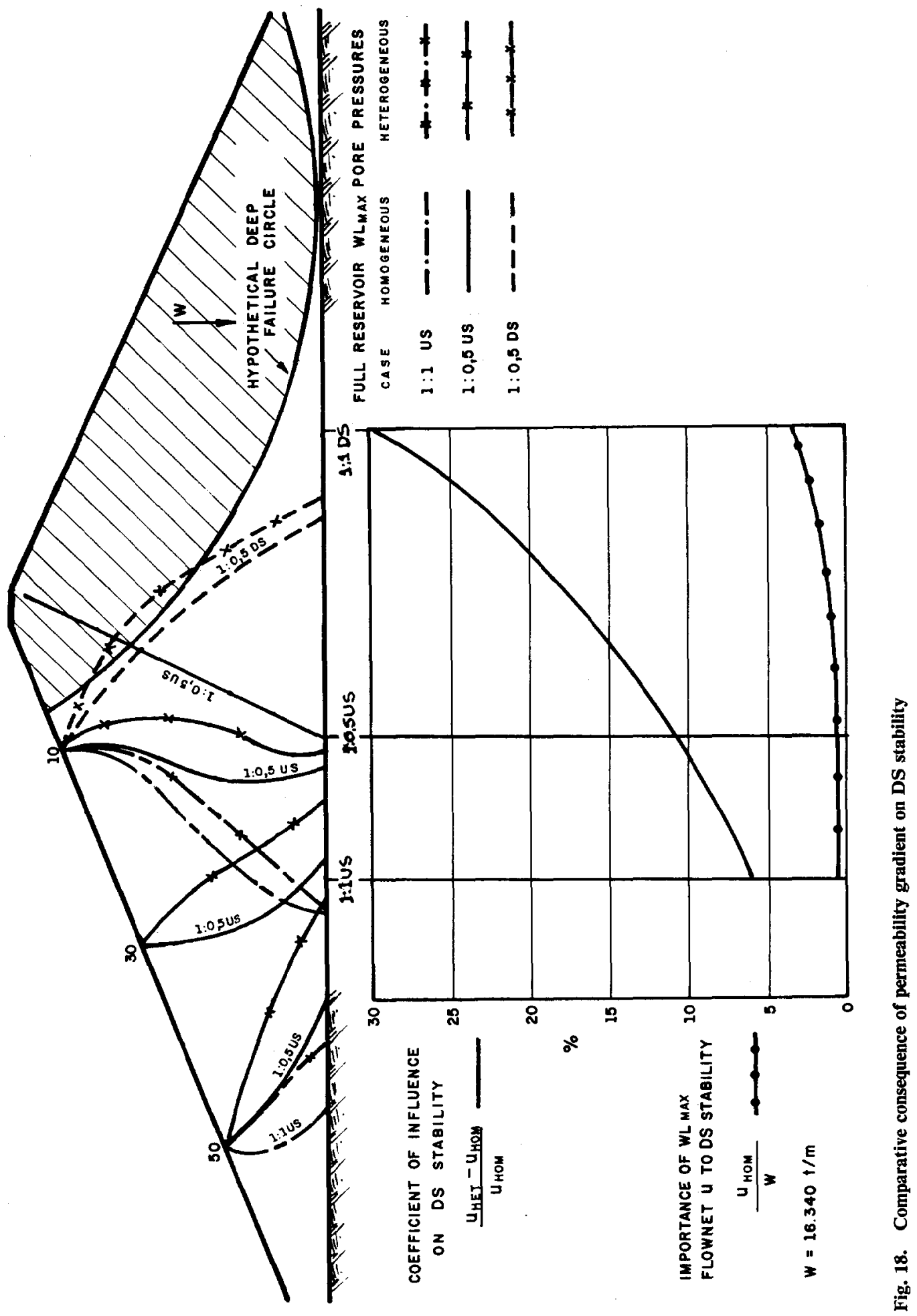




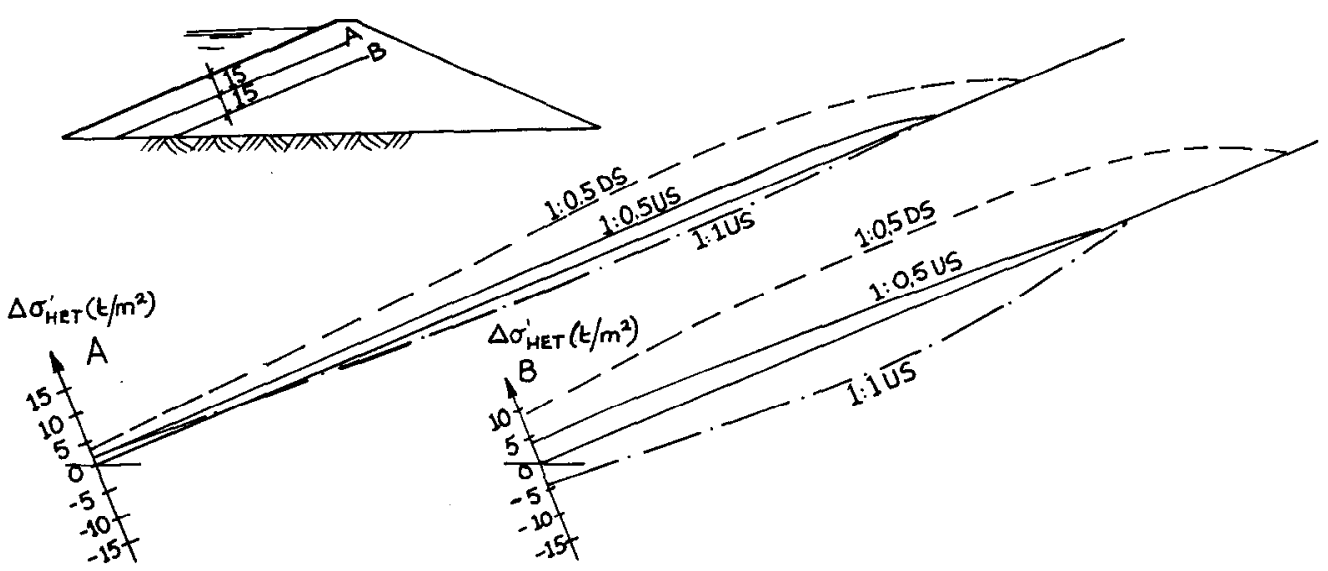

Fig. 19

RDD flow nets, principally the latter. The data on $\Delta \sigma^{\prime}$ summarized in Fig. 19 accentuate, slightly more in the HET model than in the HOM one, the preference for filters inclined at least $1: 0 \cdot 5$ US.

\section{Embankment on saprolite (pervious) foundations}

It is general experience that saprolite foundations tend to be more pervious than the compacted embankments: in the present studies they have been considered merely 10 times as pervious. The permeability gradient due to compression is even more accentuated than in sediments and compacted soils, but for convenience it has been assumed similar. It must be emphasized that in a single dam both the HOM and the HET models may be simultaneously at play since the former is more realistic towards the abutments where the preconsolidation pressures of foundation and compaction are not exceeded.

With the frequently used V chimney on dams of moderate height (acceptably HOM) the experience on saprolite foundations has been satisfactory, as can be seen from Fig. 20(a), since the pervious foundation lowers the flow net. Much depends, however, on the variations of permeabilities within the foundation. Repeatedly in our experience the proportionally worse conditions of DS uplift in saprolite foundations have occurred towards the abutments, in the shallower ends on gentle abutment slopes; in steeper abutment slopes the three-dimensional flow net comes into play in attenuating the foundation uplift. Where the embankment is higher it is suspected that the permeability gradient under the crest and central zone may be responsible for much of the satisfactory behaviour. In Fig. 20(b) presents data on $W_{\mathrm{L} \max }$ flow nets for the HET model for the two extreme practical filter positions of $1: 1 \mathrm{US}$ and 1:1 DS. The $10 \mathrm{~m}$ isobars of the HOM model on impervious foundation, retained for reference, serve to show that the net effect of the pervious foundation to depress the isobars a little, almost exactly counters the tendency of the HET as opposed to the HOM model (Fig. 18).

\section{Embankment with optimized blanket for erratic rock foundation permeability}

The frequently possible open subhorizontal US crack in upper horizons of competent rocks subjected to stress release has already been emphasized, along with the absolute need of grout for such cases. One very readily observes that as soon as one can rely on losses of head as in 

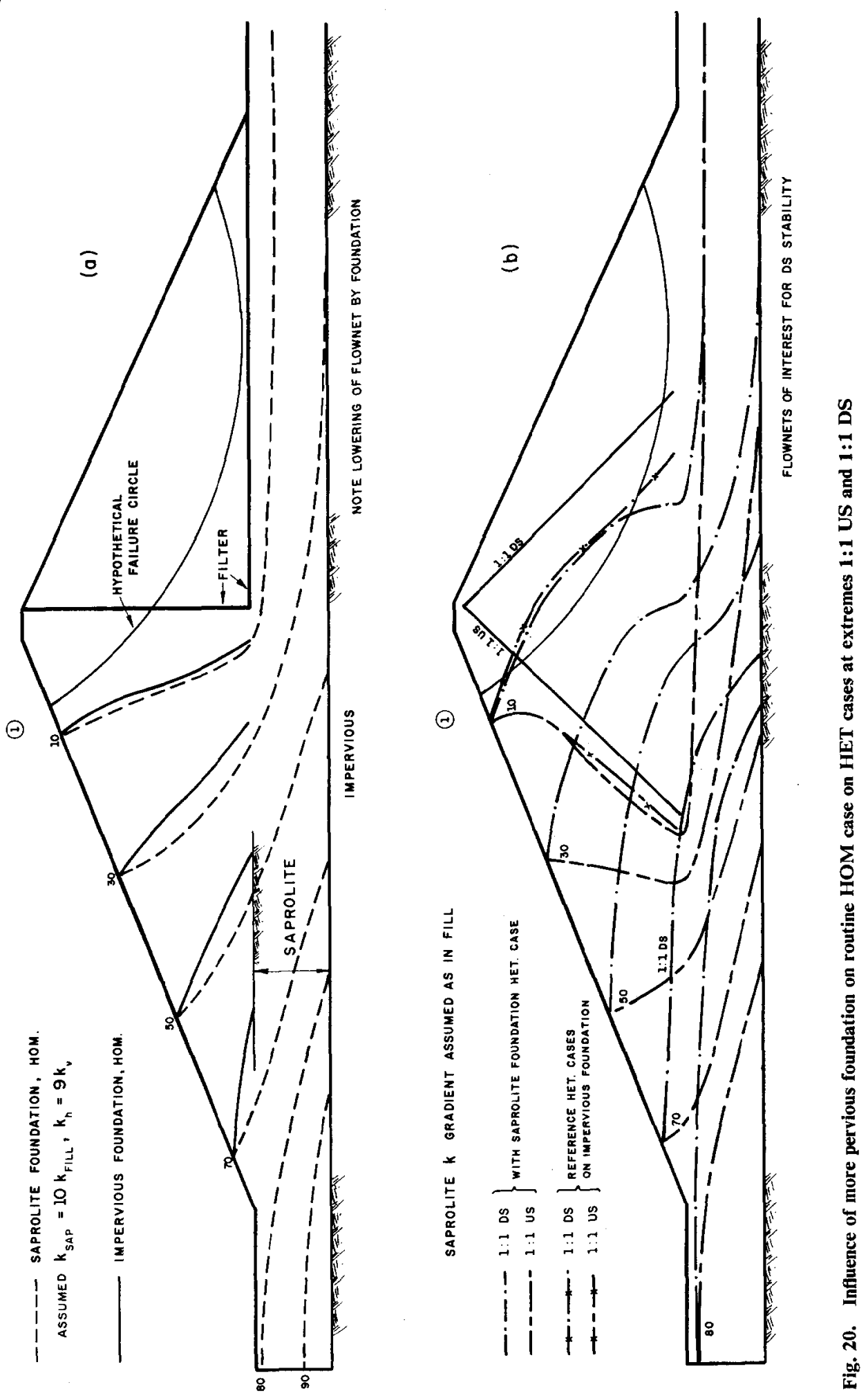
the flow nets in the crack under the embankment central zone, problems to DS stability are vastly attenuated. In accordance with DP 3 every available design measure should be employed to favour such a homogenizing action of head loss for the cracks before water exits to the filter-drainage.

Thus arose the concept of the so-called internal impervious blanket as exemplified in Figs 21 to 23 . The merits of the design concept are self-evident already in the HOM or HET dam on impervious rock (Fig. 21) and are further accentuated in the case of dams on pervious foundations (cracked rocks, or saprolites) as illustrated in Figs 22 and 23. Three salient points must be briefly emphasized. A routine external impervious blanket is useless over cracked rock because with rising reservoir the water pressure in the cracks rises in equilibrium with the reservoir and there is no net effective stress to help tighten them. The US-inclined filter that is ideal for the embankment has generally been carried to the foundation; this must be considered a very unfavourable design decision, shortening the pervious seepage paths of the foundation and taxing heavily both the unfavourable seepage exit gradients into the filter, and the flow conditions of the drainage blanket. Thirdly, no matter what the foundation conditions, since control of uplift is not necessary upstream of the 1:1 DS position, every benefit of the internal impervious blanket can and must be derived for tightening of fissures or pores under the central zone subjected to highest overburden. If fissures persist downstream, their tendency to remain wider under shallower overburden can only be favourable for drainage of the seepage under gradually increasing permeability.

\section{Embankment with optimized blanket on saprolite foundations}

The advantages of an internal impervious blanket prevail also very markedly for any dam on a moderately pervious foundation. Fig. 23 summarizes flow net data on concepts indicated in Fig. 21. Upstream impervious blankets have some well known disadvantages among which is the formation of cracks due to shrinkage or differential settlements (Lowe, 1970). Moreover, if the subsoil is unsaturated (frequent in 'porous' saprolite abutments) and the reservoir level rises quickly, there can be a seriously aggravated condition of differential loadings and settlements, as schematically shown in Fig. 21. At any rate, irrespective of any criticism on the external impervious blanket, the principal point is to avoid the mistake of losing a roughly $1.5 \mathrm{H}$ length of seepage along the foundation between the $1: 0.5 \mathrm{US}$ and $1: 1 \mathrm{DS}$ positions, particularly considering that, owing to permeability gradient under compression, this length can cause head losses of between ten and one hundred times the equivalent path under an external blanket. At present the earth-rock dams of the major projects of Salto Santiago, Tucurui and Emborcação in Brazil are being constructed incorporating this design decision (de Mello, 1975b).

\section{Insertion of equipotential adjusters}

The introduction of the facilities of finite element analyses for drawing of flow nets opens new avenues for design optimizations regarding control of flow net conditions upstream of the filter-drainage. One such design idea is herein termed an equipotential adjuster: it may be visualized also as a non-existing pervious feature interconnecting points on different equipotentials so as to force them to a common equipotential.

Figure 24 presents an example of such a design expedient, just as a reminder of the possibility. In order not to alter the basic finite element mesh, the pervious non-exiting feature was introduced with the odd polygonal shape shown. In intention it was arranged so as to improve a full-reservoir flow net parallelism in the approach to the chimney filter (see the 


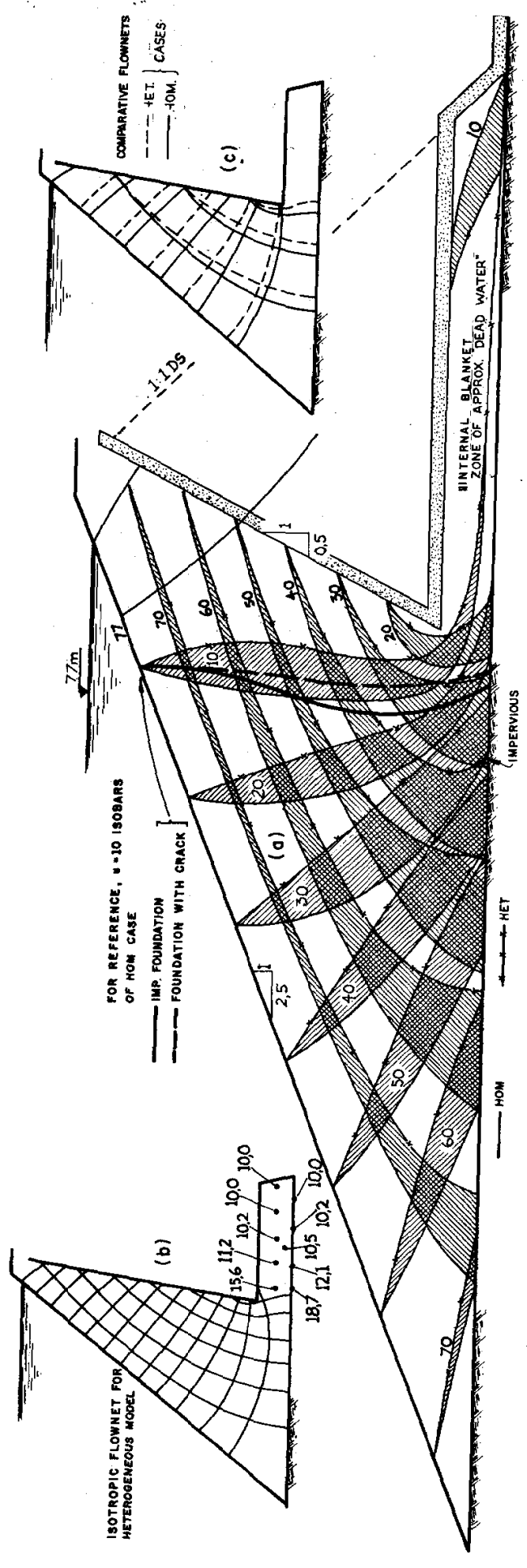

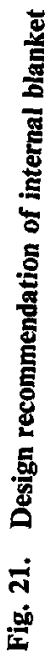




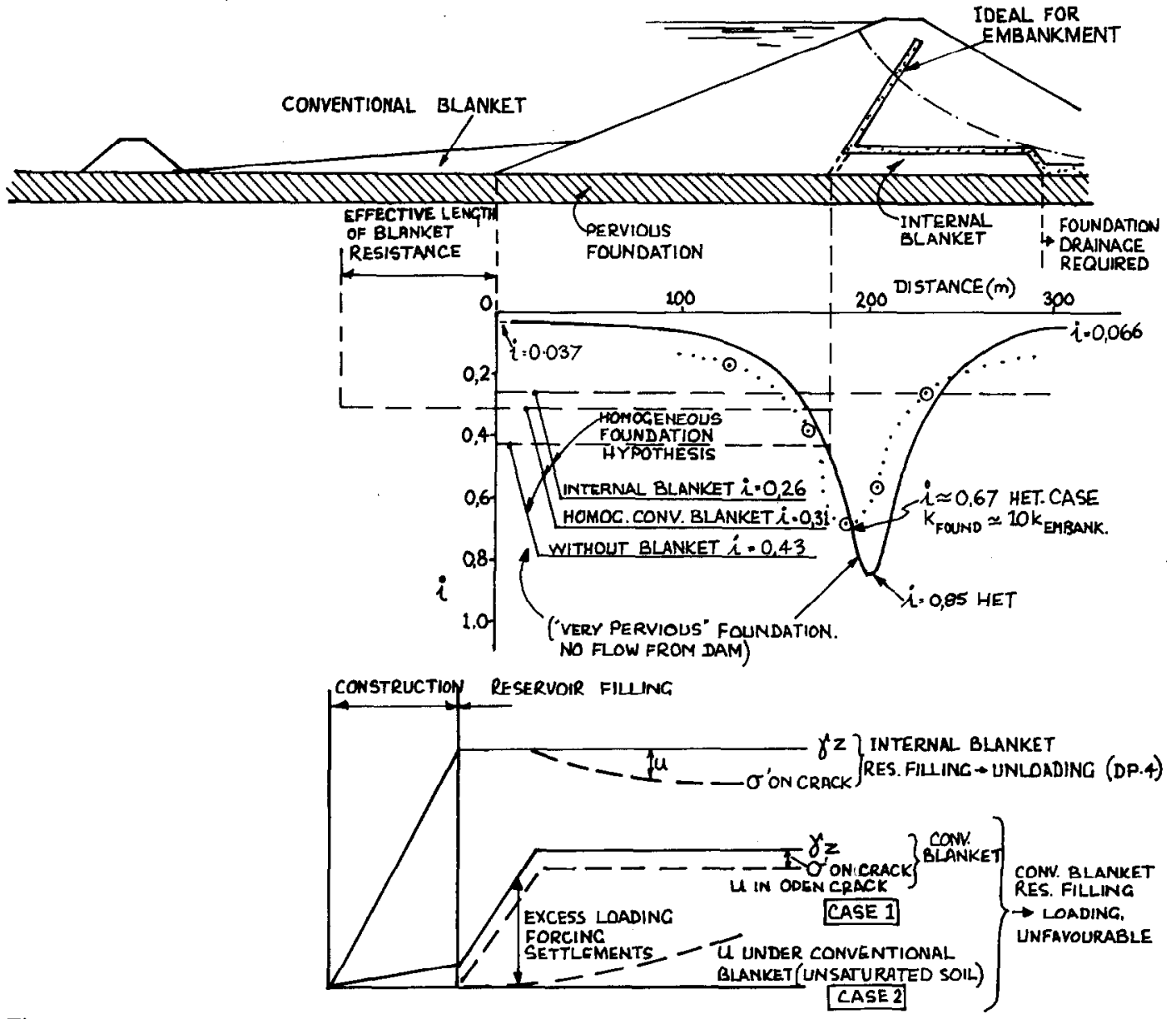

Fig. 22

suggestion of Reinius (1973)) and, if necessary, to counterbalance possible unfavourable effects of greater permeability gradients on the RDD flow net. The potent effects of the measure are well illustrated by the example but the case studied had no specific optimization in mind.

Final summary comparisons of various cases by routine stability and seepage loss analyses

The final comparisons of advantages and disadvantages of various chimney-filter positions in accordance with routine analyses are summarized in Figs 25 and 26. The advantages to both DS and US stability are well demonstrated in favour of US-inclined filters: the insignificant premium paid is of two- to three-fold increase of seepage losses. The $F$ values reported are not those of different critical circles for each case, but truly comparative values for a constant fixed circle, close to critical for all cases. Fig. 25(b) reveals the difference of upstream slope $F$ values for instantaneous drawdown, as computed by the two most recent hypotheses regarding pore-pressures. Although the difference is seen (generally) to be minor, an important point is that routinely encountered US slopes are obviously overconservative, apparently because of lack of confidence in the design analyses. 


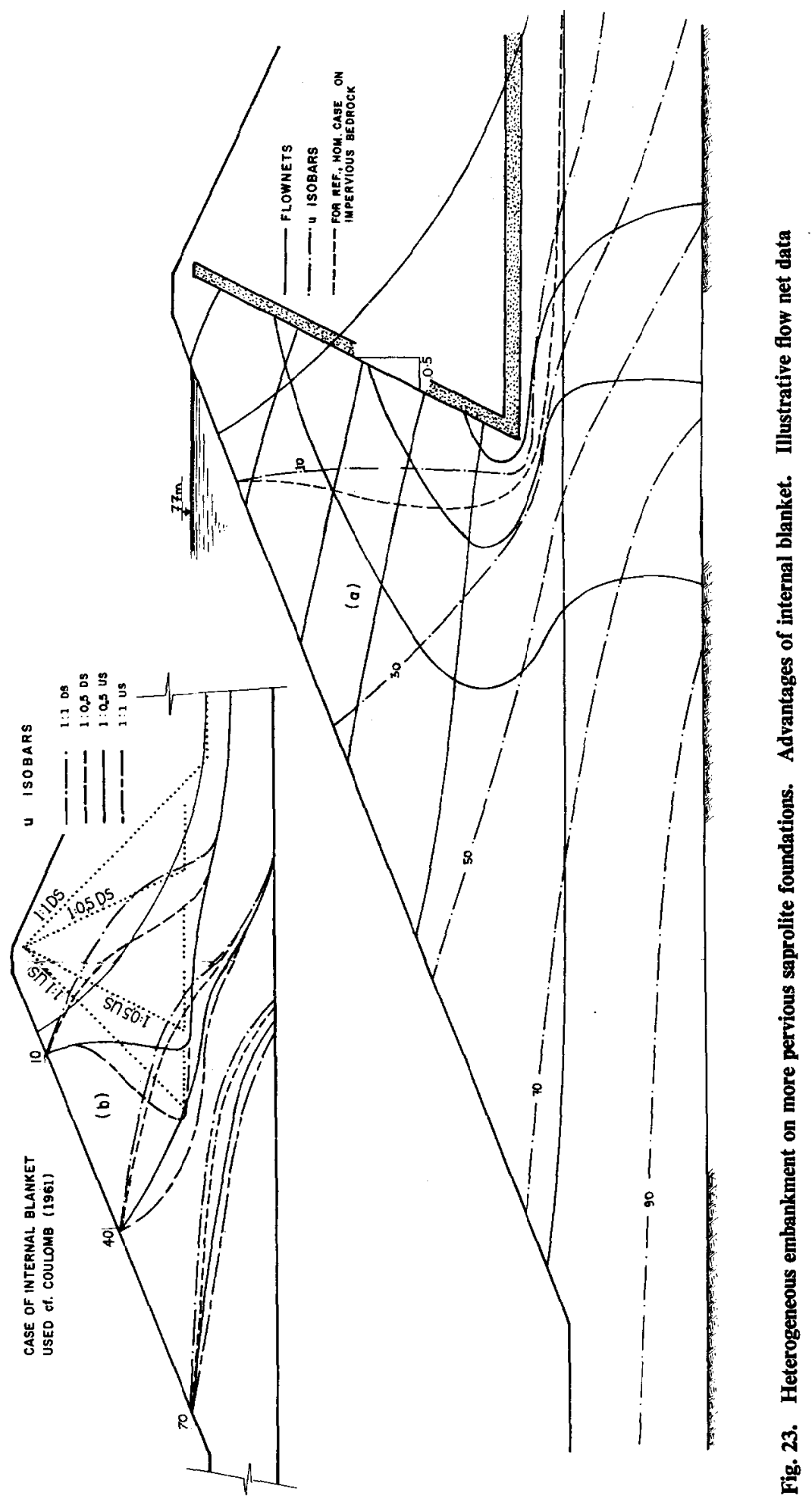




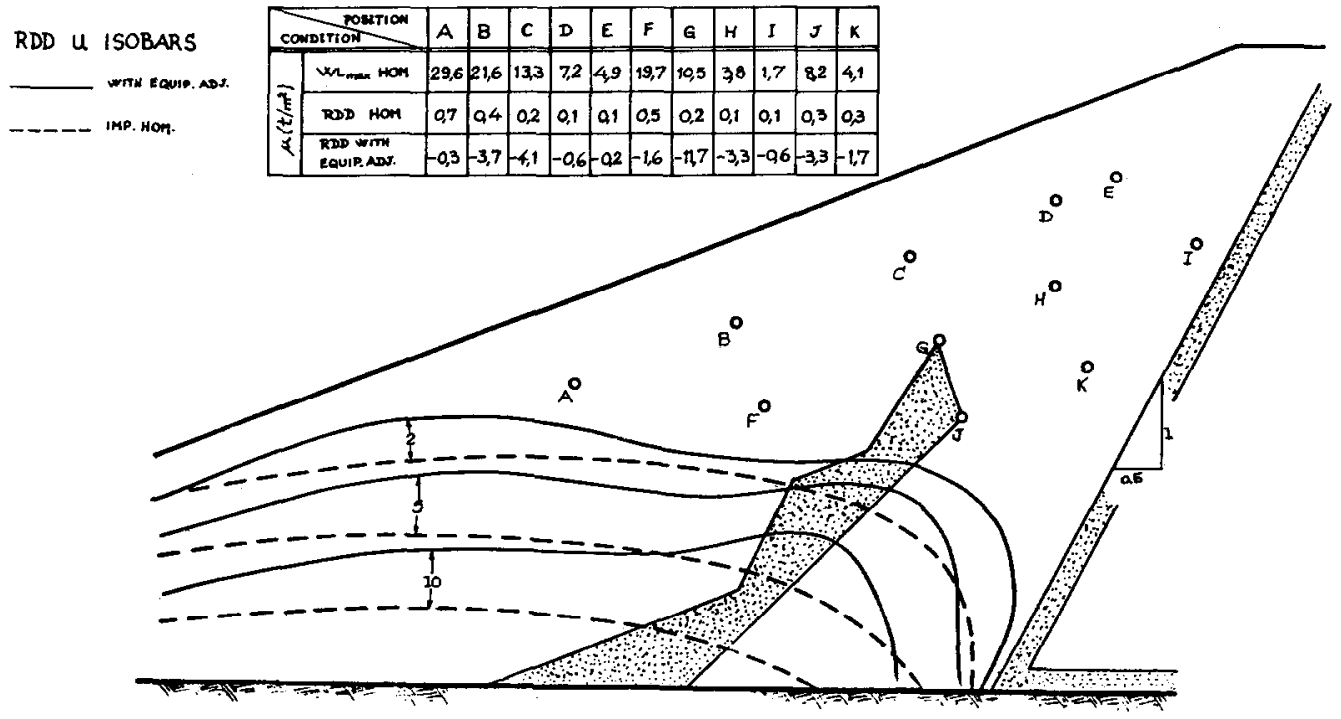

Fig. 24. Use of non-exiting drainage features as equipotential adjusters
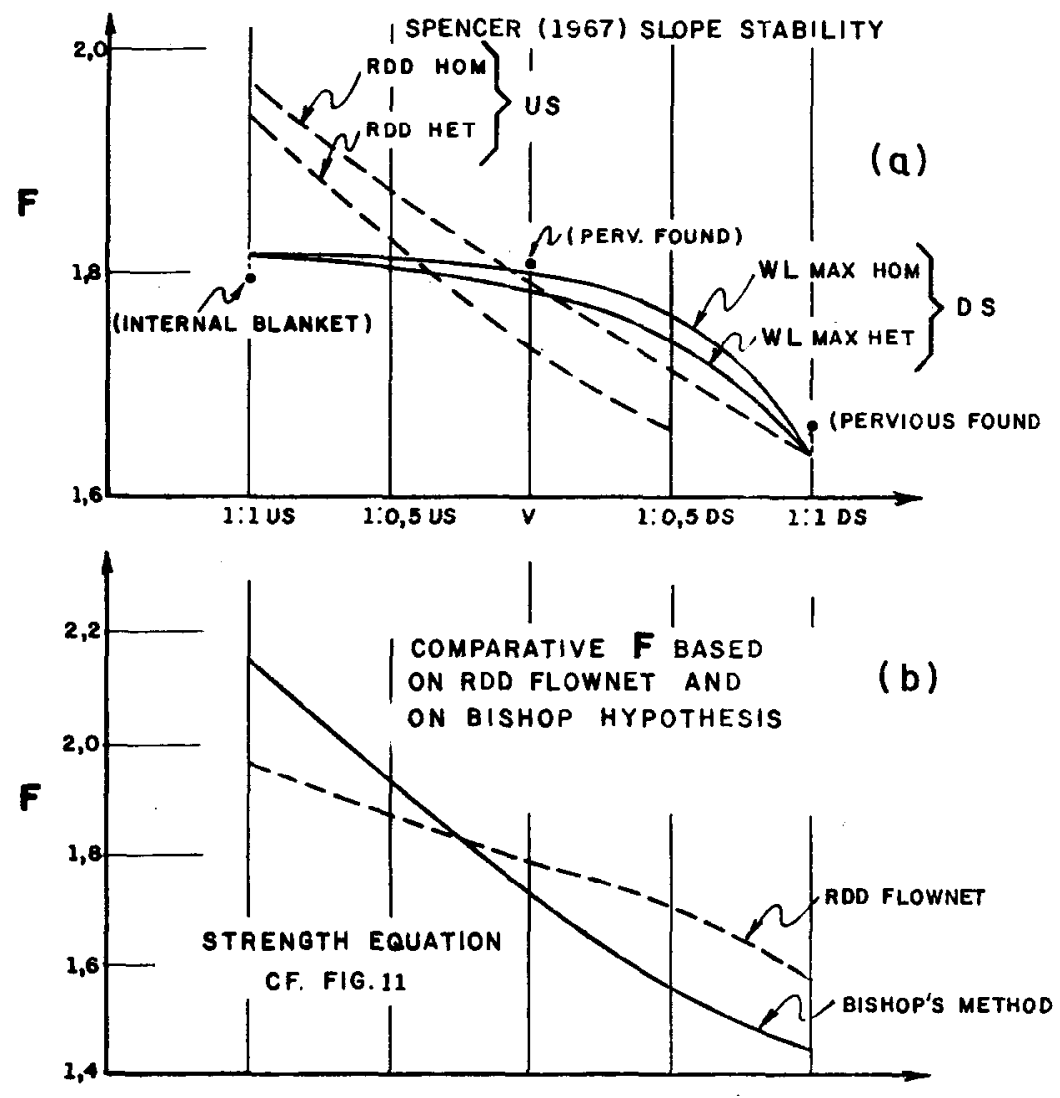

Fig. 25. Final comparisons on current stability analyses 


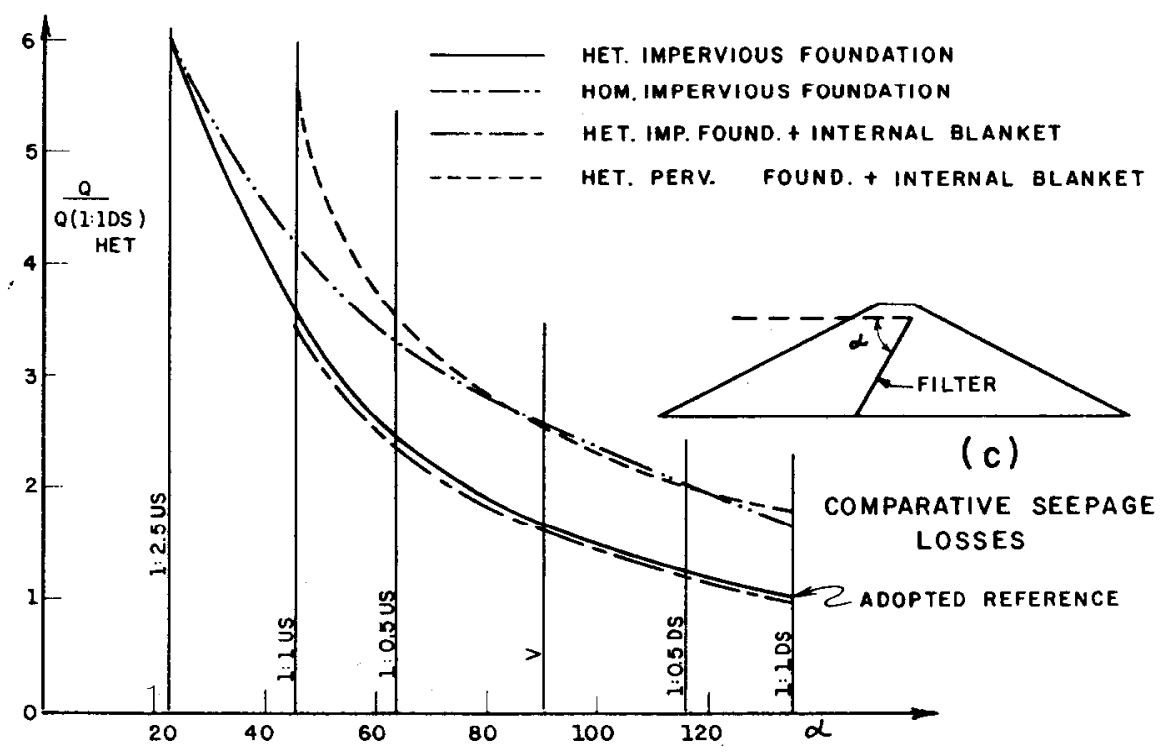

Fig. 26. Final comparison on flow net seepage losses

\section{CONSIDERATIONS ON SOME OTHER PROBLEMS PRONE TO INVOLVING EXTREME VALUE CONDITIONS}

On analysis of some of the principal concerns and failures discussed during the past score of years, one cannot but observe the striking coincidence that they are all associated with phenomena controlled by extreme value statistics: and, as has been emphasized, if there is any possibility of extreme value phenomenology we must obviate it in design choice, before undertaking optimizations within the conditions of averages involved in flow nets, slope stability, deformation computations, and so on.

\section{Filters and filter criteria, localized piping, erodibility and 'dispersive clays'}

The fundamental principle of filtering action can only be the stereometric hindrance of the movement of detachable particles of the soil through the voids of the filter; it therefore concerns particle sizes of the base material and void sizes of the filter. It should be obvious from the very nature of grain size frequency distributions that the phenomenon is entirely dependent on probabilities of a very localized condition: thus, either one were to depend on a great number of tests very well planned and conducted, if deterministically interpreted for the specification of conservative bounds (choice of change of universe), or one should accept some local or partial 'washing through' as probabilistically inevitable, and therefore decide to accumulate a universe of data of prototype behaviour. In fact, neither of the alternatives has been fulfilled. Since it is impractical to attempt to collect data on localized piping potentialities under field conditions (see the recourse to arbitrary definition of piping instability in tests as indicated by a 10-fold permeability increase, Frost (1975)) one must attentively reappraise theoretical formulations and available experimental data. Indirect field experience derives from the number of cases in which bona fide filter packings around wells have reported clogging or washing through. To my knowledge the extensively mentioned published experimental bases of filter criteria are the tests by Bertram (Waterways Experiment Station, 1941), Karpoff (1955) and 

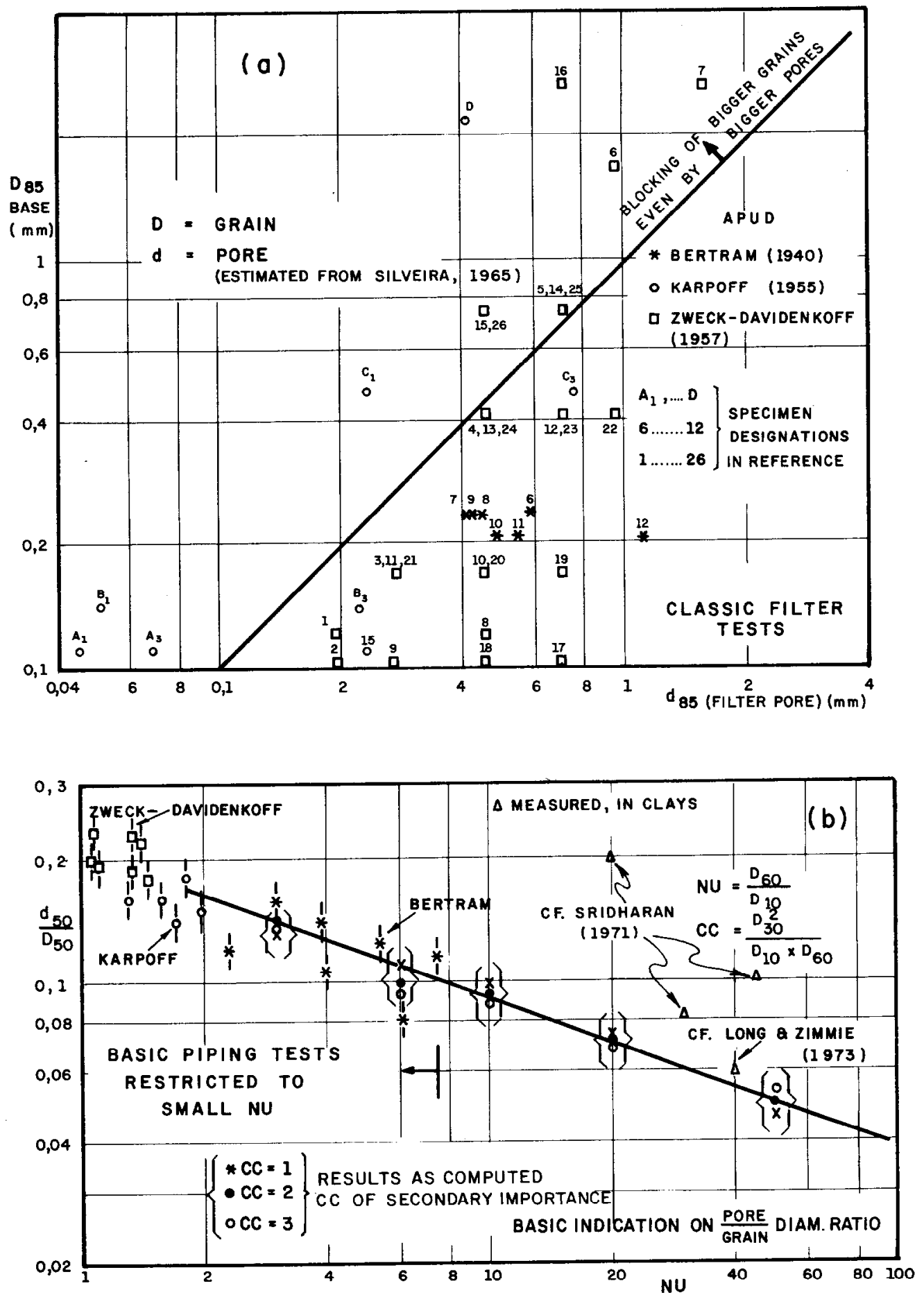

Fig. 27. Basic experimental data on filters referred to estimated nominal pore diameters by using Silveira's formulation 
Zweck and Davidenkoff (1957). Remarkable as they were for the time, they are lacking in many details desired today. However, the only theoretical formulation available (being employed in some quarters) applying the right concept of comparing base grains with filter pores is that of Silveira $(1965,1967)$ and Silveira et al. (1975). The attempt must therefore be made to examine the experimental evidence and theoretical evidence with relation one to another.

Figure 27 examines the basic experimental data on filters and piping with reference to estimated nominal filter pore diameters. In any frequency distribution curve it is preferable to avoid discussing the tail ends, and therefore the finer sizes have been rightly discussed as $D_{10}$ or $D_{15}$ sizes while the bigger sizes are generally discussed as $D_{85}$ sizes. In so doing, however, it must be conceded that the behaviour (probabilistic) at the extremes is not being considered. Now, if we assume self-filtering action within the base material grain size, it is sufficient to retain the $D_{85}$ of the base. Whereas the Terzaghi-Bertram criteria appropriately recognized the self-filtering action within the base material by its own coarser particles, thereby establishing the upper bound for the finer filter particles $D_{158}$ with reference to the coarse base particles $D_{85 b}$, the later and more systematic Karpoff (1955) tests and consequent USBR criteria (USBR, 1960) unfortunately failed to recognize such an important point of distinguishing between limiting requirements for filtering as against permeability, and concentrated merely on ratios of median $\mathrm{D}_{50}$ diameters. A conservative method for checking if there is satisfactory continuity in a grain size curve consists in subdividing (i.e. totally segregating) the curve into two parts; the self-filtering action may then be checked in exactly the same way as when dealing with two soils side by side (de Mello, 1975b). If essentially 'total hindrance' were required, one should desire the big $\mathrm{D}_{85}$ particles of base to be blocked even by the biggest probable pores. It is obvious in Fig. 27(a) that (accepting the nominal pore diameters of Silveira's $\left(d_{85}\right)$ theory) such 'ideal' filtering has not been fulfilled in the tests. Some movement of base particles into filter must take place, but the tests lacked the precision of observation to detect such minor migration.

Figure 27(b) extrapolates the theoretical background to the range of less uniform (higher non-uniformity (NU) coefficients) but continuous grain sizes, and situates the available tests against such a wider spectrum of filters in use. One sees that pore diameters in moderately uniform materials $1<\mathrm{NU}<5$ are of the order of $1 / 5$ to $1 / 10$ of the respective grain diameters, and as $\mathrm{NU}$ increases the ratio of mean pore diameter to mean grain diameter $d_{50} / D_{50}$ decreases steadily. Unfortunately the direct and indirect information for NU $>5$ is almost nil. Meanwhile one notes that the Silveira theorization incorporates an averaging effect due to the hypotheses (evidenced in pore size distribution curves being always more vertical than the respective grain size curves, and absolutely parallel for dense against loose hypotheses). That is, there is limited flexibility of visualization of particle arrangements, which may affect disproportionately the less uniform grain size curves. Nevertheless one could yet hope to apply correction factors for adjusting computed nominal pore diameters to reality.

Figure 28 summarizes the hypotheses of packing arrangements and nominal void diameters deduced by Silveira and co-workers, all on very uniform grain size soils. As mentioned above, the immediate observation is the extreme regularity of the nominal pores computed (see Fig. 28(a), for instance). The same formulation was therefore tested for grainsize curves up to $\mathrm{NU}=50$; the results of interest are plotted in Fig. 28(b). The trend for the bigger pores is obviously wrong. Whereas a well-graded non-uniform soil virtually eliminates big pores, the hypothesis leads to increasing $d_{85} / D_{50}$ ratios as $N U$ increases.

A further confrontation of the theoretical formulation with experimental evidence was tested with regard to the closely related factors of number of interparticle contacts $N$ and the probable 

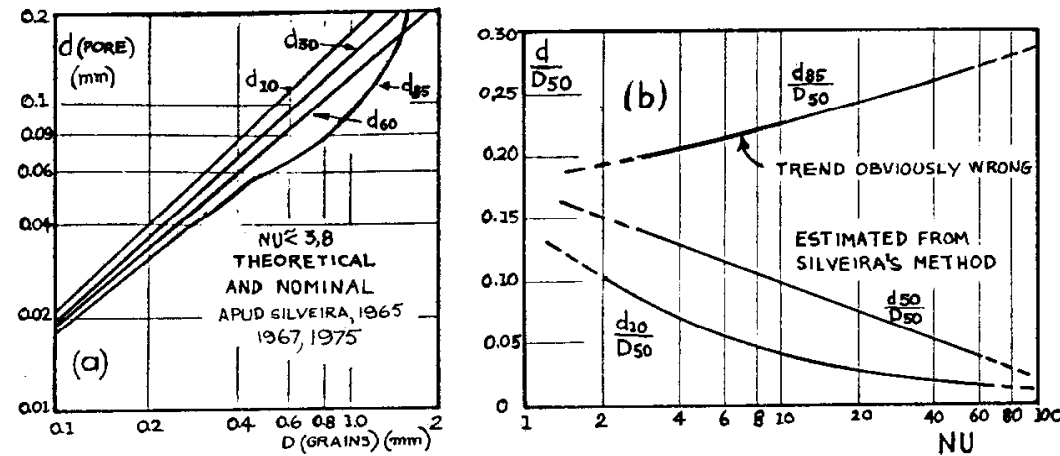

1- DENSE, TANGENT PORE 3 CONTACTS

2-LOOSE, TANSENT PORE, 4CONTACTS

3-DENSE, EQUIMLENT PORE, 5 CONTACTS

4- LOOSE, EQUIVALENT PORE, 4 CONTACTS
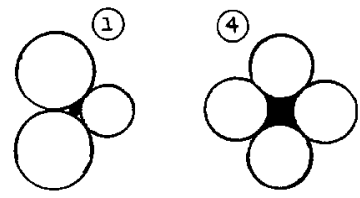

$\mu\left(\equiv Q^{d}\right.$

$\bar{d}=$ EQUIVALENT DIAMETER OF THE VOID.

Fig. 28. Summary of simplified hypotheses and results of Silveira's nominal pores, influence of grain size and nonuniformity

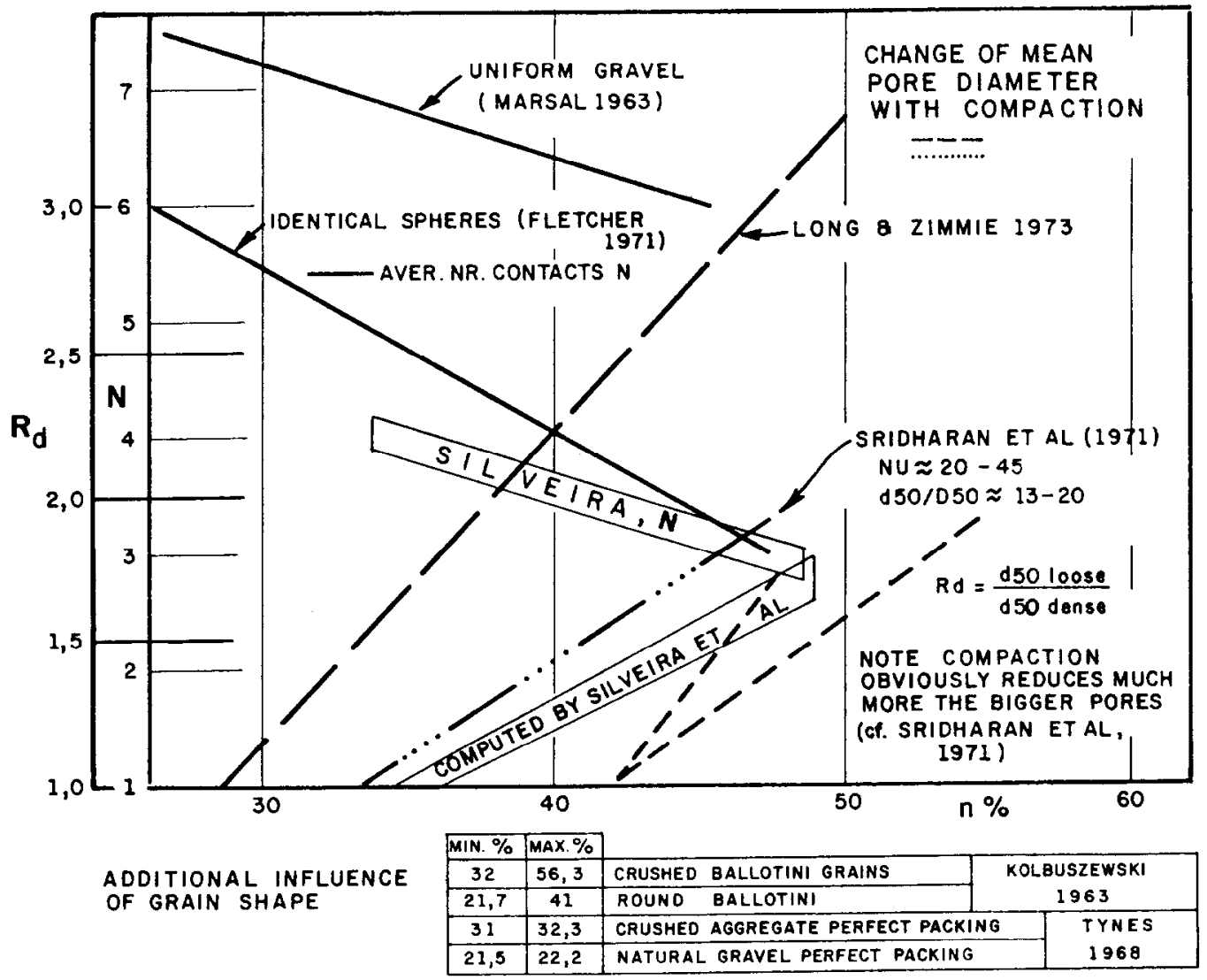

Fig. 29. Influence on compaction on number of contacts and pore diameters 

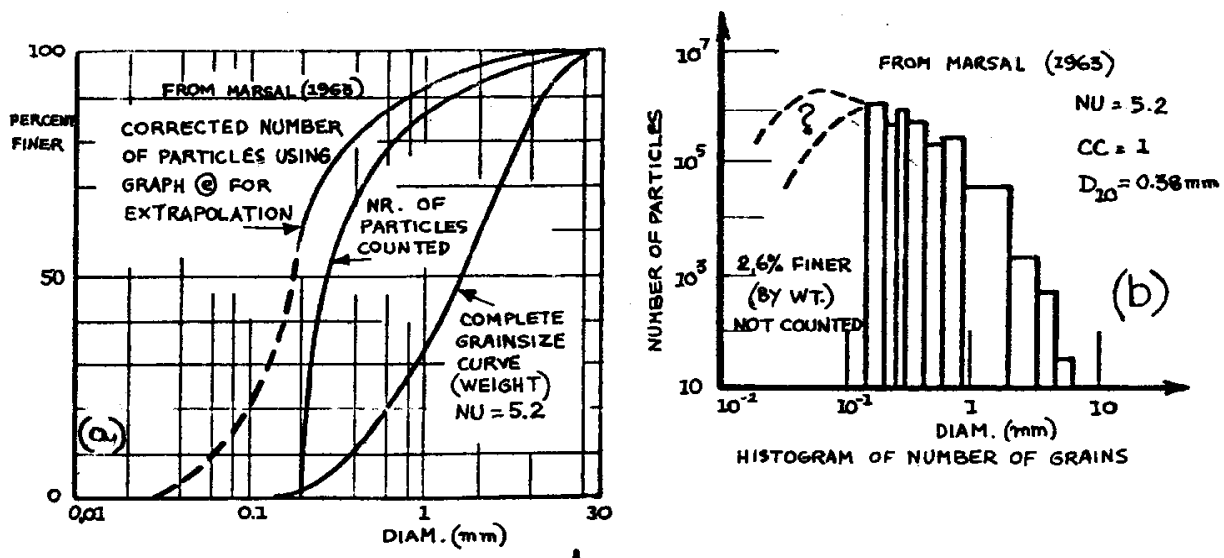

HISTDERAM OF NUMBER OF GRAINS
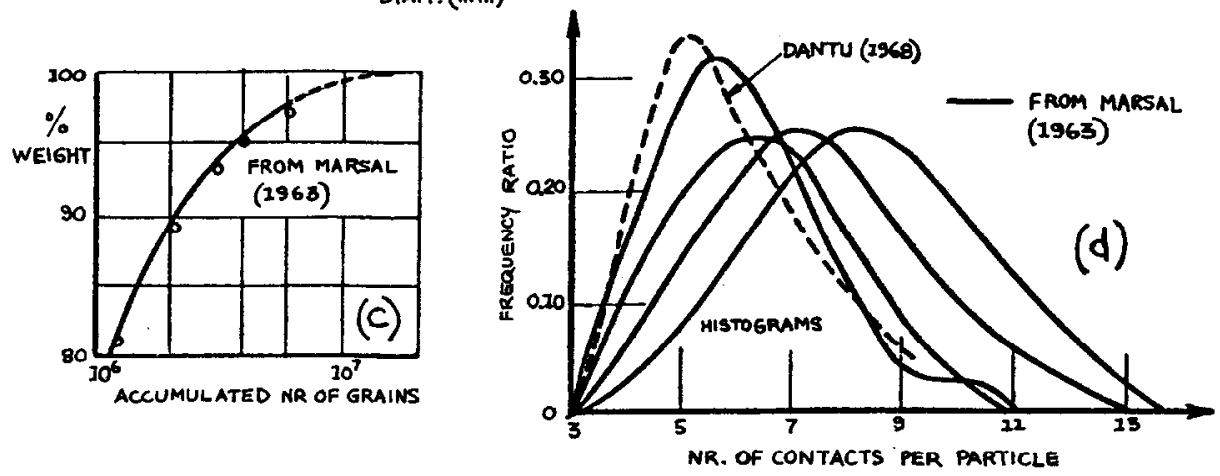

Fig. 30. Suspected source of fallacy in Silveira's formulation, from Marsal's experimental data

ratio $R_{\mathrm{d}}$ of pore sizes in loose against dense states. The data collected from publications are presented in Fig. 29. It appears that the Silveira theory visualization of three to four contacts (in a plane) as opposed to six to eight contacts observed (in space) is not likely to be the principal cause for correction of nominal pore diameters, within the average range. Moreover, the ratios of median loose to dense pore diameters computed and measured are similar.

Dense packings indicate reducing pores to about 35 to $40 \%$ of the respective sizes in looser packings, but the strange result is that all pores reduce similarly, whereas one should expect that compaction would principally exclude the bigger pores. In short, the points of special suspicion appear to concentrate on the coarser presumed pore sizes in soils of higher NU grain size curves.

Finally, Fig. 30 presents the evidence developed which would seem to uncover a basic fallacy in the known applications of Silveira's formulation: it concerns the fact that for computing the probabilities of particle arrangements a frequency distribution curve of numbers of particles (available for the contacts and arrangements) is necessary. The standard representation of grain size as a frequency of weights does not permit visualization of the disproportionate increase in numbers of particles at play in the finer fractions, especially in soils of higher NU. Fig. 30(a) shows comparatively the frequency of particles actually counted (Marsal, 1963) on a well-graded sand of $\mathrm{NU}=5.2$; the final $2.6 \%$ finer fraction were not counted, resulting in the truncated histogram of Fig. 30(b). The graph of Fig. 30(c) was employed to help in completing the frequency distribution of number of grains, and it is seen that the final $2.6 \%$ can represent $60 \%$ of the number of particles. Finally, Fig. 30(d) plots some histograms of numbers of 

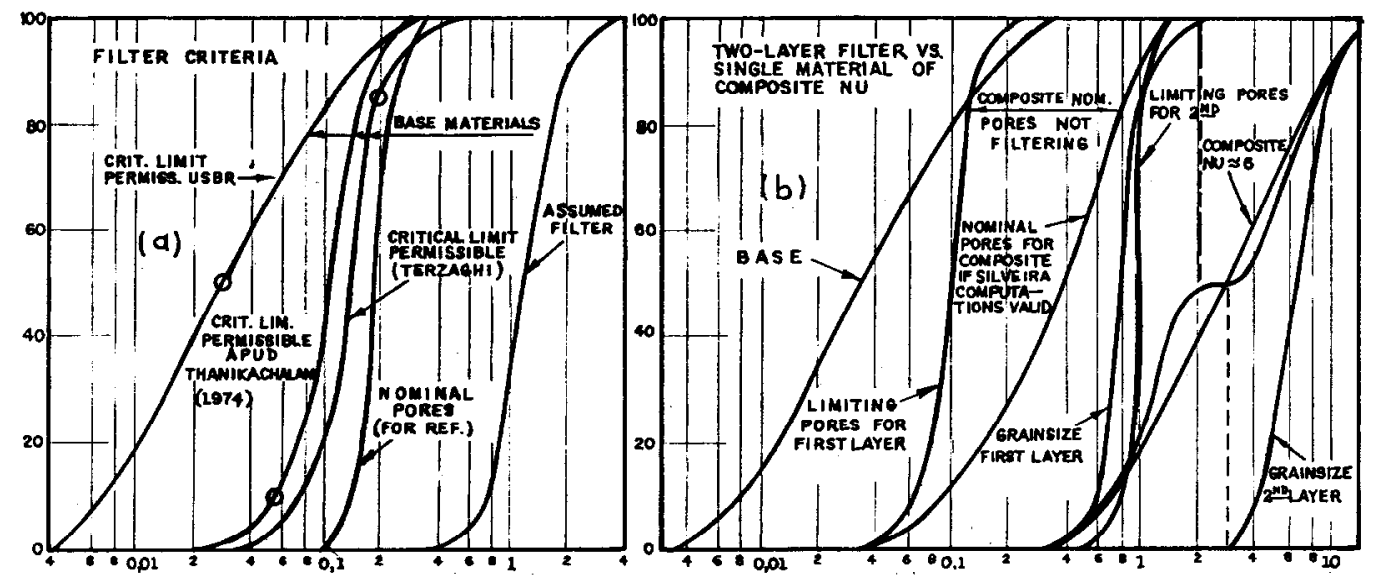

Fig. 31. Apparent inadequacies of present filter criteria regarding: (a) experimental bases for uniform filters; (b) no formulation for non-uniform filters

contacts, which show averages of the order of 6 to 7 with variations from about 3 to 13 , with modest variation from the loose to the dense state. Marsal's data show especially that there are very few big particles representing the top percent by weight; an adjustment from the weight-frequency to the number-frequency distribution curves essentially in proportion to the cubes of diameters alters the shapes of the curves radically. Moreover, as the NU increases, the number of big particles becomes minimal, and whereas the arrangements with other big particles become altogether unlikely, the number of contacts for the few big particles is very great, of the order of hundreds, with fine particles increasingly available for the denser arrangements.

In short, it must be concluded that the existing theoretical formulation for pore sizes is unsatisfactory, notwithstanding the apparently acceptable results with relatively uniform soils. The all-important subject of filter criteria for physical guarantee against extreme-value situations of piping erosions (DP 1) calls for immediate revision. In uniform soils the nominal computed pore diameters may be acceptably realistic but, as shown in Fig. 31(a), the experimentally based filter criteria appear unsafe, since the finer limits of base materials permissible (computed backwards from the assumed filter) represent grain diameters finer than those of the nominal pores of the filter. In non-uniform soils there are no tests (Fig. 27) and the theoretical formulation suffers greatly from the fallacy pointed out. Fig. 31(b) compares the nominal filtering capacity of a single material of $\mathrm{NU}=6$ against two sublayers of the respective uniform upper and lower $50 \%$ fractions: the single material would appear less satisfactory, which is contrary to all indirect evidence.

Since the significant reduction of pore sizes with increase of NU should be reflected principally at the bigger pore sizes, for filtering action there should be an unquestionable preference for materials of high NU, as long as there is no segregation in construction activities. There are no published data on tests on grain size segregation. Moreover, another important type of segregation that could occur concerns densities in the case where a finer fraction is insufficient to fill densely the voids of the respective coarser fraction: there are also no test results on such density segregation conditions. It must be noted that crushed rock filters give roughly 30 to $50 \%$ higher porosities than subrounded gravels of equivalent diameters. 
Filter criteria must also guarantee a sufficient permeability (compare the Terzaghi-Bertram lower limit) of the filter-drainage to avoid requiring excessive heads for drainage of the flows (Cedergren, 1960). Frequent recommendations are, arbitrarily, for drainage capacities 10 to 100 times the anticipated seepage. The subject can be treated by flow nets and factors of safety, because of the cumulative nature of the phenomenon. The $F$ values, however, should preferably be of DS stability, considering the range of error possible in foundation permeability estimates, being adjusted on the basis of sensitivity analyses for the design section: in short, after the presumed optimizations, in accordance with DP 5 one should check how far the $F$ value of DS stability would be affected if the drain turned out insufficient, in cases of a rapidly filling reservoir; it is such design exercises that strongly support the preference for the internal blanket. Of course, a first question concerns the permeability estimates for the filter. The right approach will employ regressions for $k \mathrm{~cm} / \mathrm{s}$ as a function of the pore size $\mathrm{d}_{10}$ (Silveira et $a l ., 1975)$ tending to correct in a logical direction the traditional, misguiding relationships on the basis of the $D_{10}$ of the grain. A frequent serious error is of gross underestimation of permeability reduction due to fines in a well-graded material, and due to compaction (a requirement to be carefully appraised). An added word of caution concerns further reduction of the permeability by compressions under high overburden stresses: the permeability gradient should favourably increase, from the 1:1 DS point where base drainage begins to be necessary, towards the toe.

Special mention must be made of the several publications concerning localized seepage pressures and statics of piping resistance, accompanied by laboratory tests under highly idealized test conditions. In the light of my concern with extreme value problems all the studies in question are felt not to avert the hypothesis of localized migration because any special exit seepage stresses and directions (Davidenkoff, 1955; Zweck and Davidenkoff, 1957; Wolski et al., 1970) or any conditions of arching equilibrium (similar to the trapdoor case (McNulty, 1965)) with probabilistic formulation (Kjellman, 1964) or with reliance on cohesion (Zaslavsky and Kassiff et al., 1965; Davidenkoff, 1965) still imply localized averages. The approach of Peter (1970) studying the dynamic equilibrium of a spherical grain in a seepage pipe might be more applicable to studies of ' self-healing' properties of graded cores already subjected to minor erosion. In the face of such excellent efforts that improve the feel for the problem at stake one must refer back to the very important design principles DP 1, and DP 3 to DP 5, and conclude that such partial solutions are devoid of the necessary guarantee. For instance, if one recognizes the importance of cohesion and tensile strength (Zaslavsky and Kassiff, 1965) and of surcharge, though minimal (Kassiff et al., 1965), one must emphasize the importance of plasticity, plastic compaction (e.g. Wolski et al., 1970), direction of seepage stresses, stress redistributions due to embankment movements, compaction gradients across lifts, construction imperfections at clay-filter interface and, inevitably, the time effect in producing the gradual swelling of the compacted clay to a possible total loss of cohesion. Construction procedures obviously result in significantly different interface conditions: in general because the contiguous sand impedes kneading, the clay, frequently quite granular (Wesley, 1973), is even more so at the interface, with a rough surface in no way similar to that of laboratory specimens compacted against metal cylinders, and in an 'unplasticized' powdery condition conducive to collapse and erosion.

Design decisions must therefore transcend such formulations. Only upstream inclined filters should be used, to guarantee positive pressures: seepage, gravity, hydrostatic, or from stress-strain redistributions. In case of doubt, or irrespective of it, err in the direction of finer filter void sizes immediately downstream of the core by use of well-graded cohesionless material. The filtering action is obviously of prime concern whereas the drainage action (that is, control of the flow net) is unaffected by such minor shifts in effective face of chimney. If 
permeability is lower than desired it is tantamount to having increased by a very modest width the impervious core; the coarser fractions of this first transition permit the next layer downstream to employ amply draining pervious material. One notes with interest that in the face of the very complex problem, the type of grossly simplified solution exemplified by Lane's creep ratio has not fallen into total disuse (Nakazima, 1968; Breth and Gunther, 1970).

Erodibility of silty soils and dispersive clay piping must yet be mentioned, and, at the opposite end, there are the problems of 'self-healing' and clogging (including presumed chemical clogging by ferruginous depositions) on which crude intuitions furnish the only support.

Within the context of this Lecture, suffice it to consider as an example the problem of socalled dispersive clays, and to refer the problem to Fig. 2, notes (e) and (f) of extreme-value failure problems, either progressive or tending towards automatic stabilization.

The recognition of inevitable medium-term chemical influences on colloidal equilibria (Aitchison et al., 1963; Ingles and Aitchison, 1969; Ingles et al., 1969; and many others) and their effects on piping failures, constituted a very important signal of caution to dam engineers with regard to catastrophic failures that would appear to transcend the determinism of the comfortable period (circa 1945-1960) of assumed flow net and stability analyses. However, the cry of caution must be even greater against the upsurge of dubiously formulated concepts and practices that have arisen therefrom, both in the scientific line of investigation and in the engineering need of positive solutions against risks of catastrophic failure. It has been the emphasis of this Lecture that it behoves the engineer to appraise first the statistical nature of the problem, whether extreme-value dictated or associated with averages. It can be directly recognized that even more than physically-induced erosions, the colloid-chemical universe of soil science that composes the soil physics and soil mechanics universes, is uncomfortably elusive within extreme-value statistics. In such conditions one cannot base engineering decisions of great risk and consequence on such tests and formulations as are accompanied by statistically undefinable qualifications such as: 'such action is probably impossible', 'in all records known to the writers', 'sample either disperses immediately or it does not', and so on (Sherard et al., 1972, 1976). A spillway design cannot hang on the partial data implied in specific records individually known.

It may or may not be proven that most cases attributed to first-filling dispersive clay piping really derived from excessively dry compaction in 'unplasticized condition' in arid regions, involve significant associated horizontal layering of compaction gradients, drying shrinkage cracks, quick filling in arid-region hydrology, and so on. The fact does stand out, however, that generally there were no fully intercepting chimney filters. However, even such a point need not be stressed, inasfar as 'generally' does not establish sufficient statistical force with regard to extreme-value conditions that require abstraction to the limit. The fact is that all tests on when erosion does take place may impede the engineering solution that requires a statistical universe of guarantee, beyond an upper or a lower bound, of when erosion is positively impeded.

Well-conducted grainsize distribution curves should employ the best available dispersant, and therefore establish a lower bound for particle sizes to be physically filtered (barring chemical solution). Next, as discussed above, the appropriate filter material should aim at stereometric hindrance of base particles by filter pores. Finally, against progressive deterioration of any start of migration, the aim is towards seepage stresses causing compressions (filter inclined upstream). Regarding guarantee against some clogging of the soil-filter interface it has already been emphasized that with an US-inclined filter, the DS stability is not impaired even if an impervious membrane develops at the US soil-filter interface. Thus, while scientific investigation proceeds on the problems of erosion, deflocculation, dispersivity, and so on, the engineering solution limits itself to requiring the fully-intercepting US-inclined chimney filter. 


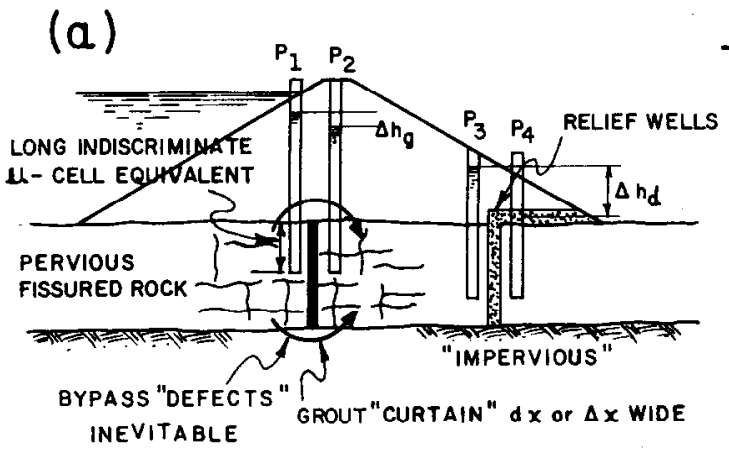

INEVITABLE
GROUT "CURTAIN" vs. DRAINAGE

MENTAL MODEL :-

ROCK HOMOGENEOUS, PERVIOUS;

CURTAIN EXPECTED TO BE $d x$ WIDE,

i. IMPERVIOUS DISCONTINUITY

IN PERVIOUS MEDIUM.

OBSERVATIONS: $\triangle$ hg $\ll \Delta h$ d

$\therefore$ gROUT CURTAIN INEFFICIENT.

EXPLANATIONS (DACHLER, AMBRASEYS, ETC)

DEFECTS IN CURTAIN OF $k \approx 0$; REASONINGS QUITE OBVIOUS BASED ON FLOWNETS ETC. STATISTICS OF AVERAGES.

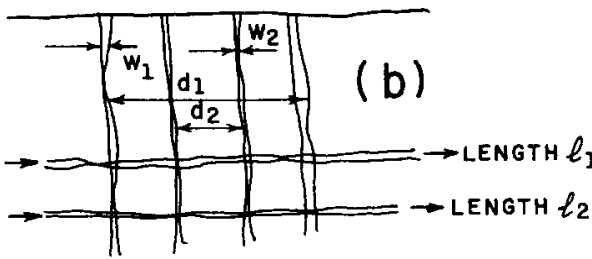

IN MANY ROCKS CORRECT MENTAL MODEL:

FREQUENCY DISTRIBUTION OF CRACKS: HIGHLY HETER, PERMEABILITIES SEPARATING IMPERVIOUS ROCK $\therefore$ DISCONTINUOUS MEDIUM. (ESPECIALLY IN DENSE BRITTLE ROCKS, TENSION CRACKEDETC)
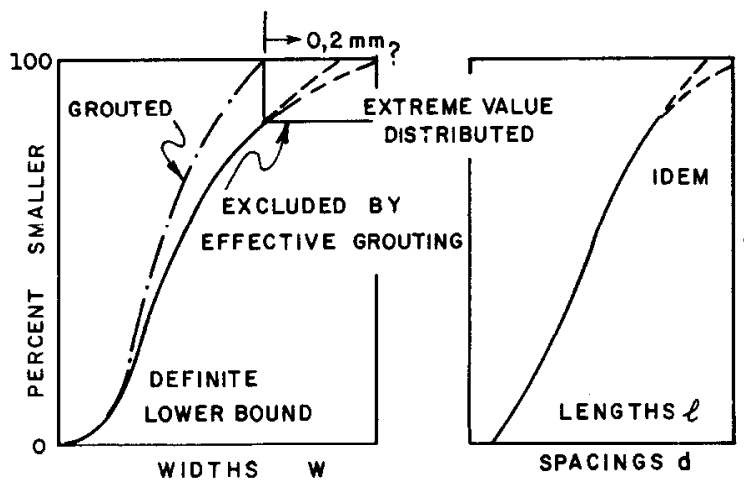

FLOW $Q=f_{1}(W)^{3}$ PLANE FISSURES $=f_{2}(w)^{4}$ CYLINDRICAL "

$\therefore$ FLOW DOMINATED BY FEW WIDER (AND LONGER) CRACKS. EXTREME-VALUE INDETERMINATION EXPONENTIALLY AGGRAVATED.

TYPICAL BORE HOLE LUGEON TEST DATA AND PINCHING - IN PROBING BY DOUBLE - PACKER

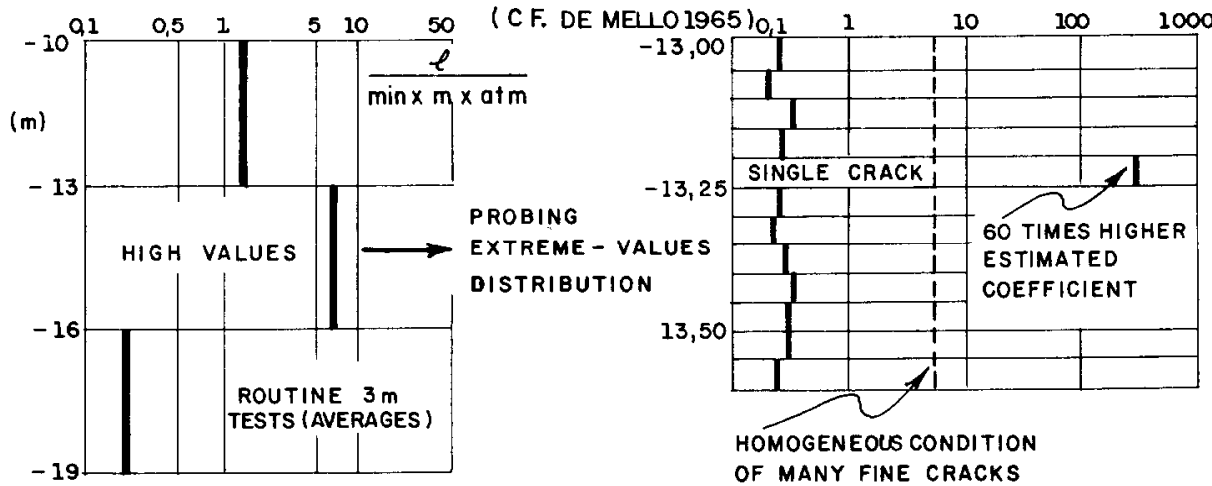

Fig. 32. Grouting of fissured rock viewed as homogenizing treatment attempting to exclude extreme-value conditions 

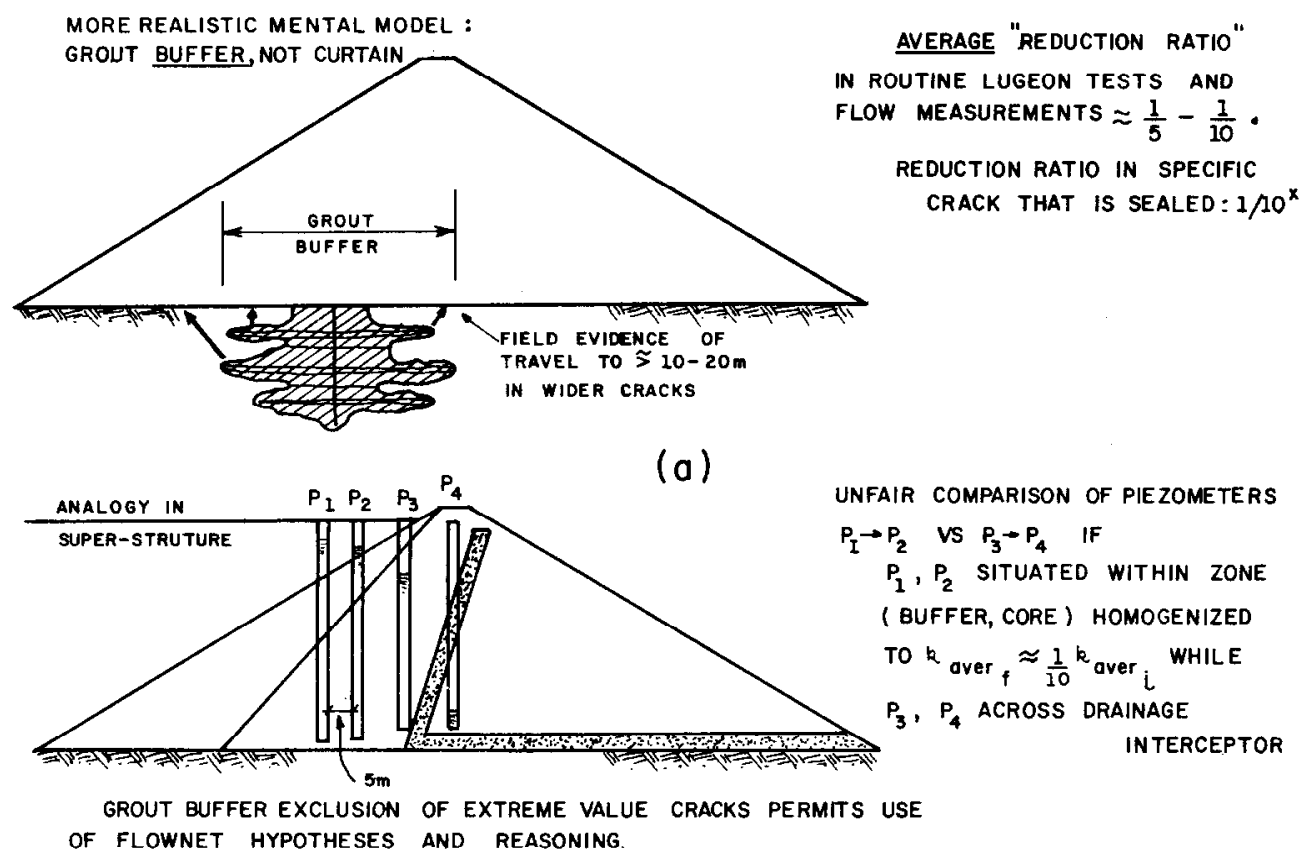

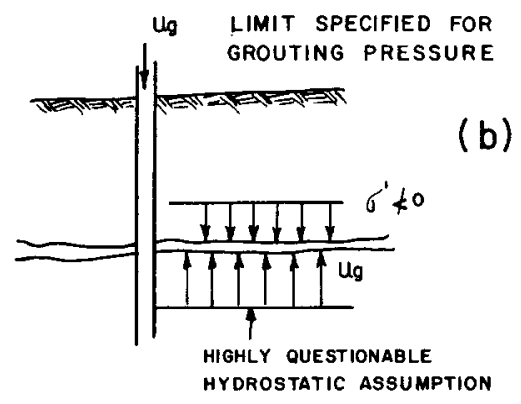

PRESSURES DURING

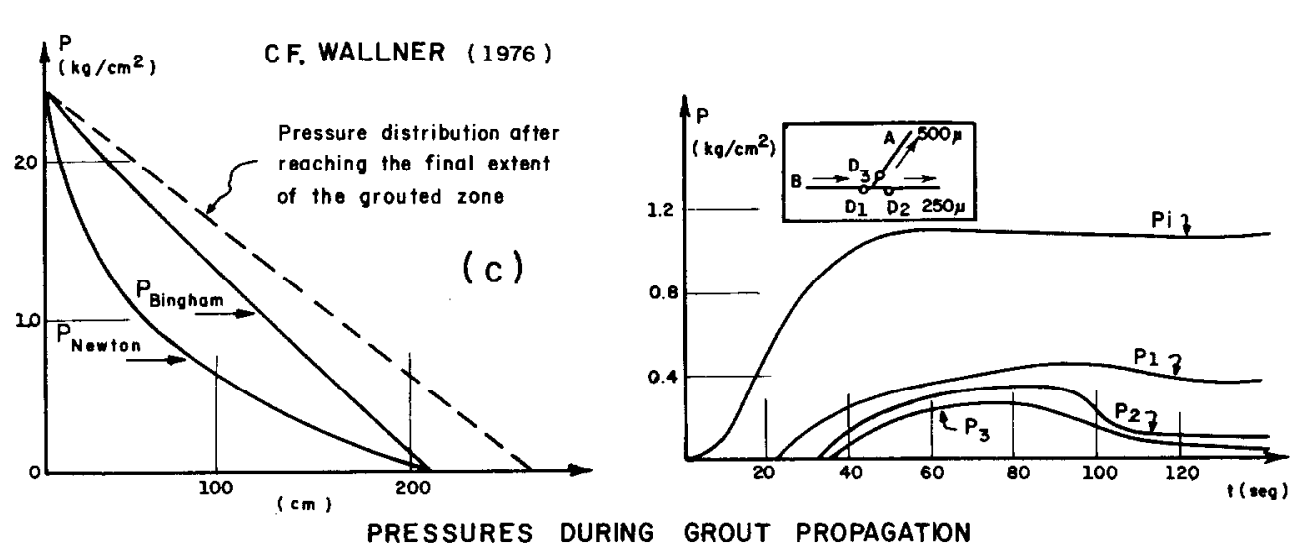

INEVITABLE STRICTIONS IN ASSUMED

CONSTANT-WIDTH CRACKS

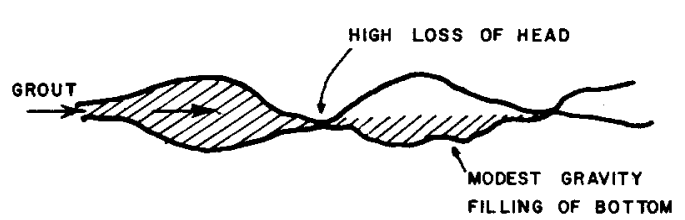

ESPECIALLY DANGEROUS IN ROCKS WITH FUMAROLES, CAVITIES ETC

Fig. 33. Effect of grout buffer compared with drainage interceptor. Some questions on grouting procedures 


\section{Foundation grouting and drainage}

The very important debate initiated by Casagrande's (1961) Rankine Lecture has been mistakenly interpreted as a call for a stand in favour of one of the treatments as if accompanied by dismissal of the other. A more realistic attitude generally adopted has been to consider drainage as obligatory, and to accept a so-called 'exploratory grout line' as a permissible complement. As both measures end up being used, one may encounter reasoning towards minimizing the extent and expense of either or both, since the prevalent assumption is that both aim at achieving the same effect; thereupon, the danger lies in concepts and practices that, when transplanted from one site to another without appropriate interpretation of the conceptual model, might thwart the effectiveness of both. One must caution the designer, that a mental model applicable to one type of rock and foundation condition may be quite inapplicable to another type of rock and foundation; it is not because a subject is complex that one may with impunity apply over-simplified reasonings digressing completely from reality, as assuming a rock to be a soil, a grout line to simulate a curtain equivalent to a steel sheetpile cut-off, injection pressures generating radial flow conditions to be hydrostatic, and so on.

In the light of this lecture's leitmotiv, chronologically it is the grouting that must be decided on first, and, if applicable, must be given priority. In pervious foundations subject to the statistics of averages it is accepted as reasonable that one should first hinder seepage infiltration into the foundation (blankets, cut-offs) and subsequently provide drainage for control of the seepage (i.e. control of pore-pressures and exit gradients) that would have penetrated anyway. In a rock with open joints, hindering infiltration is a definite $a$ fortiori prerequisite. The fundamental point is that flow through open discontinuities represents an extreme value condition which must be excluded in accordance with DP 1, before the drainage treatment, applicable on the flow net principle of statistics of averages.

Grouting has been mistakenly conceived as a 'curtain' of very limited thickness (due to association with driven sheet-pile cut-offs in alluvia) and, therefore, being presumed to constitute a thin discontinuity within a continuum, has been challenged as to its effectiveness by comparison of uplift a few meters upstream and downstream of the grout-curtain centre line (Casagrande, 1961 ; Bolognesi et al., 1965). The mental model in question is shown schematically in Fig. 32(a). Obviously one can recognize some margin of error in the assumptions of upper and lower impervious boundaries to the pervious foundation, of flow net assumed intercepted, as well as in the acceptance of pore-pressures across a significant stretch of hole as piezometer readings, for questioning the overall grouting benefits, although the sealing of a particular crack is unquestionable. However, the basic point herein raised is with the mental model itself, and with the right to employ flow nets to a discontinuous rock medium of absolutely impervious masses separated by cracks of permeabilities varying exponentially.

Figure 32(b) presents a more appropriate mental model of a rock with open joints or irregular cavities as a mass statistically interspersed with discontinuities. If we postulate frequency distributions of widths of cracks, and of spacings between cracks of different widths, some indications on such distributions of the highly pervious discontinuities within the impervious rock material may be extracted from water pressure tests between packers. By pinching in the distance between packers to practicable limits of a few centimetres, often a significant water loss initially attributed to a $3 \mathrm{~m}$ stretch may be detected to pertain to a single wide crack. Thus by carrying to the limit a single crack hypothesis, a local permeability may be proven to reach about 500 times the average initial Lugeon indication. Such a variation must be superposed on the initial variations of Lugeon indications from stretch to stretch, which frequently run to one hundred to one thousand-fold. Obviously in such rocks one faces difficult extreme value 
conditions. Snow (1968) tackles the problem statistically with results of considerable interest; however a Poisson distribution is assumed (not an extreme-value PDF), and therefore the worst possiblc conditions may not be covered.

Alternatively and concomitantly, further indications on frequencies of crack widths, spacings and lengths are obtained from measurements in geologic investigations (Priest and Hudson, 1976). Once again, by determining the average possible distributions of discontinuity spacings, and utilizing a negative exponential distribution function, the extreme value statistics are not covered. Moreover, in the case of direct measurement of crack widths (which is a more indirect index of desired permeability indications) the further trouble is that permeability is proportional to the cube or fourth power of the width or diameter. In short, in many rocks one evidently may face an extremc valuc condition. Fig. 33 accordingly presents schematically what is believed to be a more appropriate model. No grout penetrates into fissures below a certain width, and therefore, as shown in Fig. 32(b), all that can be done is to exclude the upper part of the width frequency distribution. Grouting constitutes a buffer zone (not a curtain) within which wide cracks tend to be excluded. The effectiveness of such action is manifold, including increased moduli of elasticity as shown by tests before and after grouting. The favourable point is that grout may travel farthest (given appropriate pressure, and stability of the suspension) in the widest cracks, which generally tend to be longest (and at more irregular and distant spacings). It may thus be concluded that, if properly conducted, grouting is a selfproving treatment (as jacked piles) capable of giving greatest improvement where most needed (and absolutely none where not needed): it is a homogenizing treatment in a discontinuous medium.

In Fig. 33(a) by analogy with the dam superstructure one can immediately see why two piezometers within a grout buffer (equivalent to the core zone) cannot reflect a perceptible loss of head. Once the flow net has been established free of extreme conditions, the control of pressures by drainage is the only obvious solution. Finally, Fig. 33(b) schematically summarizes some indications of how physical models poorly postulated may very much affect the efficient achievement of the grout buffer. The principal question concerns the hypothesis that grouting pressure should not be permitted to exceed a geostatic vertical effective stress, disregarding residual stresses in rocks, grout pressure propagation in homogeneous cracks, influences of inexorable constrictions, and so on. The results of recent finite element analyses and tests (Wallner, 1976), some of which are reproduced in Fig. 33(c) confirm what has been accepted as intuitive from field observation. It is mandatory to consider each rock and foundation, with respect for its probable discontinuities and behaviour.

\section{Instrumentation}

It might seem strange that instrumentation should be included as an item of design decision of practical significance to embankment dams, and even stranger to see it inserted in a section dedicated to extreme value problems. However, a moment's reflection on the importance presently assigned to instrumentation and performance observation of a dam during and after construction, will surely confirm that some appreciation of the problem is appropriate and necessary. On attempting to interpret the facts concerning some of the more difficult and daring dam designs of recent geotechnological times, one perceives that an important consideration was the faith in instrumentation and observation, coupled with the presumed recourse to the observational method as a hopeful design philosophy for innovative cases fraught with 'calculated risks'. It appears fair to postulate that were it not for the faith in instrumentation and performance surveillance, dams such as the Terzaghi, Aswan and Baldwin Hills, among others, might not have been considered for design and construction at the time when they were. 
BAYES' THEOREM - PRIOR DISTR. $\varepsilon-N\{\bar{\varepsilon}, V(\varepsilon)\}$, NORMAL DISTR. OF MEAN $\bar{\varepsilon}$ VARIANCE $v(\varepsilon), n$ TESTS ESTIMATES $\{\bar{x}, v(x)\} \rightarrow$ POSTERIOR DISTR. OF THE MEAN Eै IS $N\left\{\bar{\varepsilon}^{*}, V\left(\bar{E}^{*}\right)\right\}$ WHERE :

$\bar{\varepsilon}^{*}=\frac{\bar{x} \cdot v(\varepsilon)+\frac{1}{n} \cdot \bar{\varepsilon} \cdot v(x)}{v(\varepsilon)+\frac{1}{n} \cdot v(x)}, v\left(\vec{\varepsilon}^{*}\right)=\frac{1}{n} \cdot v(x) \cdot \frac{v(\varepsilon)}{v(\varepsilon)+\frac{1}{n} \cdot v(x)}$

EX. $\bar{r}_{u}=0,2 \quad V_{\left(r_{u}\right)}=0,0056$

19I OBSERV. $r_{u}^{\prime}=0,05, V_{\left(r_{u}\right)}^{\prime}=0,0056$

$r^{\prime \prime}=\frac{0,05 \times 0,0056+0,2 \times 0,0056}{0,0056+0,0056}$

$r^{\prime \prime}=0,125$
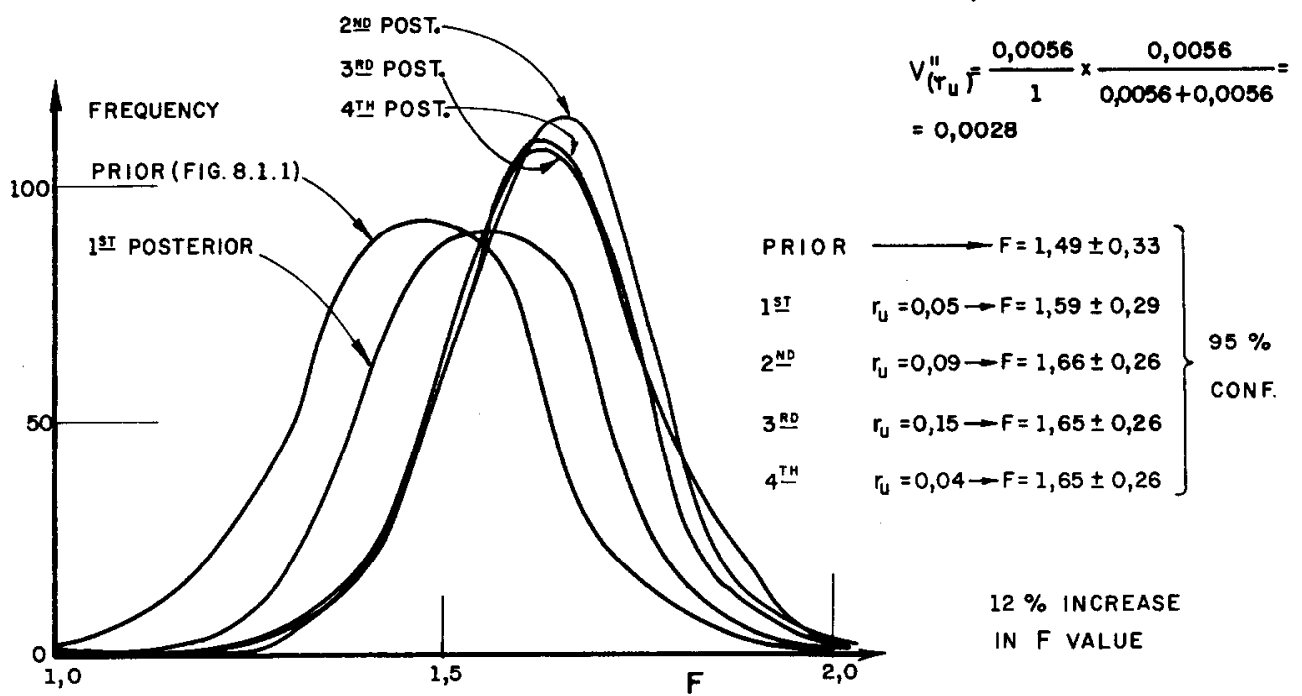

$12 \%$ INCREASE

in F value
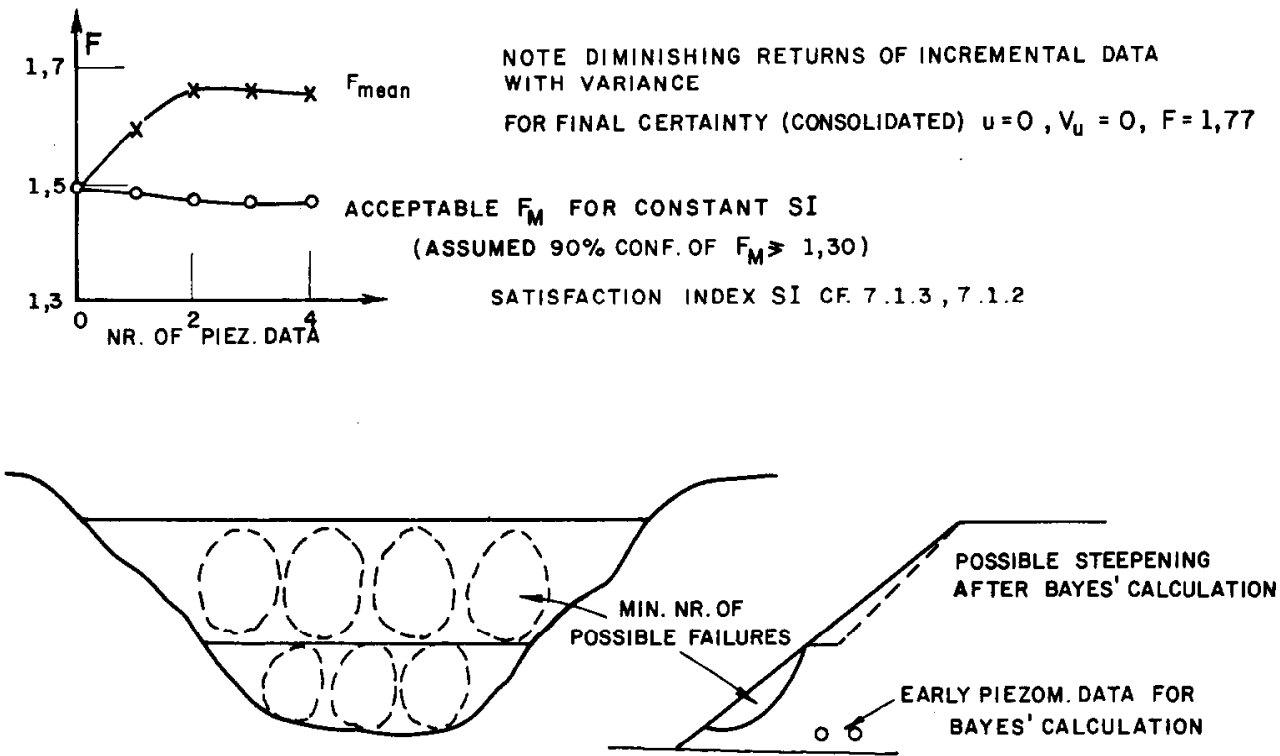

Fig. 34. Quantifying observational method through Bayes' theorem with early data on critical parameters 
Moreover, there are cogent reasons, summarized forthwith, that justify the consideration of instrumentation on a specific dam as a problem still dominantly influenced by extreme values. Suffice it to say that engineering preoccupation continues to centre on the limit condition of failure and on assessing performance through a factor of safety with respect to failure, which presumably is a rare event. However, indeed the additional implications associating much instrumentation with extreme value conditions have possibly not been duly apprehended. And possibly as a consequence it may be noted with some sense of frustration, that some of the catastrophic failures of recent times have not been restricted to poorly instrumented or badly observed dams. Two basic points must be made $a$ priori. First, any planning of instrumentation and interpretation automatically presupposes an anticipated model of theoretical behaviour (physical and mathematical) and therefore tends to inhibit, or condition, a truly flexible visualization of unsuspected problems. For instance in a case such as that of the Malpasset dam, attention had been concentrated on deformations due to low moduli of elasticity of the rock mass, whereas the factor of unsatisfactory behaviour asserted itself as a plane of excessive weakness and deformation in shear. Secondly, if instrumentation is to be of any value to the specific project, it is fundamental $(a)$ to establish prior criteria of the green, yellow and red traffic signals for decision on action incumbent as the observed results exceed anticipated limits and tolerances, $(b)$ to confirm whether or not factors of timing and rates of phenomena under observation will permit any timely intervening action and $(c)$ to possess a rcalistically planned strategy of control and correction of any undesirable performance. In fact, instrumentation and observations have been continually planned and executed without due cognizance of some entirely different purposes that can and may be met, and others that simply cannot, except in illusion. In the context of statistical reasoning it will thus appear that the indirect implications of some recent important failures are inevitable. In the Baldwin Hills failure, one is humbled into recognizing that the 'observation' that minimized the catastrophe was 'the sound of gushing water' (California Water Resources Department, 1964) heard by the dam attendant; and in the case of the Teton dam, the good fortune that the first signs of the final downstream piping developed in daylight.

A first examination of conscience regards credibility of the instrument readings themselves. Surprisingly, on essentially all instrumentation the credibility is merely established by tacit or explicit comparison with 'what should be thought expectable' (i.e. through some prior theorization on averages) or, at best, by comparison of some point observations against others (but all, inevitably, interrelated implicitly through the same prior theorization). The danger of such a subconscious conditioning cannot be overemphasized with regard to extreme value situations. Over and above the very low probability of having located the instrument and readings in space and time so as to have chanced to record the specific condition or event, there is the neardeterministic improbability of accepting an unusual reading as a significant indication rather than a freak occurrence.

The second important point of critical self-analysis concerns the ability or not to calibrate the instrument in situ as installed, and during a plausible set of initial imposed conditions; and the further ability to confirm under certain conditions of the later life of the instrument whether it continues alive and credible. Whereas the in situ calibration of as-installed conditions is not known to have been required or applied for any instrument, the checking of adequate response in later life has constituted a strong point in favour of some piezometer types, in which the pressure may be forced to alter at will and accompanied as it returns to the original reading. The third general point of emphasis concerns the need for an honest cross-examination as to what is the real purpose and intent of the instrumentation, both regarding the dam itself, and regarding dams in general. One should visualize (i.e. postulate, theorize) in anticipation how 
the foreseeable results, and/or parametric variations thereof, will really be applied and achieve the aims set. A wealth (or rather an expensive mass) of field performance data is wasted because there simply was no hypothesis context to which it should contribute. Incidentally, such brilliantly executed, documented, and interpreted instrumentation cases as the Infiernillo dam might suggest contesting such a disillusioned view, but really support the thesis that the very same set of results was satisfactorily used to support successive interpretations, first that results were as expected and somewhat better, and later that results would justify implications of compaction prestressing (Skermer, 1973). Thus the vast cumulative expenditures on instrumentation have apparently implicitly served to perpetuate 'the establishment' of theorization that had been chosen a priori. Had instrumentation been planned, this would have been done according to some theory, and therefore used principally along an engineering preoccupation with the ability to develop a more fitting computational mask; but this is generally insufficient to overcome the prior theorization conditioning. In short, whereas we should be aiming at developing instrumented observations for the development of performance satisfaction indices (SI) in non-failure conditions, unwittingly most of the planning is aimed at what may be called back computation ability indices (BCAI).

If instrument monitoring is to provide premonition of failure (Vanmarcke, 1974; Vaughan, 1974) it can only be in mass failures associated with statistics of averages (flow nets, general slope instability), and a better guarantee against such cases is an appropriate design coupled with the development of SI indications (Fig. 34) for adverting with respect to evolution of situations and probable proximity to thresholds of unsatisfactory behaviour. One must definitely abolish hopes of instrumentation help with respect to extreme value failures such as piping or cracking. The probability of cross-correlation between one extreme-value condition (instrumentation on point observations at discrete intervals) and another extreme-value condition (catastrophic failure) must be recognized as being hopelessly remote, notwithstanding both being associated with the same dam. Fig. 35 summarizes the principal points herein considered.

SLOPE STABILITY FACTORS OF SAFETY, PROBABILITIES, SATISFACTION INDICES AND QUANTIFICATION OF THE OBSERVATIONAL METHOD

\section{General}

It is presently recognized that conventional limit analysis factors of safety $F$ are rather unsatisfactory in concept and in application, in the light of inexorable statistical realities. That is, one presently questions the single computational exercise that in dam engineering gives such elation to the junior designer that he even confuses it with the very notion of design, and that is commonly taken by the geotechnical engineer to be the most crucial problem of the speciality. Although it has been emphasized that the root problem in design might be to obviate the very need for a stability computation, understandly one must not forego some conventional computation of $F$. The first obvious hope is that the $F$ value should be developed to reflect a real estimate of the probability of failure. It is thus that probabilistic developments have been put forward, purporting to substitute the conventional deterministic $F$ values by estimations of risks of failures or reliability concepts (e.g. Alonso, 1976; Matsuo and Asaoka, 1976). Accepting such a premise for a moment one should immediately conclude that required design $F$ values to be used in different materials and situations must take into account $(a)$ dispersions of the principal intervening factors, $(b)$ importance and economic value of the volume likely to slide, $(c)$ consequences, economic and miscellaneous, to the project and to society, if the slide occurs and so on. Many of the latter considerations become rather intangible. However, the adjustment of $F$ values to being compatible with regard to $(a)$ is an obvious engineering 
CHART 2

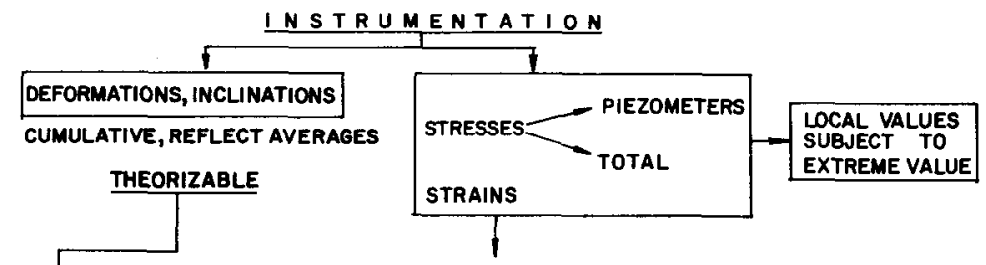

FOR APPLICATION IN THEORIZABLE(AVER.) BEHAVIOUR

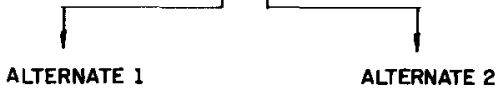

STATISTICAL AVERAGING OF NR. OF POINT INSTRUMENTS

GIGGER VOL. OF INFUENCE

UNSATISFACTORY

PHYSICAL AVERAGING RETARDING,

WITH MARKED ATTENUATION OF
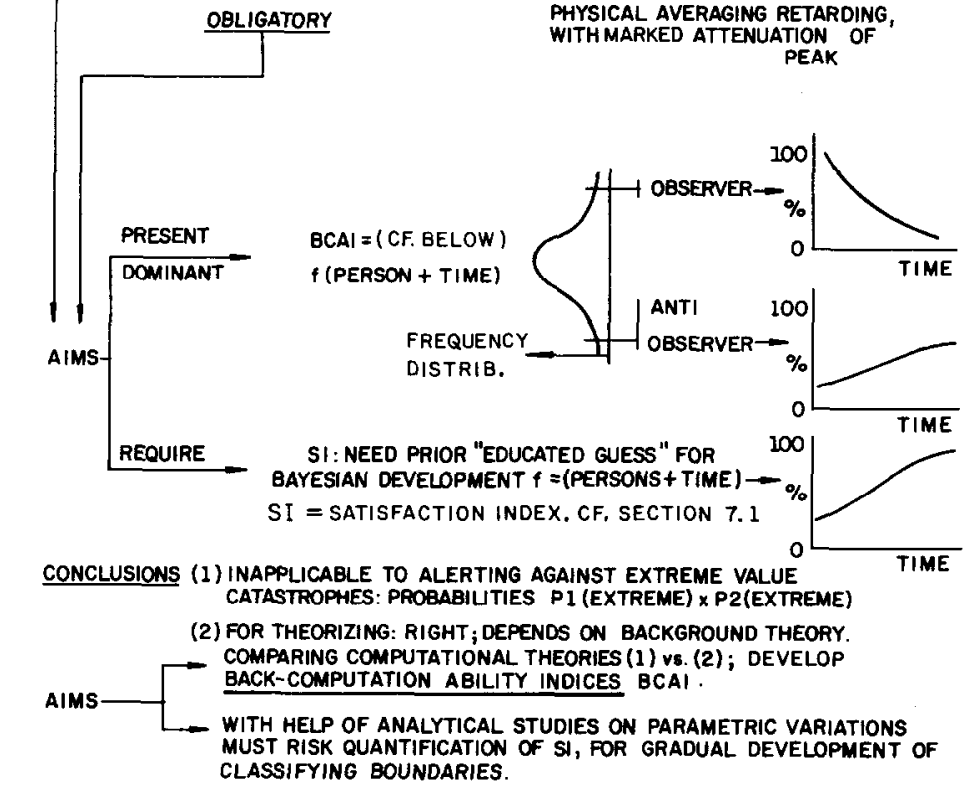

Fig. 35. Conceptual classification of instrumentation problems and perspectives

obligation equivalent to the manufacture of a chain of links of presumed equal resistance. Firstly, however, one must establish a single uniform basis of treatment for all materials. Theorization for calculation of $F$ must be as realistic as possible notwithstanding the random factors; that is, computations should not be permitted to cloak the principal recognized nonrandom cause-effect factors. At present, therefore, by recognition of $u$ as the principal contributor to instability, and as an observable parameter for control of the embankment slope, one must accept that nothing but effective stress analyses and strength envelopes should be used consistently, while intentionally concentrating all variability and discussion in the single parameter of greatest and most influential variability. It should even be remarked that for the same reason one should basically rely on $\phi^{\prime}$ values extracted from drained tests, and if various undrained tests are justifiably employed, with pore-pressure measurements presumed valid, the consistent theoretical failure criterion of maximum effective stress ratio be employed 


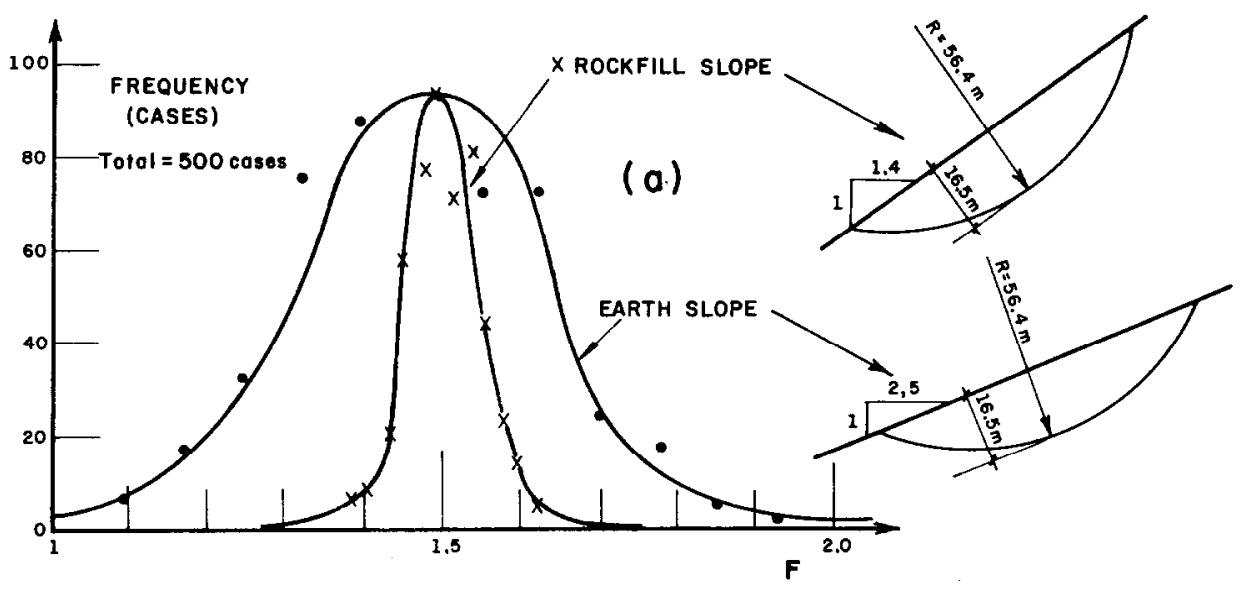

ROCKFILL

EARTH

$\begin{array}{lll}F_{\text {mian }}=1.502 \quad \sigma=0,0408 \text { (STANDARD DEviation) } & F_{\text {mean }}=1.492 \quad \sigma=0.1669 & \\ c^{\prime}=0, r_{u}=0 & c^{\prime}=4.08 \pm 1.30 t / \mathrm{m}^{2}( \pm 32 \%) & 95 \% \text { conf. } \\ \varphi^{\prime}=41^{\circ} \pm 1,6^{\circ}( \pm 4 \%) 95 \% \text { CONFIDENCE } & r_{u}=0.2 \pm 0.15( \pm 75 \%) & 95 \% \text { CONF. } \\ \text { FELLENIUS } \rightarrow F=1.72 \tan \varphi^{\prime} & \varphi^{\prime}=20^{\circ} \pm 1^{\circ}( \pm 5 \%) & 95 \% \text { CONF. }\end{array}$
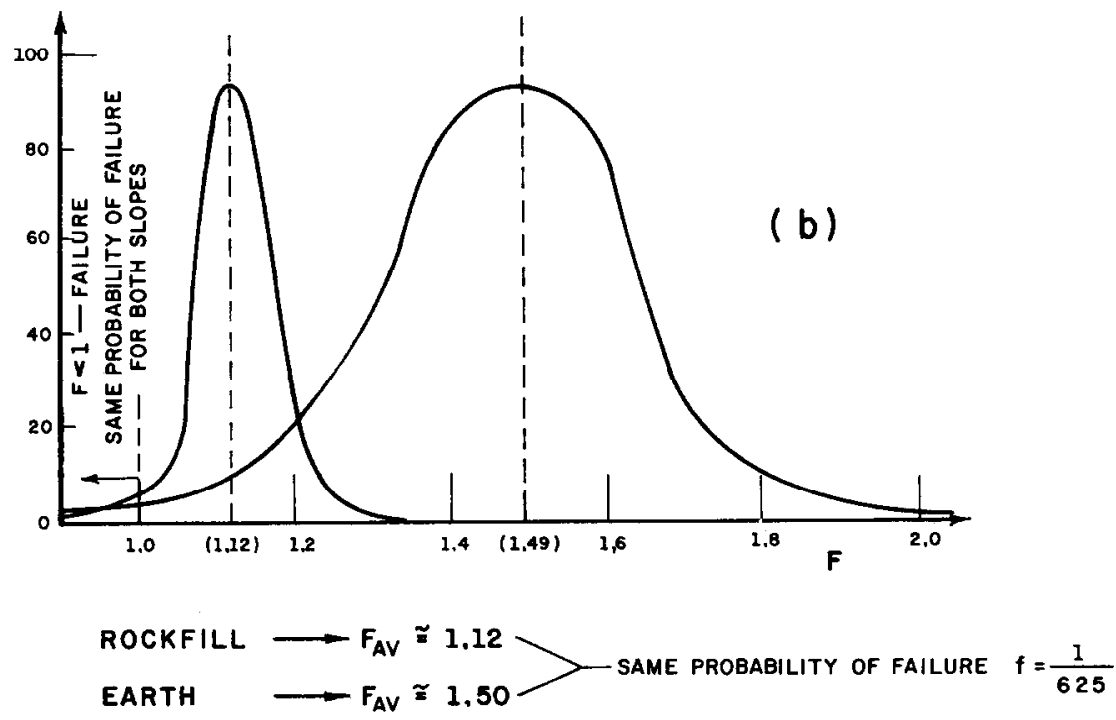

Fig. 36. Equivalent design $F$ requirements for rockfill and clayey embankment slope 
for the strength equation, while peculiarities of specimen or soil behaviour (e.g. regarding collapsing structures) be relegated to judicious adjustments in estimated $u$ values, depending on hypotheses of applicable constant volume failure conditions within the prototype.

Figure 36 has been prepared to emphasize, by routine limit analysis, that in as far as the $F$ value is to guard against uncertainties, obviously a rockfill slope should be calculated to $F \approx 1 \cdot 1$, to match the same risks of failure as compacted clay fill slopes of $F \approx 1 \cdot 5$. The data are hypothetical though realistic. The principal dispersion forcing such a requirement is in the $u$ and $c^{\prime}$ values, notably in the $u$. The Monte Carlo generation of 500 cases was used for two slopes adjusted to the same average $F$ value of about $1 \cdot 5$, maintaining a fixed failure circle and soil density, and assuming normal distribution of all the variates. The resulting histograms are represented in Fig. 36(a). By shifting the histograms to match the same probabilities of failures, as shown in Fig. 36(b), the conclusion regarding the permissible computed average $F$ values is obvious. Such computations involve less than $30 \mathrm{~s}$ in a Burroughs 6700 computer.

Based on such simple reasonings, that are irrefutable and well accepted, one realizes the need to establish the statistical dispersions of intervening parameters, and may well quantify the economic gain (and final waste) in gradual increase of numbers and quality of data (affecting principally the $95 \%$ confidence limits). The special point that must be made herein is that within the same material (e.g. clayey), on recognizing the distinct universes I and II caused by compaction, one should require different $F$ values if the critical sliding circle turns out to be shallow (contained in universe II) from the case where it is deep (involving different proportions of universes II and I). On this count alone (to be complemented by comparative slide-volume and risk consequence considerations) one would conclude that design values imposed should be significantly smaller for hypothetical shallow circles. There is, however, a very important fundamental fallacy of statistical and engineering concepts in such direct formulations referring to the probability of real failure.

Although limit analysis must continue to be used (to tie in with the past and for convenience) it should be definitely dissociated from any implication that $F=1.0$ signifies incipient real failure. This point is very important on several counts, starting with the philosophical recognition that although we conclude that various methods of analysis give nearly identical results (e.g. Wright, et al., 1973) the respective certainty is only of equivalence of various computations within a presumed model, and not of equivalence of the model to reality. However, for the present purpose only two points will be emphasized: firstly, that failures are (fortunately) extreme value situations; sccondly, that what we require as engineers, is a tool for building up cumulative quantitative support for decisions. Consistent with DP 1 we must avoid any decision on computation connected with extreme value conditions. One cannot fail to note the fallacies in presuming to adjust the nominal $F$ values of just under 1.00 to the back-figured extreme conditions of a few real failures (as has been systematically done in soil mechanics in justifying deterministically the adequacy of methods of analysis). Moreover real failures are rare (except possibly in cut slopes in highway engineering) and it cannot be an honest engineering hope that a sufficient number of them, well-documented, become available for one to determine the appropriate distributions etc. One must recall the tremendous variations of frequencies associated with different extreme-value distributions (Fig. 1), and realize that unless the applicable distribution is determined (by experimentation plus abstraction), the proposed methods of probabilistic calculations are mere hypothetical examples of the procedures that might be followed. Finally, the presumed engineering answer of relying on very low (e.g. $10^{-5}$ ) probabilities to compensate for the very high risk values (e.g. Vanmarcke, 1974) is conceptually as absurd as the hope of extracting a finite answer by multiplying $1 / \infty$ by $\infty$. 
Are there not understandable innate dissatisfactions of the engineer with present failure probability formulations? If one concludes that risks of embankment slope failures reach 15 to $20 \%$ (Matsuo and Kuroda, 1974), there is a justified hesitation at accepting the result in the light of experience, when we just 'know' that sliding failure is much more remotely at stake. How then may one match the mandates of experience and the needs of revision and yearnings of progress, without requiring the impossible, which is refining knowledge on hundreds of failures of the same non-random phenomenological universe?

The answer proposed is that one should work in the universe of tangible $F$ values and tangible measures of satisfactory behaviour of the slope in order to develop, appropriately and rapidly, a statistical universe of averages correlating $F$ with behaviours. This is akin to relinquishing bearing capacity calculations on foundations, to appraise a foundation's adequacy on the basis of fissures due to differential settlements. Let us recognize such $F$ values as strictly nominal, and denominate them $F_{\mathrm{N}}$. No matter how solidly we found our theories as demonstrating absolutely 'true' $F$ values, in a realistic engineering sense we must concede that these 'true' values of today will inexorably become 'nominal' values tomorrow. The advent of finite element analysis has provided a new tool for systematic analysis of deformations, and of change of the probable trends of deformations as an incipient failure develops. The modern trend of computation and field observation in earthwork engineering is obviously centred on deformation problems, and a vast amount of information is being collected, at considerable cost, but the principal problem is that once the deformations have been computed and/or observed there is absolutely no yardstick whereby one should conclude whether conditions are satisfactory, tolerable, or unsatisfactory. Let us postulate that, based on measured deformations and the development of a universe of such data in comparisons of elastic against plasticizing conditions in elasto-plastic analyses, one may develop a feel for remoteness from real failure ( $F$ rather less than unity) and may thereby qualify the condition of each slope by its satisfaction index (SI) (average and standard deviation). Note that in most statistical analyses of $n$ slopes, each slope has been wrongly considered as a single sample; depending on the probable depth of the critical circle, one may estimate the dimensions of the slide face and thereby consider $m$ independent samples on a single embankment slope (see Fig. 34).

Two graphs are therefore visualized as necessary: one of measured relevant slope deformations against SI, and the other of SI against $F_{\mathrm{N}}$. Although thousands of surface benchmarks have been observed on embankment slopes, since no thought was given as to how to use such observations, they have probably been no more than filed. Lacking any immediate information for the formulation of the graphs postulated, those presented in Fig. 37 must be considered merely illustrative for quantification of the observational method. If we must reappraise and revise design practices it must be with regard to SI values correlated with $F_{\mathrm{N}}$, and not with respect to presumed probabilities of $F$ being less than 1.0 . One intuitively employs 'experience' and the observational method, and feels much greater comfort at design decisions when one senses the average behaviour; that is, "we are, we cannot help but be Bayesian in all our root culture' (de Mello, 1975c).

In Fig. 38 a simple hypothetical case of shallow-slide rotational movement is used to exemplify setting the background for the development of quantifications on SI values. By means of finite element analyses we can establish the vertical and horizontal purely 'elastic' movements that would occur after the end of construction; such consolidation movements have been computed very roughly by introducing gradually decreasing $E$ values. The point is that if we have deformation measurements along the slope, we must try to sort out what might be purely elastic movements, and the excess, that may be attributed to smaller or greater proportions of 'plasticization'. Elasto-plastic analyses in which the threshold of plasticization were 

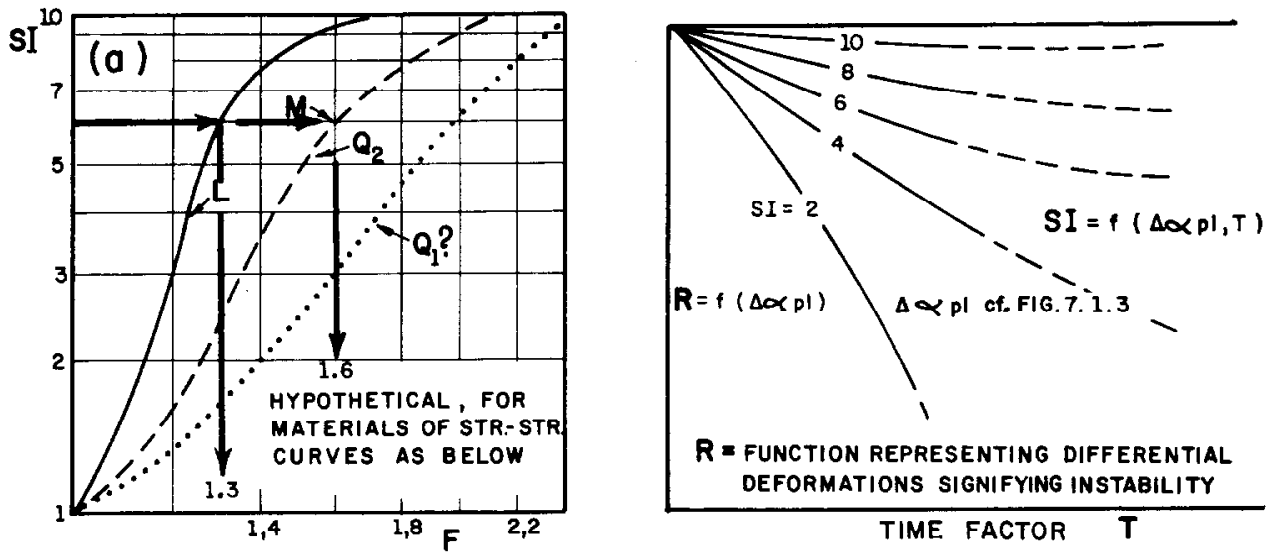

$R=$ FUNCTION REPRESENTING DIFFERENTIAL DEFORMATIONS SIGNIFYING INSTABILITY

TIME FACTOR $\mathbf{T}$
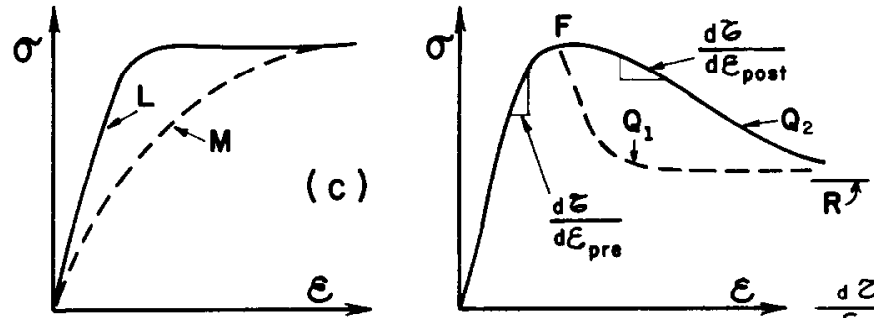

BRITTLENESS INDEX

$$
I_{B}=\frac{\zeta_{F}-\sigma_{R}}{\delta_{F}}
$$

(ct. BISHOP, 1971) POSSIBLY INSUFFICIENT. EXAMINE CRITERION

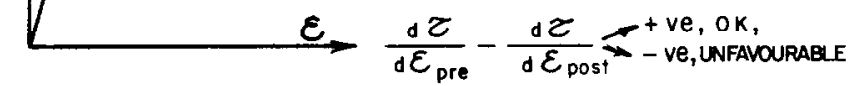

$V_{\text {ROCK }}=2,2 \times 10^{-3}$

$V_{\text {EARTH }}=2,8 \times 10^{-2}$

$V=$ VARIANCE,FOR COMPUTING $90 \%$ CONF. VALUES

MEANWHILE, ASSUMING CURVE M

FOR COMP. CLAY DEEP CIRCLE

ASSUMING CURVE $L\{$ ROCKFILL

FOR BOTH COMP. CLAY SHALLOW CIRCLE

$\therefore F_{N \text { MIN }}>1,6$ FOR SI $>6$

i.e. $S I>6 O K$

i.e. $F_{N}$ MIN $90 \%$ CONF. $=1,3$

i.e. $10 \%$ PROBABILITY $F_{N}<1,3$

$\therefore$ REQUIRE $\left\{\begin{array}{l}F_{\text {N AVER. }}=1,36 \text { ROCKFILL } \\ F_{\text {N AVER. }}=1,51 \text { EARTH }\end{array}\right\} \begin{aligned} & \text { FOR EQUIV. SI } \\ & \Delta F_{N}=0,15\end{aligned}$

$\therefore$ REQUIRE $F_{N}$ AVER. 1,81 EARTH

IF ROCK FILL RETAINS CURVE $L$,

FOR EQUIV. SI

$\Delta F_{N}=0,45$

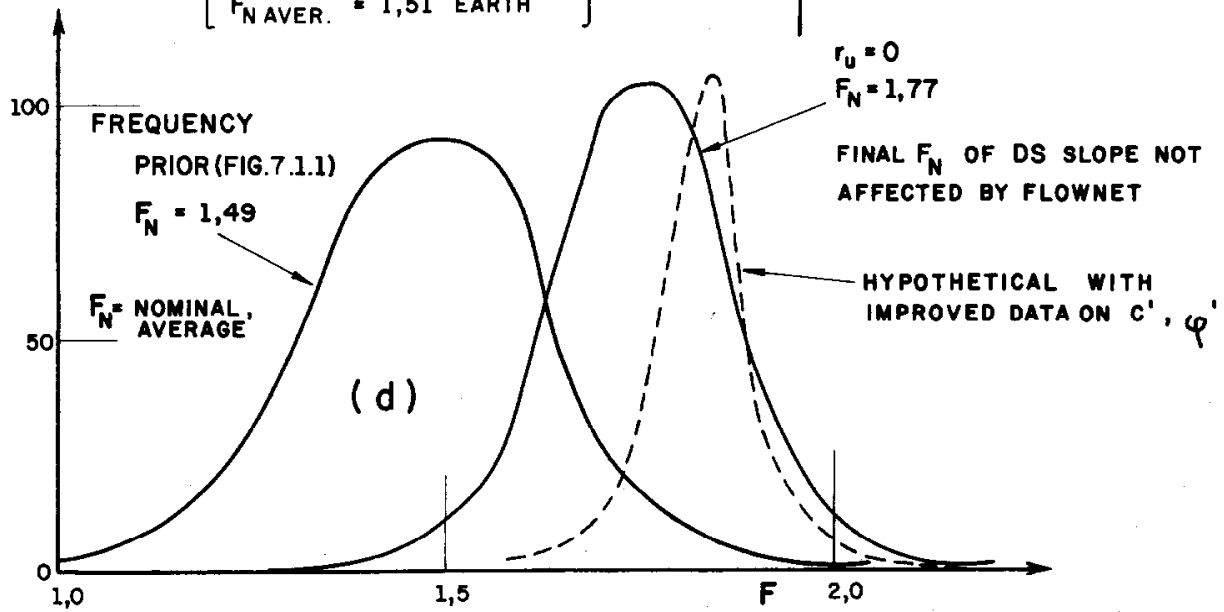

Fig. 37. Judicious adjustments on nominal $F_{\mathrm{n}}$ required for equivalent satisfaction indices SI 
lowered could furnish very useful indications. At any rate, the rotation of the surface plane associated with presumed plastic movements (excess over the elastic) is indicated in Fig. 38 for computation of a $\Delta \alpha_{\mathrm{pl}}$ which could constitute the basis for SI values. Referring to the table of Fig. 38, the value $7^{* *}$ might be used as an example as follows. If at time $T_{1}$ the $H$ and $V$ measurements were merely 14 and $120 \mathrm{~cm}$ respectively one could attribute the rotation $\alpha=33^{\prime}$ merely to 'elastic accommodations'. The real measurements, 17 and $155 \mathrm{~cm}$ would lead to a rotation of $42 \cdot 3^{\prime}$, permitting the conclusion that $\Delta \alpha_{\mathrm{pl}}=9 \cdot 3$ '. Thereupon, from field evidence and 'feel', one might classify such a condition as $S I=7$, because reaching $\Delta \alpha_{\mathrm{pl}}$ between 5 and $10^{\prime}$ at time $T_{1}$ would merit grade 7 in satisfaction index regarding potential instability.

Such information is visualized as incorporated into a function $R$ representing differential slope deformations signifying instability (Fig. 37 (b)). Such functions would obviously require adjustment from material to material, depending on the stress-strain curves (Fig. 37 (c)), more or less as visualized in Fig. 37 (a). It is herein postulated that the adjustments of required nominal $F, F_{\mathrm{N}}$, values for two materials such as compacted clay and rockfill should not be based on hypothetical failure probabilities, but on equivalence of SI values. Unfortunately no data are available for such a formulation at present, but just to exemplify the principle, the computation is carried out in Fig. 37 under two hypotheses. Assuming temporarily that the same curve type L of Fig. 37(a) represents both the rockfill and the compacted clay one should require in the clay a $\Delta F_{\mathrm{N}}=0 \cdot 15$. Meanwhile, assuming curve type $\mathrm{M}$ for the clay while the curve type prevails in the rockfill, the requirement in the clay should be of $F_{\mathrm{N}}$ roughly 0.45 higher than in the rockfill.

Finally, Fig. 37(d) shows what a significant irrefutable increase of $F_{\mathrm{N}}$ occurs in a clay in the zone downstream of the chimney filter, as we determinstically introduce the knowledge that, with consolidation, $u$ is forced to be zero. Also the effect of improved knowledge on $c^{\prime}, \phi^{\prime}$ is shown, demonstrating the benefits of testing of undisturbed block samples of the fill.

Figure 34 indicates the computations whereby the construction period observational data should be employed to improve the stability evaluation. The successive results from four construction period piezometers are introduced by Bayes' theorem to revise the prior probability distribution function of $F$. The value of instrument observations can well be assessed. This subject and its limitless possibilities for revising construction period stability cannot be expatiated herein because of lack of space; suffice it to emphasize the interest in instrumenting as early as possible, in positions as consciously representative as possible, including purposely sought conditions beyond the customary bounds.

The following topics on slope stability problems of embankment dams (foundations assumed unquestionable) are discussed in detail in a companion paper in publication, but are herein briefly mentioned principally to focus on the above concepts of progressive evaluations based on changes of conditions and Bayesian probability formulations.

\section{Slope stability in dense rockfll and granular materials}

Rockfill construction began (associated with upstream deck dams) with dumped rock and 'angles of repose'. Stability behaviour, proven in the field, was unquestioned. Sound clean rock became a requirement to attenuate deformations, and heavy watering by monitors incremented construction-period deformations by promoting crushing at infinitesimal-area interparticle contacts. Under the action of monitors some shallow sliding accommodations were observed at the 'angle of repose' slopes; at no time was any deeper sliding reported; yet current design practice absurdly penalizes cohesionless slopes. Curiously, when dumped rockfill was used, steeper slopes were automatic, and when compacted lifts began, accompanied by laboratory-based theorization, there has been a flattening of slopes in two steps. Firstly, 

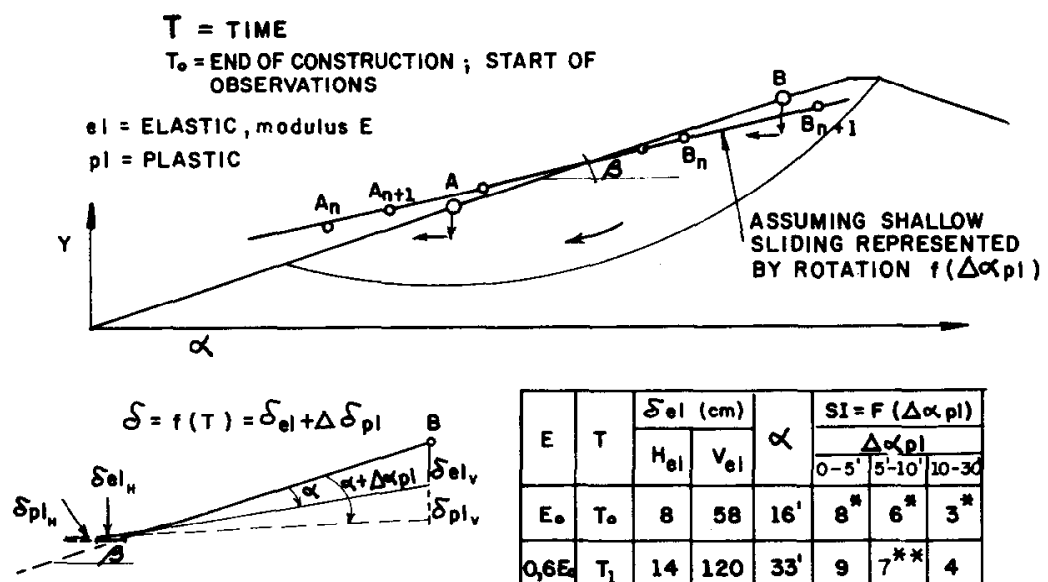

IN PRACTICE, ROTATION $\Delta \alpha p$ I TO BE ESTABLISHED BY REGRESSIONS ON MANY OBSERVATION POINTS

\begin{tabular}{|c|c|c|c|c|c|c|c|}
\hline \multirow[b]{2}{*}{$\mathbf{E}$} & \multirow[b]{2}{*}{$T$} & \multicolumn{2}{|c|}{$\delta .1(\mathrm{~cm})$} & \multirow[b]{2}{*}{$\alpha$} & \multicolumn{3}{|c|}{$S I=F(\Delta \alpha p \mid)$} \\
\hline & & $H_{e l}$ & $v_{\text {el }}$ & & $0-5^{\prime}$ & $\begin{array}{l}\Delta \times p \mid \\
5^{\prime}-10^{\prime}\end{array}$ & $10-30$ \\
\hline E. & To & 8 & 58 & $16^{\prime}$ & $8^{*}$ & $6^{*}$ & $3^{*}$ \\
\hline 0,6E? & $T_{1}$ & 14 & 120 & $33^{\prime}$ & 9 & $7^{* *}$ & 4 \\
\hline 4E. & $\mathbf{T}_{2}$ & 19 & 170 & $47^{\prime}$ & 9 & 7 & 7 \\
\hline
\end{tabular}

* possible si values

** example in TEXT

Fig. 38. Possible suggestion for start at data collection for satisfaction indices on slope subject to shallow instability

under the impossibility of running laboratory tests, constant $\phi^{\prime}$ values of $45^{\circ}$ were routinely assumed, and the flattening may be attributed to the imposing of a computed $F=1 \cdot 5$, quite unwarranted as discussed elsewhere. Secondly, when triaxial testing of rock fragments began (c. 1960) and the use of dirty rock became accepted (and even advocated, in recognition of its advantage by avoiding infinite interparticle contact stresses), the added problem has been the adoption of much lower $\phi^{\prime}$ values. Moreover, the mental model associated with compaction hardly reflected any strength and stability benefits due to compaction, possibly because the introduction of compaction was exclusively concerned with deformations.

In short, the critical stability of a cohesionless slope has been equated as $F=\tan \phi^{\prime} / \tan \beta$ although this is really an over-simplified truth or white lie, valid only for a sliding mass of volume $\mathrm{d} V \rightarrow 0$ and under the crudely simplified assumption of a constant single $\phi^{\prime}$ material property dictating such sliding resistance. Those who automatically resort to computer programs and, on being disconcerted to find that no critical surface results cxcept the slope itself, apply the expedient of assigning a small arbitrary cohesion value just to permit the computer to come to rest, merely shift the absurd situation, because the shallow resulting slide circle is of depth dependent only on the $c^{\prime}$ value adopted.

The fact is that on the 'infinite slopes' of US and DS rockfill masses, the satisfactory stability condition is tested and proven, irrespective of the nature of the core or membranefacing (laid on the slope after it has been proven stable), emphasizing the acceptability of slopes not flatter than the freely tipped angle of repose. Statistically the evidence of stability of the $\mathrm{d} V$ surface volumes is documented beyond any measure of desire both in dumped rockfills and, a fortiori, in rockfills that have risen, lift by lift, a few metres; the slope rock includes the loosest and most unstable blocks (rolled only as far as necessary to stop) and any slope involves hundreds of areas and masses (statistical samples) involving more than 100 blocks (Iribarren, 1965) to comprise a perfect representation of the universe and its extremevalue conditions. 
One question that might be raised concerns the interference of the curved strength envelope (Fig. 12) in forcing a deeper-seated slide surface. In summary of extended discussions of different failure models and analyses of the companion paper, Fig. 39 presents an indication of the results reached consistently by limit analysis concepts; for the constant $\phi$ ' case the impact of the rapid increase of $F$ with importance of slide volume is evident; for the curved envelope case there is still a small increase of $F$ with depth although appearing to go through a condition of minimum $F_{\mathrm{N}}$ very slightly smaller than at the surface (material assumed perfectly homogeneous). Because of the limited number of rocks known to have been investigated, the results are not conclusive and would suggest prudence in cases of greater loss of $\phi^{\prime}$ with increased stress, if one could consider the hypothesis of homogeneity valid.

Notwithstanding the intimacy with limit analyses, one should forthwith emphasize that its very concept is strange on a built slope, in the case of a material of instantaneous stress-strain effects, if no additional stressing occurs after the end of construction. The reasonable objective should be to confirm whether or not the stability is automatically self-tested and proven, as the fill rises at its constant slope. In any granular material, in which very shallow sliding is the only possibility, it behoves us to extract the necessary lessons on progressive changes of conditions as the slope rises and provides data pertinent to SI values. In the case of rockfills rising in compacted lifts, the least that one should recognize is the probably significant $\phi^{\prime}$ difference from surface to interior.

An additional consideration submitted as conjecture concerns the possible effects of compaction residual stresses. As discussed in the companion papers, awareness of residual internal stresses in soils has been growing rapidly. The principal questions raised and discussed are three: would residual stresses develop also in granular (and coarse granular) materials; is there supporting evidence of measured residual stresses in the field; do such residual horizontal stresses persist? The indications appear irrefutably favourable. Under such conjectures, of the very important compaction effect of generating residual lateral stresses, Fig. 40 summarizes indications of the companion paper, of the very significant influence that even small residual horizontal stresses can have on the stability of the fill as it rises (Fig. 40(b)). As shown in Fig. 40(c) and (d) there should be dissipations of the horizontal stresses, but there is no reason why the dissipation should be to exact equivalence with normally consolidated geostatic conditions. The results are of sufficient interest to justify a concentrated effort to record stresses by instruments placed in the rockfill before it is spread and compacted.

Revised design decisions on use of compacted rockfills should permit very significant savings. The fact is that the field engineer has felt sure of the ability to use compacted rockfills at slopes of $1: 1$ or more, while computational models in vogue have been requiring slopes of about $1: 1 \cdot 7$. Moreover, such considerations are equally applicable to any granular compacted fill, if by proper drainage isolation it fulfils the guarantee of $u=0$; densely compacted gravels are well known to exhibit better shear strength behaviour than crushed rock and rockfill.

\section{Construction period stability, clayey material}

Conceptually, in limit analysis of the stability of a slope one checks on how big a change of conditions (additional stressing, or decrease of resistance) might be resisted. In building up a slope in a progressively 'more risky condition' one senses that though the mechanics of analysis be identical, there is a conceptual strangeness in postulating a completed slope, to check, at the end, what is its normal factor of safety $F_{\mathrm{N}}$. In such a case with considerable control (even 'full control', with exception of statistical variance and cost considerations) of the material 'as manufactured'; moreover, one presumably employs adequate means for observing the principal intervening parameter (pore-pressures) right from the early stages of 


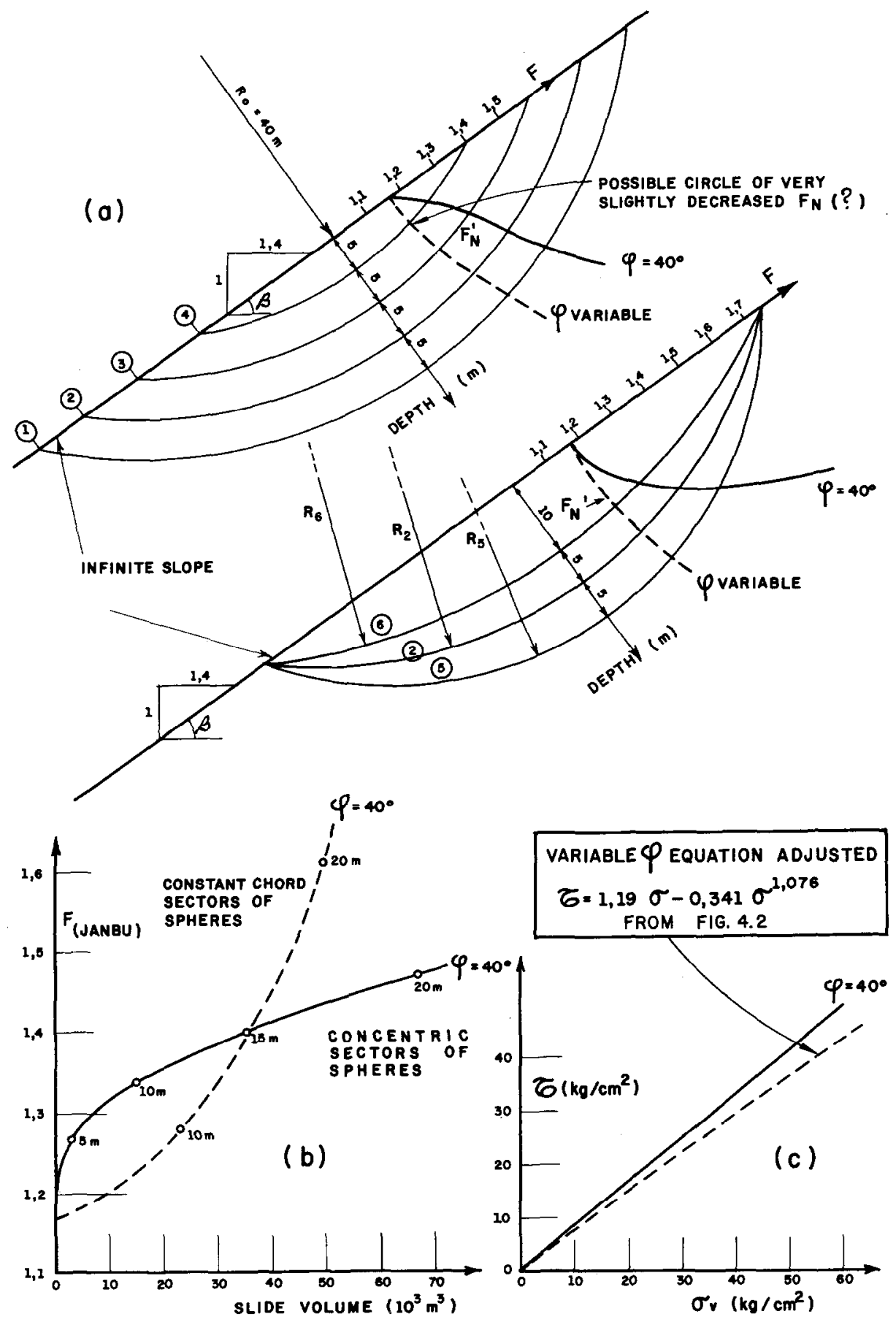

Fig. 39. Increase of $F$ with depth of slide surface and slide volume even in rock of noticeable curved envelope 


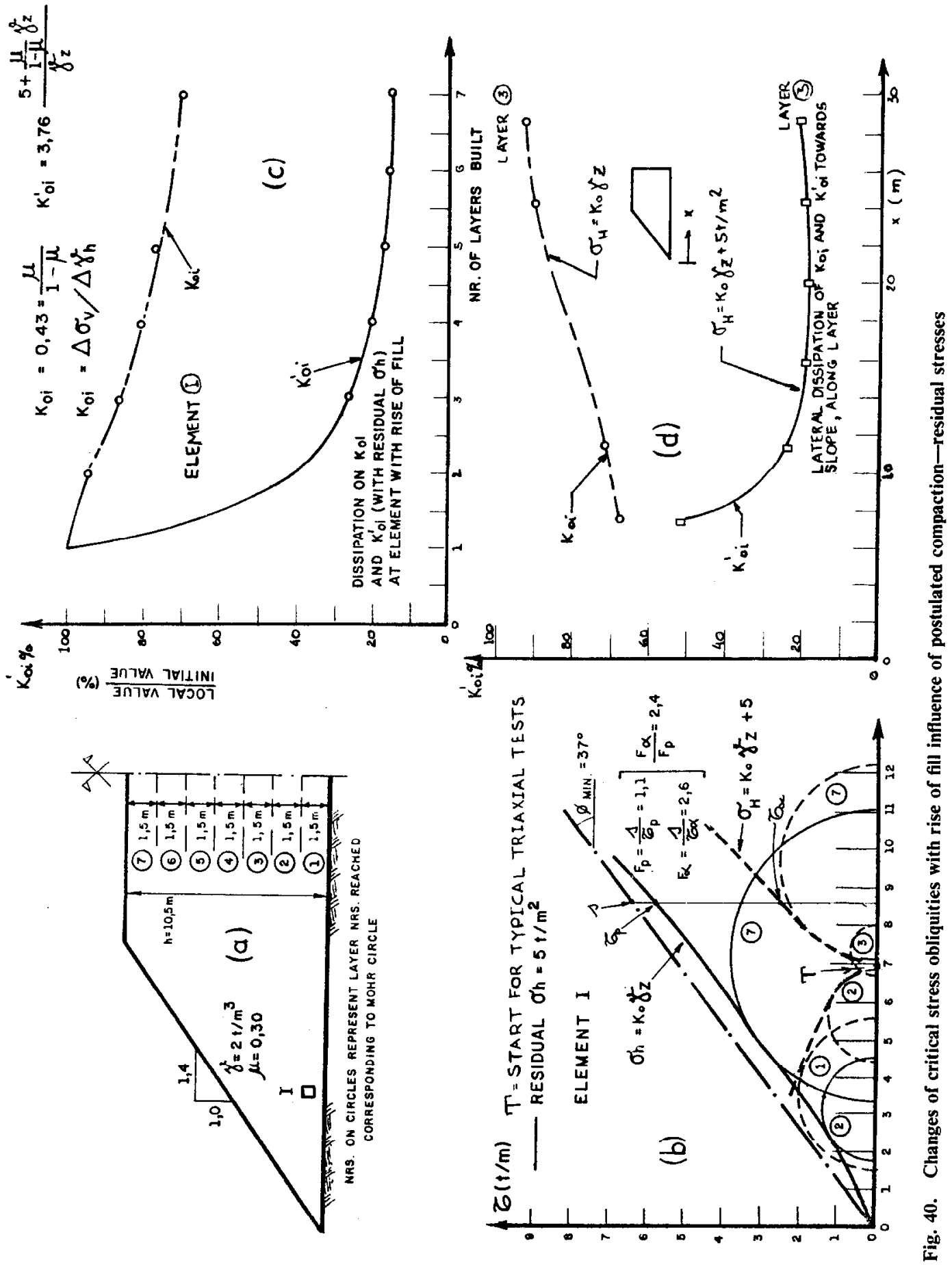


stressing, and consequently may predict the development of conditions as the fill rises. Obviously therefore, conditions of DP 4 are well fulfilled, and through the observational method the advantages of Bayes' theorem may be employed with considerable efficiency (Fig. 36).

Since the independent parameters of decision are $\Delta w \%$ (water content deviation from the Proctor optimum) and PC (percent compaction), and the subsequent inexorable variation is overburden stress (assumed $\left.\sigma_{1}\right)$, what one requires are plausible regressions for $r_{u}=f(\Delta w, \mathrm{PC}$, $\left.\sigma_{1}\right)$; and, in lieu of the apparently impotent passivity with which routine compaction specifications are transcribed from project to project, and maintained constant within a dam crosssection, the principal design and redesign decisions should be on what compaction specifications to enforce, discriminatingly.

In the companion paper in which the reasonings and procedures recommended are expatiated, summarized here in Fig. 41, the test results of Casagrande et al. $(1960,1962)$ are used because they furnish a 'complete' set of systematic data (even if somewhat hampered by not having measured negative $u$ values). The simplest satisfactory regressions thus obtained from it are set out in Table 1, with $\Delta w(\%) ; \mathrm{PC}(\%) ; \sigma_{1}\left(\mathrm{~kg} / \mathrm{cm}^{2}\right)$. As exemplified, by use of such regressions, it is possible to set out for the contractor upper and lower bounds of permissible compaction parameters with regard to end-of-construction EC stability.

The discussion will be limited to the US zone because within the DS zone there are many expedients for controlling construction period pore-pressure (e.g. Bishop, 1957; Bishop et al., 1960; Sills, 1975) and the thought of efficient drainage layers may be extended with great practical and economic interest to the hypothesis of using non-exiting $u$-adjusters by periodic lifts compacted very dry of optimum. Such a practical design decision of field inspection (Fig. 41(b)) was much used in the Tres Marias Dam (1959) although supported at the time with only qualitative intuitions.

The US zone of our compacted clay dam may be subdivided into three zones with regard to which compaction specifications should be recognized to embody different conditioning factors. Firstly, every lift as it is compacted is automatically tested with respect to trafficability, which is a bearing capacity equivalent establishing a homogenizing criterion on all soils and all conditions of a soil with regard to roller acceptance. Since the net effect of such compaction is a preconsolidation pressure (Fig. 11), and overburden pressure up to the same value causes much less shearing than localized pressure of the roller tyre, there is an outer horizon within which the critical condition is purely of trafficability and desirable preconsolidation as a function of PC. In principle a sliding failure cannot be generated within this outer sliver.

The immediately underlying zone is in principle the critical one for possible generation of a sliding failure and within it the values should be maintained below an upper bound. By plotting the above regressions on graphs of co-ordinates $(\Delta w, \mathrm{PC})$ for each different pressure, one finds that these compaction parameters can be easily bounded so as to guarantee upper limits of $r_{u}$ for each limiting overburden stress, irrespective of type of test. The permissible limiting $r_{\mathrm{u}}$ values can be established with considerable unequivocal conservatism by considering at each point within the embankment what value of $u$ (and thus nominal $r_{u}$ referred to the

Table 1

\begin{tabular}{l|l|l|l|}
\hline PH tests & $r_{u}=-3.944+0.145 \Delta w+0.044 P C+0.019 \sigma_{1}$ & $n=91$ & $r=0.93$ \\
PC tests & $r_{u}=-0.420+0.112 \Delta w+0.006 \mathrm{PC}+0.027 \sigma_{1}$ & $n=91$ & $r=0.89$ \\
PN tests & $r_{u}=-1.792+0.119 \Delta w+0.021 \mathrm{PC}+0.012 \sigma_{1}$ & $n=65$ & $r=0.92$ \\
\hline
\end{tabular}




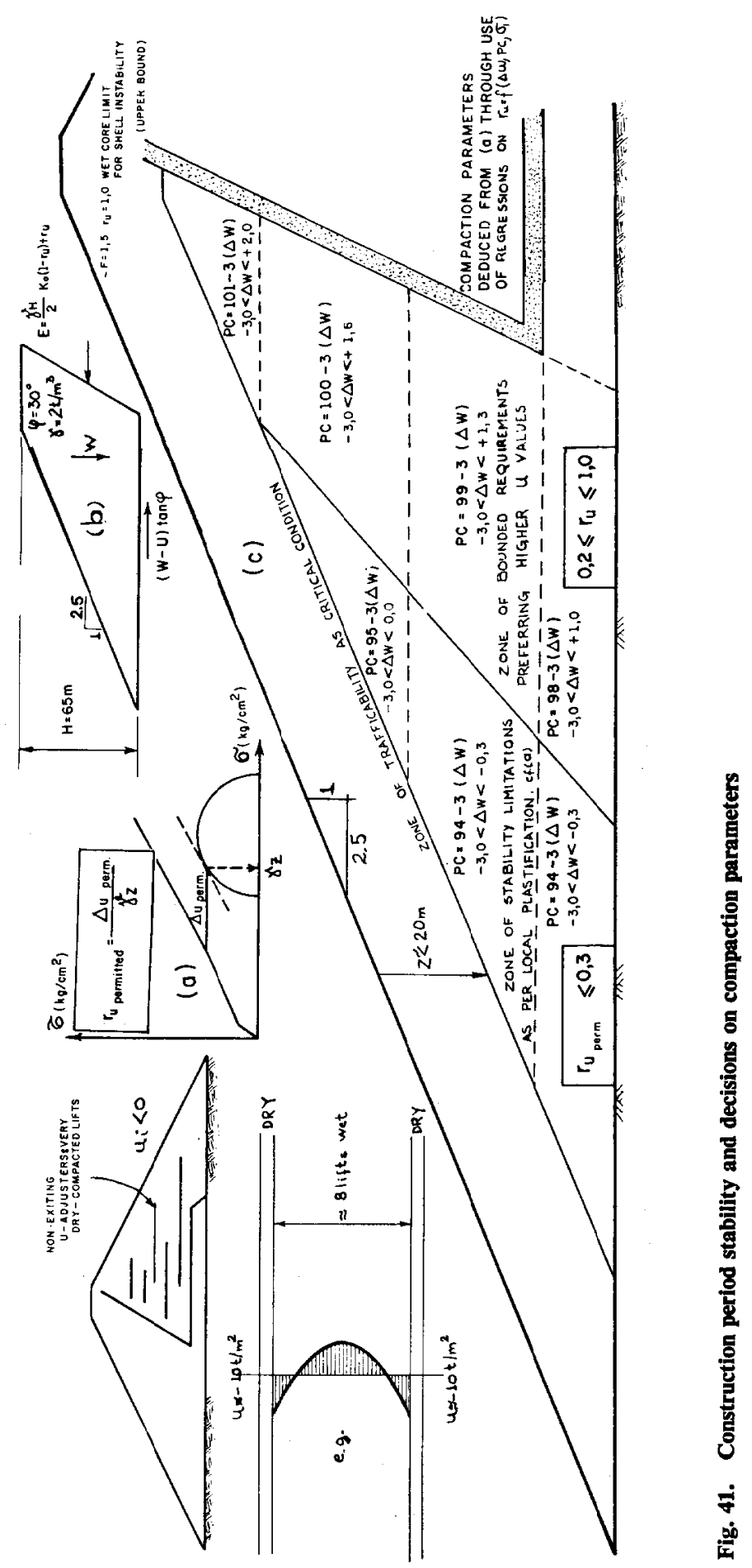


assumed $\sigma_{1}=\gamma_{z}$ ) would be the absolute maximum at the moment of plasticization (tangency of the Mohr circle to the effective stress envelope as indicated schematically); it is well-known that $F_{N}$ values tend to be quite satisfactory (e.g. $>1 \cdot 3$ ) when local plasticization begins.

Finally within a third zone, more central and akin to that of puddled clay cores, it is of interest to seek higher $r_{\mathrm{u}}$ values so as to approximate the likely $r_{\mathrm{p}}$ conditions of $W_{\mathrm{L} \max }$, to avoid significant and unfavourable changes of conditions on first filling (DP 4). Therefore, compaction specifications may well seek developing higher $E_{\mathbf{u}}$ values, with lower bounds established in the ( $\Delta w, \mathrm{PC})$ graphs of the regressions. In order to establish the concomitant upper limit of $r_{u}$ values for this central zone, one may resort to computation of the wedge stability of the outer shell against outward pushing by the lateral pressures of the wet core (as shown schematically in Fig. 41(c), similar to the classic stability of shells of hydraulic fill dams (Gilboy, 1934) employing an ample $F$ value.

One tends to find that as regards EC stability the permissible latitude of compaction parameters is much wider than that imposed by trafficability of modern equipment. Fig. 41 exemplifies the results computed; depending on the water content of the lift and its position within the cross-scction onc could opt for different desired PC values, most of them achicvable without too much adjustment of lift thickness, roller weight, and number of passes. It has been fallaciously assumed that compaction specifications should be strictly constant, for greater facility to the contractor. In many conditions much greater construction facility, and improved behaviour, may be achieved by judicious compaction zonings.

Settlement and permeability problems have not been mentioned, but must obviously be considered in parallel.

\section{Special considerations on long-term downstream slope stability}

Routine design recommendations presently base DS slope stability computations on the use of full reservoir flow net pore-pressures (HOM). Generally the effective stress equation is accepted as applicable, although scattered references persist in favour of using the consolidatedundrained (isotropic) $R$ strength envelope. Intuition has generally suggested requiring a minimum $F_{\mathrm{N}}>1 \cdot 5$, higher than for EC or RDD conditions, both of which involve risks of comparatively minute consequence.

The entire situation is not far from conceptually absurd if one really considers the magnitude of consequences of a hypothetical deep-seated failure upon reservoir filling, or with full reservoir. It has been repeatedly emphasized that the risk of DS mass instability upon reservoir filling must be made zero by choice of design such that there is certainty of stability even if porepressures rise to the extreme value (hydrostatic) physically possible. Since reservoir filling can be permitted only after the DS stability at EC condition has been fully accepted (through appropriate observations, computations and SI values) it seems conceptually absurd to analyse DS stability as a 'total stability analysis' starting from scratch; what must be done is to apply the judicious analysis of change of conditions from $\mathrm{EC}$ to $W_{\mathrm{L} \max }$.

For instance, for hypothetical shallow DS failure circles on which there will be no $\Delta u$ due to reservoir there is certainty that $\mathrm{EC}_{\mathrm{u}}$ will dissipate to zero and therefore by Bayes' theorem the $F_{\mathrm{N}}$ value can only improve (e.g. to 1.77 as in Fig. 37). Note that in the steady improvement of $F_{\mathrm{N}}$ in Fig. 34 only the additional variate knowledge on $u$ has been considered, while the final improvement on Fig. 37 is given by the deterministic certainty on $u$; meanwhile, during a well inspected construction of the dam, accompanied by appropriate shear testing etc., by gradual Bayesian introduction of information on $c^{\prime}, \phi^{\prime}$, doubtless a further improvement of $F_{\mathrm{N}}$ should be recorded as shown in Fig. 37. 

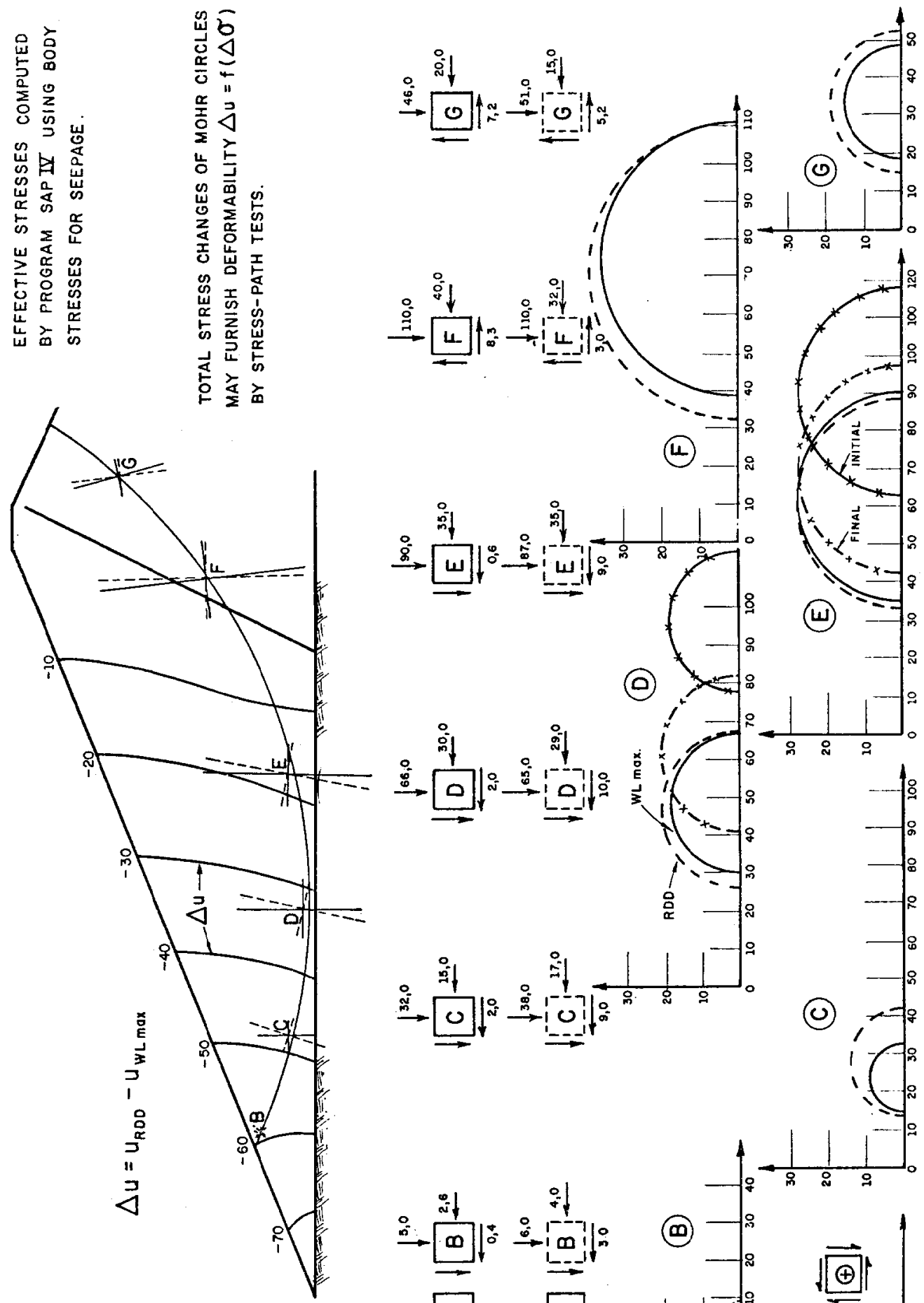
是 
In the case of deeper-seated circles, if there is a possibility of change of $u$ from EC to $W_{\mathrm{L} \max } \rightarrow$ HYD, as regards driving forces the only concern might arise if the change of conditions involves an increase of $u$. However, if there is an increase in $u$ value (presumably minimized as in DP 4) firstly, the soil elements will be moving into an overconsolidated condition; secondly, the change of conditions is at any rate from one anisotropically-consolidated situation to the next; there is never any possibility of loading a saturated specimen from the isotropic condition (CU or R test) to failure; saturation itself is a slower process than establishment of the new flow net $u$. One therefore concludes that present routines of DS stability analysis incorporate major cloaked compensations for the conceptually too low $F_{\mathrm{N}}$ value. In the case of sudden earthquake loading and of possible complementary $\Delta u$ due to rapid undrained failure deformations conducive to compressions around the shear surface, prudence would indicate inclusion of slightly increased $\Delta u$ values beyond the presumed hydrostatic extreme. Although such estimated compression $\Delta u$ values may not be certified by measurements, it is preferable to use them in accordance with the physical reality conceived, rather than to cloak them under higher required $F_{\mathrm{N}}$ values (Morre, 1970b).

Many factors are at play in assuring the desired DS stability of many a poorly conceived dam section, but it is proposed to relinquish current stability analyses and to envisage merely the change of conditions from EC to $W_{\mathrm{L} \text { max }} \rightarrow$ HYD by Bayesian computations associated with performance observations and SI evaluations prior to reservoir filling.

\section{Upstream slope stability under instantaneous drawdown}

Much study has been devoted to the problem of upstream stability under instantaneous drawdown, but extreme conditions for observation are unlikely to occur. It is accepted that current computations lead to over-conservative designs (see Mackellar et al., 1974; Johnson, 1974, for example) but, lacking support for judicious reduction of conservatism through lower $F$, and recognizing the need to examine abstractly the extreme hypothesis (instantaneous drawdown and fully saturated material), simplifications (Morgenstern, 1963) and authoritative recommendations (Wilson and Squier, 1969) tend to increase conservatism.

As discussed in the companion paper, the two main reasons for dissatisfaction are, firstly, that it is conceptually unacceptable to emanate from two totally different criteria, one for socalled 'free-draining fills of low compressibility' and the other for so-called 'fill material with low permeability ... characteristically compressible' (Morgenstern, 1963) on the basis of qualitative presumptions of the compressibility at stake. Secondly, with regard to the method more authoritatively recommended for clayey material (Bishop, 1954; Bishop and Bjerrum, 1960; Bishop, 1964) the designer feels the frustration that no direct measure except slope flattening (and that, too, very inefficiently) is available for cause-effect benefiting the stability in question (Nonveiller, 1957; Dupas et al., 1973). Moreover, the principal design measure of inclining the chimney filter to US leads to the physically unacceptable hypothesis of negative $u$ values below (i.e. DS of) the chimney.

There would be considerable interest in using short stretches of purposely steepened US slopes for the purpose of developing satisfaction indices SI even at the inconsequential risk of small scoop surface slides. Fundamentally it is proposed that as a design tool, for choice of optimized dispositions of the drainage feature etc., the only profitable avenue is, as discussed earlier, to use the $W_{\mathrm{L} \max }$ and RDD flow nets to assess what instantaneous changes of stresses would tend to occur if pores and pore fluid were incompressible; the consequences in generating instantaneous excess pore-pressures may then be estimated by examination of the change of total stresses to which the various soil elements would tend to be subjected. Fig. 42 exemplifies the procedure, by summarizing the data from the companion paper on changes of stresses 
at representative soil elements. Firstly, by assuming incompressible materials and consequent validity of instantaneous change from one flow net to the next, one derives (e.g. by finite element analyses) the sets of consecutive Mohr circles of effective stresses. The initial indication in favour of a design comes from the minimized change of effective stresses. Secondly, in order to acquire indications on the interference of compressibility, and consequent compressibility, $-\Delta u$, that may be involved, one may compare the successive Mohr circles of total stresses. These total stress Mohr circles furnish the indications for the starting adjustment of stress-path triaxial tests from which one would evaluate the deformability-compressibility $\Delta u$ that would be generated, due to the fact that the ideal incompressible condition is not fulfilled.

It is contended that the Bishop method of RDD analysis should be set aside, in as far as the use of the $W_{\mathrm{L} \max }$ and RDD flow net comparison may be adjusted to be conceptually more fruitful. The latter method begins by providing a clearcut indication of how an incompressible material would behave, and thereby incorporates the very tool for assessing the added influence of relative tendencies to volume changes.

\section{DESIGN CONSIDERATIONS AT THE CRITICAL WRAP-AROUND DETAIL}

The critical points of design of embankment dams are at discontinuities, and yet on such all-important details design recommendations are most scant. One such detail that repeats itself very frequently when the layout requires in-river concrete hydraulic structures, is the longitudinal transition from earth-rock section to concrete-gravity. The core-concrete contact is well-known to be a problem of great responsibility with respect to cracking and piping.

Fear of a preferential seepage path along the soil-concrete contact has frequently led to designs increasing the core contact to the US face and even to the DS face (serious error); 'creep ratio' recommendations have been used, flagrantly out of context or reasoning. The differential movements of any US clay section with regard to the concrete face, particularly towards the top, can only lead to questioning the respective sealing ability, especially if reservoir filling is rapid; along the US and DS faces well-graded purely cohesionless filter materials are imperative, and the use of steep compacted rockfill slopes minimizes costs by reducing length of concrete gravity section. As a matter of fact, if slopes are somewhat steeper than conventional the movements would only help tighten the clay contact against the concrete face.

Many are the options and details for such a design. The intention herein is merely to exemplify a design recommendation in favour of improved performance and significant economy. The basic point is to rely only on the face-to-face contact of core-concrete (analogous to an artificial, especially favourable abutment); it is of interest to incline the concrete-gravity block considerably US of the routine condition in order to meet the inclined core. Fig. 43 furnishes the simplest of indications that such adjustments can be made without difficulty; for prudence the possible advantages which can be derived from more appropriate uplift and earth pressure estimations than are routinely employed (Fig. 43(c)), have not been considered in a first approximation, so as to avoid adjustments regarding deformations and differential behaviour of 'soft' water loading and 'hard' earth-pressure loadings.

The second basic point comprises the introduction of a subvertical filter-transition along the slightly-skewed US-DS section that extends the plane of the core-concrete contact. One can thus change abruptly from an optimized 'homogeneous' earth section to an optimized earthrock section. The subvertical break that occurs due to different external slopes can be taken up easily by a fillet of rockfill. Fig. 44 compares the routine conventional design (perspective and plan A) with the improved design recommended herein (perspective and plan B). Details of improved filter-transition at the DS edge of the concrete block are not mentioned but are 


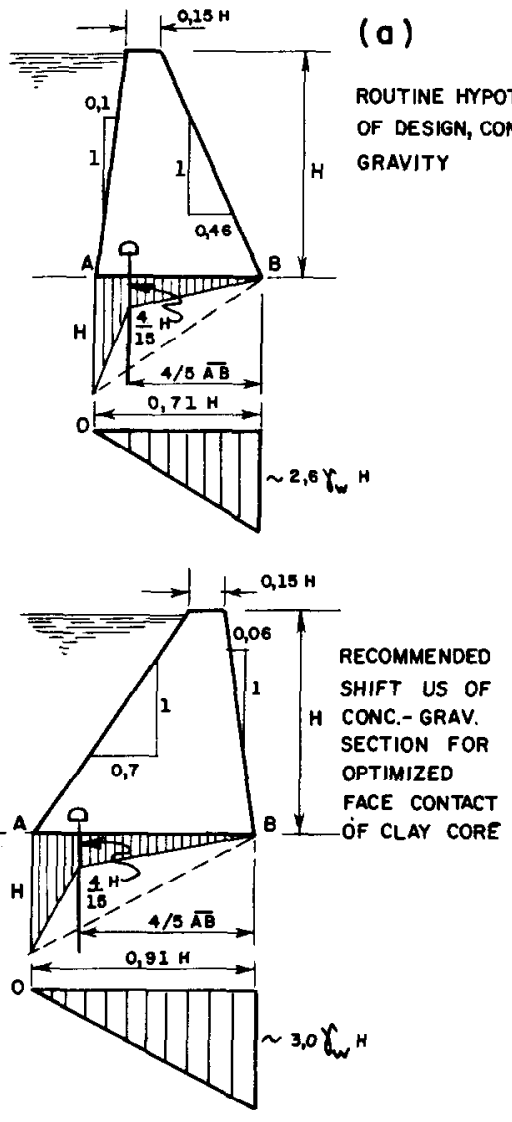

(b)

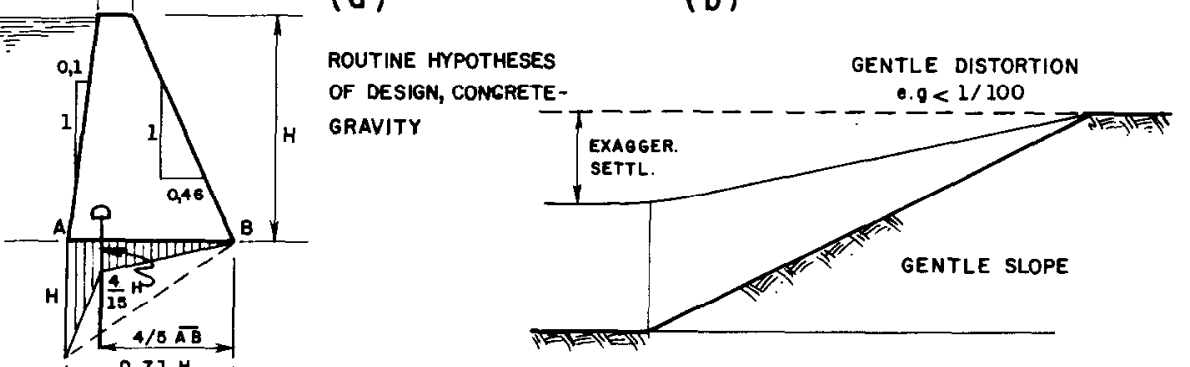

UNFAVOURABLE INTERM. SLOPE, CONTACT SHEAR RESIST. HIGHER THAN STRESSES : FORCES TENSION CRACKS

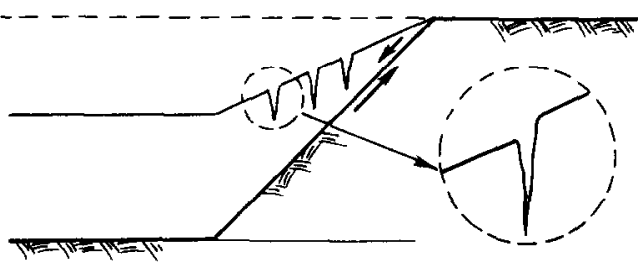

STEEP CONTACT, SHEAR RESIST. INCAPABLE OF SUPPORTING STRESS OBLIQUITIES : ACCEPTABLE, FAVOURS TIGHT SHEAR PLANE.
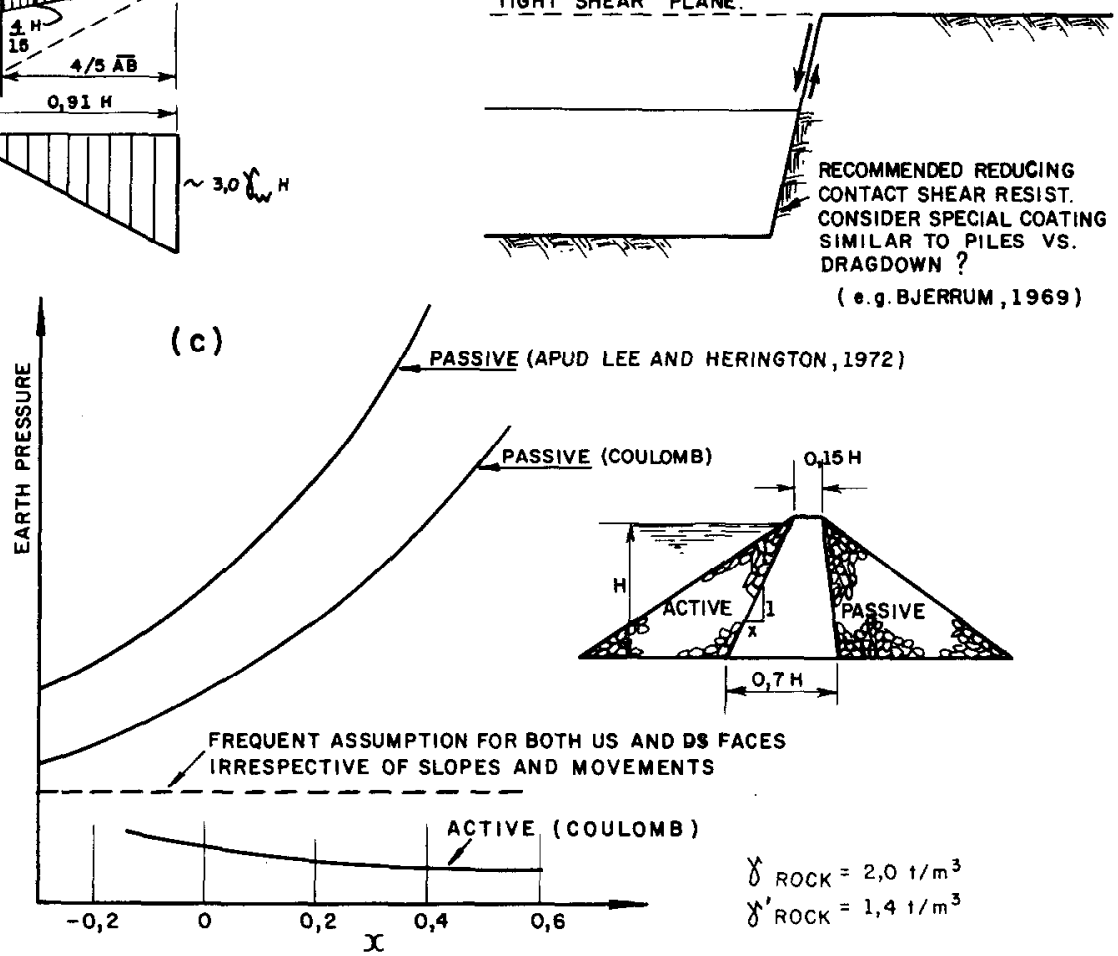

Fig. 43. Bases for optimization of wrap-around section and details 
very critical in any design of wrap-around; rockfill placed against edges and rigid faces naturally incorporates the biggest blocks, least rearranged into desired dense interlocking.

Finally, Fig. 43(b) indicates schematically the fact that critical conditions for tensile cracking as a function of abutment inclinations tend to occur precisely with slopes of intermediate steepness. Economic considerations forced concrete slopes of about 10:1 and satisfactory performance, doubtless because at the steep obliquity the differential movement is absorbed along shear cracks (tight). Along steep rock abutments ill-advised geotechnicians have felt more free to impose requirements of trimming to intermediate slopes, along which shear strength easily resists the stress obliquities (especially at the top) and consequently the differential movements are accommodated through tensile cracks, generating serious problems. The attempts to rely on tensile strengths and secondary variations of tensile strains to failure must be definitely set aside as dangerous, in accordance with DP 1, since tensile failures and subsequent piping erosions are quite definitely extreme-value dominated. The choice of appropriate statistical universe for design should explore weakening shear resistance as necessary, so as to guarantee that the conditioning differential movement will always be of shear. An engineering solution that might be explored could profit from the very successful coatings employed to minimize downdrag on piles (Bjerrum, 1969).

\section{CONCLUSION}

Design practices in embankment dams are heavily conditioned by an historical context that has contributed to important advances regarding behaviour pertaining to statistics of averages and amenable to routine computations. It is emphasized, however, that statistical chance may have contributed to the exclusion of extreme-value conditions in many cases, in a manner similar to the statistics with which a spillway may not be called to face any more than an average flood in the first year; one may not conclude from this that spillways may be designed for an average flood.

Embankment dams can be the safest and best dams if designed in such a manner that reservoir filling becomes almost irrelevant to the behaviour. A full interceptor drainage feature well inclined to upstream, coupled with the important internal blanket feature, achieves such a condition by which it is nearly immaterial whether it is efficiently draining, or clogged and fully impervious, so that one might demonstrate having guaranteed adequate safety against catastrophic mass instability of the DS slope even under the extreme condition of full hydrostatic pressure on the filter membrane rendered hypothetically fully clogged. Stereometric hindrance of particle movement by filter pore sizes, grouting for homogenization of a minimum buffer zone to exclude conditions of erratic highly pervious discontinuities, and favouring a minimized shear resistance zone to absorb differential movements without any hypothesis of tensile cracking, are examples of imperative prior design expedients of choice of statistical universe. The basic interceptor drainage feature separates the greatest proportion of the dam volume to simple functions wherein one acquires the right to play at computations and optimizations.

If prior exclusion of extreme value catastrophic failure has been respected as a sine qua non requirement to permit meaningful calculations, it will be concluded that significant economies may be introduced in both the US and the DS zones by use of the advances of the theoretical tools of geotechnics. Present slope stability computations employ $F$ values devoid of any meaning; one has hesitated to accept conscious reductions of required $F$ simply because the two entirely different classes of consideration, of extreme-value situations and of averages, were subconsciously mixed into the same requirement.

Respect for precedent is not the respect for a given practice, but for the cumulative distilled evidence of principles that derive from all practices. 


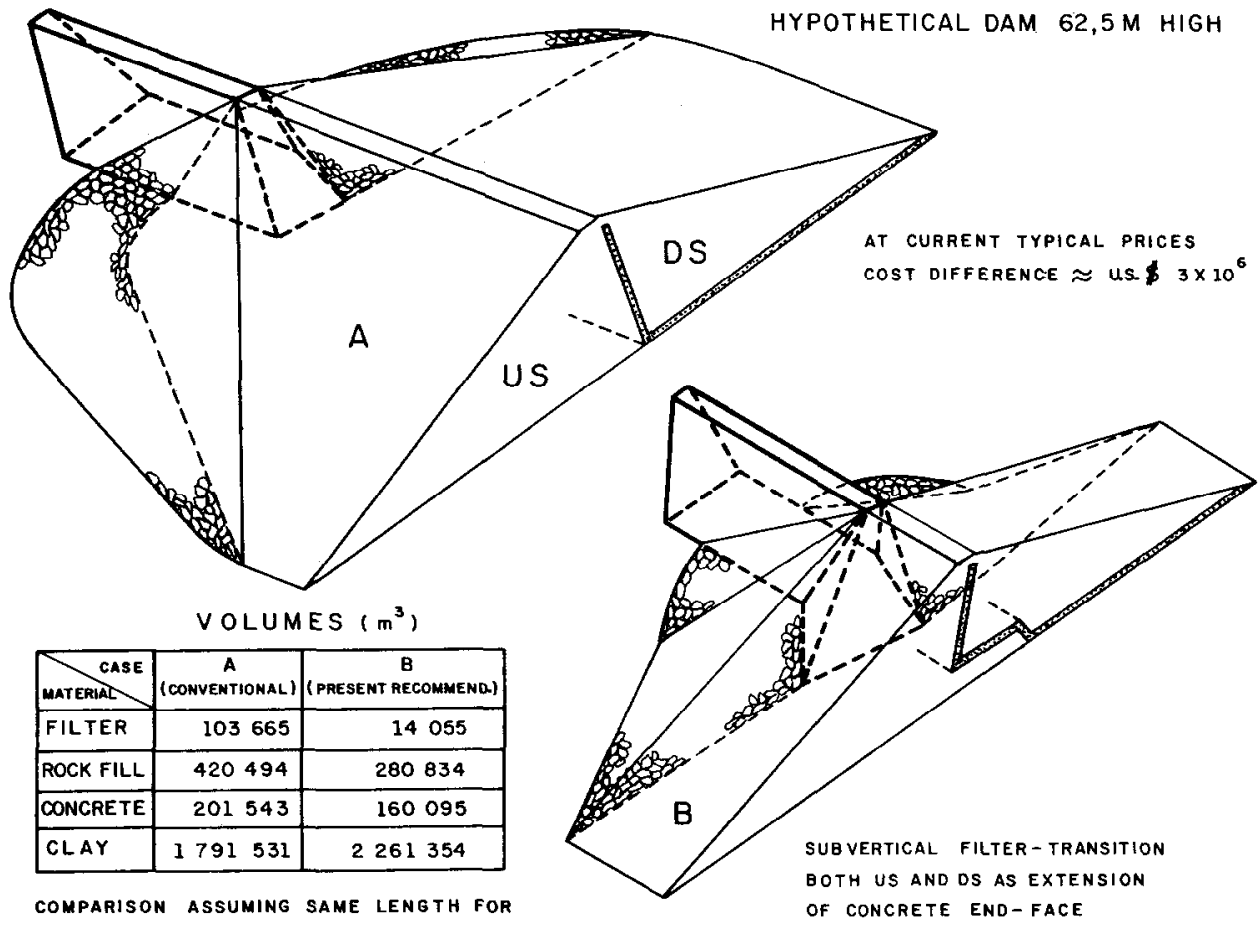
BOTH SOLUTIONS

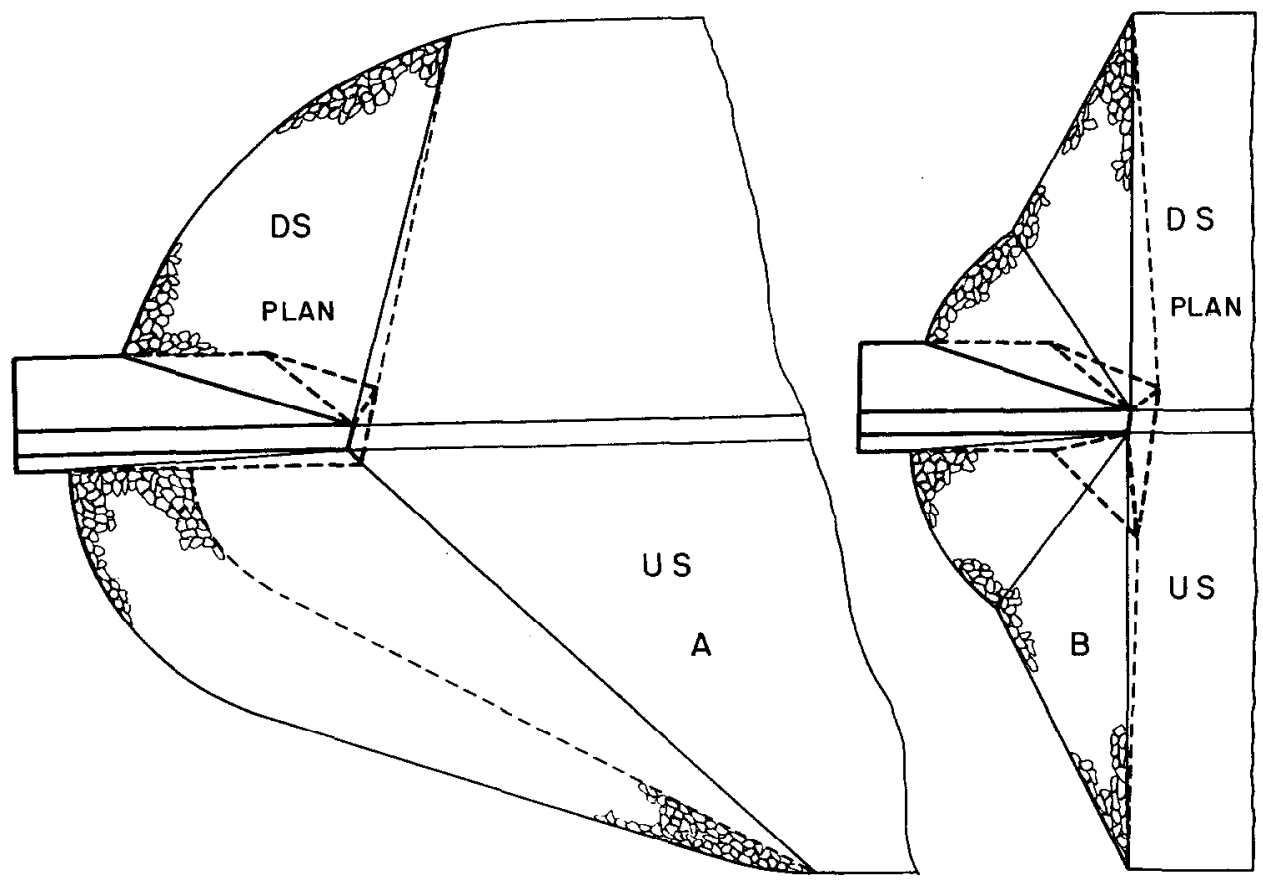

Fig. 44. Design recommendation for wrap-around: concrete core face-to-face contact and techmical and economic optimization 
It has been repeatedly mentioned that the civil engineer learns most from failures. He must indeed learn from failures (which are extreme events) how to avoid the physical universe associated with generating them. Subsequently it is within such chosen physical models, that by iterative Bayesian revisions of computations, as associated with average performance conditions of different degrees of satisfaction, he must gradually adjust his potent computational tools to reality. There is room for much ingenious engineering and considerable economies, once one has acquired the right to play at the game.

\section{ACKNOWLEDGEMENTS}

It is especially gratifying to acknowledge the enthusiastic assistance received from F. Massad, Waldemar Bon Jr and Ely B. Jardim of the computation centre of the Instituto de Pesquisas Tecnolōgicas, São Paulo, and also particularly from Messrs. J. B. Nogueira, Paulo Neme, Melvin Cymbalista, L. G. de Mello and M. Cepollina. Deep gratitude is also expressed to the many mentors who significantly influenced the thoughts expressed, and particularly to Dr Eulalio J. Badillo for recent stimulating exchanges of views. Finally, the most special thanks go to Drs Peter Vaughan, Angus Skinner and Mrs Janet Skinner, for the very kind and great help in improvement of the presentation of this Lecture.

\section{APPENDIX}

In Fig. 2, items (a) through (f) have been inserted as a summary reminder of further insufficiently dominated problems in the formulations of statistics and probabilities in geotechnical engineering, especially as may concern extreme value conditions and if associated with the requirements on design decisions of serious consequence and as the downstream stability of dams under full reservoir. Well recognized is the seriously aggravated extreme-value problem (Note (a)) associated with the very small size of sample (leading to wider scatter) both in the statistical sense of sample of the universe (number of tests) and of volume of test specimens or of points of field observation; McAnally (1975) suggests the investigation of two significant units, the ehus (equivalent homogeneous units, specimen interpreted under uniform averaged behaviour) and the sui (significant unit of influence). Indeed, whereas the frequently suggested use of 'least values' of test results as design parameters must be considered wrong and unacceptable under any concept, one lacks any help towards estimation of the suis in the face of specific problems (e.g. piping erosion). Meanwhile, whereas in the common applications of extreme value probability computations the occurrences are assumed randomly varying and independent in spatial and time frequency distributions (Notes (b), (c), (d)), it may be reasoned that such engineering overriding conditioners as compaction (which acts most where most needed) and the 'solid body' action imposed in slip movements and the corresponding conventional limit analyses, definitely impose correlation conditions' such as the Pretorius (1972) proven weakness correlation; and, because of the inexorable effects of time and stress-strain history in soils, the time-random extreme-value conditions are relaxed, it being likely that the risk due to a $1: 1000$ recurrence loading may be much higher if it occurs in the first year of the life of the new structure than if it occurs in the $N$ th year.

Finally, it is important to visualize the occurrence of induced extreme-value conditions (Notes (e),(f)) and within them to distinguish between opposite follow-up trends of the failure (first passage, e.g. Yang (1975)) initially triggered. For instance if there is piping erosion carrying away a small volume of sand, automatically the prevailing stresses are altered, by a shortening of the seepage path and by stress concentrations around the cavity; if the net stress concentrations turn out to be yet more unfavourable (e.g. tensile) there is progressive acceleration of the initially random extreme failure condition; on the contrary, however, there may be a rapid attenuation and stabilization if there are compressions and arching. If the unfavourable extreme-value localized behaviour comprises a chemically calalysed iron-oxide clogging, or a colloid-chemical alteration of clay-particle cluster equilibria, in similar fashion one should have to interpret the phenomena at play and whether Nature's tendencies of self exhaustion and 'antibody formation' will set in, or vice versa.

\section{REFERENCES}

Aitchison, G. D. et al. (1963). Post-construction deflocculation as a contributory factor in the failure of earth dams. Fourth Australia-New Zealand Conf. Soil Mech. Fdn Engng, p. 275.

Alonso, E. E. (1976). Risk analysis of slopes and its application to slopes in Canadian sensitive clays. Géotechnique 26, No. 3, 453-472.

Ambraseys, N. (1961). Correspondence. Géotechnique 21, No. 4, 362. 
Ang, A. H-S. \& Cornell, C. A. (1974). Reliability bases of structural safety and design. Proc. Am. Soc. Civ. Engrs 100, ST9, 1755.

Arulanandan, K. et al. (1975). Pore and eroding fluid influences on surface erosion of soil. Proc. Am. Soc. Civ. Engrs, GT1, 51.

Banks, D. C. \& Maclver, B. N. (1971). Discussion: Review of shearing strength of rockfill. Proc. Am. Soc. Civ. Engrs 97, SM5, 791.

Belbachir, K. et al. (1973). Observation des mouvements de la digue en terre de la Cheffia: influence des vidanges rapides. 11th ICOLD Congress, Madrid 4, 1007.

Bjerrum, L. et al. (1969). Reduction of negative skin friction on steel piles to rock. Proc. Seventh Int. Conf. Soil Mech. Fdn Engng, Mexico 2, 27.

Benjamin, J. R. (1974). Needed developments in probabilistic methods. Stanford Univ. Conf. on Probability in Civil Engineering, 13-19.

Bird, J. M. (1961). Uncertainties in embankment dam design. Jnl. Soil Mech. Fdn Div. Am. Soc. Civ. Engrs 87, SM3, Part 1, 33-68.

Bishop, A. W. (1954). The use of pore-pressure coefficients in practice. Géotechnique 4, No. 4, 148.

Bishop, A. W. (1957). Some factors controlling the pore pressures set up during the construction of earth dams. Proc. Fourth Int. Conf. Soil Mech. Fdn Engng, London 2, 294.

Bishop, A. W. (1964). Discussion. 8th ICOLD Congress, Edinburgh 5, 318.

Bishop, A. W. (1966). The strength of soils as engineering materials. Géotechnique 16, No. 2, 91.

Bishop, A. W. (1971). Shear strength parameters for undisturbed and remoulded soil specimens. Roscoe Memorial Volume. Stress-strain behaviour of soils, p. 3.

Bishop, A. W. \& Bjerrum, L. (1960). The relevance of the triaxial test to the solution of stability problems. Am. Soc. Civ. Engrs. Research Conf. Shear Strength of Cohesive Soils, 437.

Bishop, A. W. et al. (1960). Pore-pressure observations at Selset Dam. Proc. Conf. Pore Pressure and Suction in Soils, London, 91.

Bolognesi, A. J. L.et al. (1965). Behaviour of a single-line grout curtain. Proc. Sixth Int. Conf. Soil Mech. Fdn Engng, Montreal 2, 456.

Borges, J. F. \& Castanheta, M. (1971). Structural safety. Lisbon: Laboratório Nacional de Engenharia Civil.

Brand, E. W. \& Armstrong, R. (1968). Sand model studies of seepage through earth dams. Proc. Symp. Earth and Rockfill Dams 1, 188.

Breth, H. \& Günthcr, K. (1970). About the safety from subsurface erosion on earth dams subjected to underseepage. 10th ICOLD Congress, Montreal 2, 431.

Casagrande, A. (1937). Seepage through dams. Jnl New England Waterworks Association 51, No. 2.

Casagrande, A. (1961). Control of seepage through foundations and abutments of dams. Geotechnique 11, No. $3,161$.

Casagrande, A. (1965). Role of calculated risk in earthwork and foundation engineering. Jnl Am. Soc. Civ. Engrs 91, SM4, Part 1, 1-40.

Casagrande, A. et al. $(1960,1962,1963,1964)$. Investigation of stress-deformution and strength characteristics of compacted clays. Harvard Soil Mechanics Series, Nos 61, 65, 70, 74.

Catalán, J. M. \& Cornell, C. A. (1976). Earth slope reliability by a level-crossing method. Proc. Am. Soc. Engrs 102, GT6, 591.

Cedergren, H. R. (1960). Seepage requirements of filters and previous bases. Proc. Am. Soc. Civ. Engrs 86, SM5, 15.

Cedergren, H. R. (1967). Seepage, drainage and flow nets. New York: John Wiley \& Sons.

Chandler, R. J. \& Skempton, A. W. (1974). The design of permanent cutting slopes in still fissured clays. Géotechnique 24, No. 4, 457.

Charles, J. A. (1975). Strains developed in two rockfill dams during construction. Géotechnique 25, No. 2, 321.

Charles, J. A. (1976). The use of one-dimensional compression tests and elastic theory in predicting deformations of rockfill embankments. Building Res. Estab. Current Paper 51 CP 51/76.

Comité National Tchecoslovaque des Grands Barrages (1967). Rapport de synthèse No. 2. 9th ICOLD Congress, Istanbul 4, 585.

Cornell, C. A. (1971). First-order uncertainty analysis of soils deformation and stability. First Int. Conf. Applications of Statistics and Probability to Soil and Structural Engineering, Hong Kong, 130.

Coulomb, M. R. (1961). Discussion. Proc. Fifth Int. Conf. Soil Mech Fdn Engng 3, 360.

Cour, F. \& Vincent, A. (1973). Détermination de la perméabilité du noyau d'un barrage à partir des mesures in situ des pressions interstitielles. Géotechnique 23, No. 3, 383.

Dantu, P. (1968). Étude statistique des forces intergranulaires dans un milieu pulvérulent. Géotechnique 18, No. $1,50$.

D'Appolonia, D. J. et al. (1969). Sand compaction with vibratory rollers. Proc. Am. Soc. Civ. Engrs 95, SM1, 264.

Davidenkoff, R. (1955). De la composition des filtres dans les barrages en terre. 5th ICOLD Congress, Paris 1, 385. 
de Mello, V. F. B. et al. (1959). Construction period stability of homogeneous compacted earth dams, using Q tests. First Panam. Conf. Soil Mech. Fdn Engng, México 2, 673.

de Mello, V. F. B. (1965). Discussion. Proc. Sixth Int. Conf. Soil Mech. Fdn Engng, Montreal 3, 577.

de Mello, V. F. B. (1973). Panel discussion on Question 42. 11th ICOLD Congress, Madrid 5, 394.

de Mello, V. F. B. (1975). Panel discussion on analysis and design in geotechnics. Proc. Istanbul Conf. Soil Mech. Fdn Engng 3, 153.

de Mello, V. F. B. (1975b). Some lessons from unsuspected, real, and fictitious problems in earth dam engineering in Brazil. Proc. Sixth African Conf. Soil Mech. Fdn Engng, Durban 2, 285.

de Mello, V. F. B. (1975c). The philosophy of statistics and probability applied in soil engineering, general report. Second ICASP, Stuttgart 2, 63.

Department of Water Resources, California (1964). Investigation of failure, Baldwin Hills Reservoir. California Department of Water Resources.

Dixon, R. K. (1967). New techniques for studying seepage problems using models. Géotechnique 17, No. 3, 236.

Dupas, J. M. et al. (1973). Stabilité au glissement des ouvrages en terre, méthodes de calcul. Proc. Sixth Int. Conf. Soil Mech. Fdn Engng, Moscow 4.3, 156.

Fletcher, E. H. (1971). Random walk model of ideal granular mass. Proc. Am. Soc. Civ. Engrs 97, SM10, 1379.

Freitag, D. R. \& Green, A. J. (1962). Distribution of stresses on an unyielding surface beneath a pneumatic tire. High. Res. Bd Bull., 342, 14.

Freitag, D. R. \& Knight, J. S. (1962). Stresses in yielding soils under moving wheels and tracks. High. Res. Bd Bull., 342, 24.

Freitag, D. R. et al. (1965). Normal stresses at the tire-soil interface in yielding soils. High. Res. Bd Recd, No. $74,1$.

Frost, R. J. (1975). Four unusual cores for fill dams. Second Australia-New Zealand Conf. Geomech. Brisbane, 125.

Fumagalli, E. et al. (1970). Laboratory tests on materials and static models for rockfill dams. IOth ICOLD Congress, Montreal 1, 531.

Gamboa, J. \& Benassini, A. (1967). Behaviour of Netzahualcoyotl dam during construction. Proc. Am. Soc. Civ. Engrs 93, SM4, 211.

Gilboy, G. (1934). Mechanics of hydraulic fill dams. Jnl Boston Soc. Civ. Engrs 221, No. 3, 127.

Gordon, B. B. \& Wulff, J. G. (1964). Design and methods of construction Oroville Dam. 8th ICOLD Congress, Edinburgh 4, 877.

Gould, J. P. (1953). 'The compressibility of rolled fill materials determined from field observations. Third Int. Conf. Soil Mech. Fdn Engng, Zürich 2, 239.

Hall, J. W. (1968). Soil compaction investigation. US Army Corps of Engineers, Tech. Memo. No. 3-271. Vicksburg, Mississippi: US Army Corps of Engineers.

Ingles, O. G. \& Aitchison, G. D. (1969). Soil-water disequilibrium as a cause of subsidence in natural soils and earth embankments. Actes du Colloque de Tokyo. Association Internationale d'Hydrologie Scientifique.

Ingles, O. G. et al. (1969). Soil and water observations in Flagstaff Gully Dam, Tasmania. Soil Mechanics Tech. Report No. 11, CSIRO, Australia.

Iribarren (1965) cf. Jiménez Salas, J. A. et al. (1976). Geotecnia y cimientos 11, p. 608 . Madrid: Editorial Rueda.

Jaeger, J. C. (1971). Friction of rocks and stability of rock slopes. Géotechnique 21, No. 2, 97.

Johnson, S. J. (1974). Analysis and design relating to embankments. State-of-the-art: Analysis and design in geotechnical engineering 2,1. American Society of Civil Engineers.

Karpoff, K. P. (1955). The use of laboratory tests to develop design criteria for protective filters. Proc. Am. Soc. Test. Mat. 55, 1183.

Kassiff, G. et al. (1965). Analysis of filter requirements for compacted clays. Proc. Sixth Int. Conf. Soil Mech. Fdn Engng, Montreal 2, 495.

Kjellman, W. (1964). Unorthodox thoughts on filter criteria. Proc. Swedish Geotechnical Inst. 6.

Kolbuszewski, J. (1963). A contribution towards a universal specification of the limiting porosites of a granular mass. Proc. European Conf. Soil Mech. Fdn Engnrs, Wiesbaden 1, 265.

Kolbuszewski, J. \& Frederick, M. R. (1963). The significance of particle shape and size on the mechanical behaviour of granular materials. Proc. European Conf. Soil Mech. Fdn Engng, Wieshaden 1, 253.

Lambe, T. W. (1973). Predictions in soil engineering. Géotechnique 23, No. 2, 149-202.

Lane, E. W. (1935). Security from underseepage. Masonry dams on earth foundations. Trans. Am. Soc. Civ. Engrs, 1235-1272.

Lee, I. K. \& Herington (1972). A theoretical study of pressures acting on a rigid wall by a sloping earth or rock fill. Géotechnique 22, No. 1, 1.

Lieblein, Julius (1974). Efficient methods of extreme-value methodology. US Dept. of Commerce, National Bureau of Standards, Report NBSIR 74-602. 
Long, R. P. \& Zimmie, T. F. (1973). Mean pore sizes from flow measurements. Proc. Am. Soc. Civ. Engrs 99, SM7, 583.

Lowe, J. (1970). Recent development in the design and construction of earth and rockfill dams, General Report. IOth ICOLD Congress, Montreal 5, 19.

Mackellar, D. C. R. et al. (1974). Instrumentation of some embankment dams in Southern Africa. Symp. Field Instrumentation in Geotechnical Engineering, 249.

Markland, J. T. (1973). Risk of failure estimation for a predetermined non-circular slip surface. Géotechnique 23, No. 1, 120.

Marsal, R. J. (1963). Contact forces in soils and rockfill materials. Second Panam. Conf. Soil Mech. Fdn Engng, Brazil 2, 67.

Marsal, R. J. (1967). Grain forces in non-cohesive soils. Third Panam. Conf. Soil Mech. Fdn Engng, Caracas 1,227

Marsal, R. J. (1973). Mechanical properties of rockfill. Embankment dam engineering. Casagrande Volume. New York: J. Wiley and Sons.

Matsuo, M. \& Kuroda, K. (1974). Probabilistic approach to design of embankments. Soils and Fdns 14, No. 2,1 .

Matsuo, M. \& Asaoka, A. (1976). A statistical study on a conventional Safety Factor Method. Soils and Fdns 16, No. 1, 75.

McAnally, B. E. (1975). A method for the application of soil mechanics to non-homogeneous soils. Proc. Second Australia-New Zealand Conf. Geomech. Brisbane, 26.

McNulty (1965). An experimental study of arching in sand. PhD thesis, University of Illinois.

Morre, J. P. (1970). The factor of safety against undrained failure of a slope. Soils and Fdns 10, No. 3, 81.

Morgenstern, N. (1963). Stability charts for earth slopes during rapid drawdown. Géotechnique 13, No. 2, 121 .

Nakazima, Y. (1968). Study on the failure by piping in polder dykes for land reclamation. Soils and Fdns 8 , No. 4,30 .

Nawaz, K. S. \& Nagvi, S. A. (1970). Foundation treatment for underseepage control at Tarbela Dam Project. 10th ICOLD Congress, Montreal 2, 1117.

Nonveiller, E. (1957). Pore pressure in the Lokvorka Dam. Proc. Fourth Int. Conf. Soil Mech. Fdn Engng 2, 341.

Parry, R. H. G. (1972). Some propertics of hcavily overconsolidated clay at a site near Bedford. Géotechnique 22, No. 3, 485 .

Patel, V. J. \& Maheshwari, B. L. (1961). Pore pressure in earth dams. Proc. Fifth Int. Conf. Soil Mech. Fdn Engng 2, 687.

Patel, V. J. et al. (1964). Mechanics of inclined filters in earth dams. Jnl Am. Soc. Civ. Engrs 90, SM2, 87.

Paton, J. \& Semple, N. G. (1960). Investigation of the stability of an earth dam subject to rapid drawdown including details of pore pressures recorded during a controlled drawdown. Proc. Conf. Pore Pressure and Suction in Soils, 85.

Peck, R. B. (1969). Advantages and limitations of the observational method in applied soil mechanics. Géotechnique 19, No. 2, 171.

Penman, A. D. M. \& Charles, J. A. (1975). The quality and suitability of rockfill used in dam construction. Building Res. Estab. Current Paper CP 87/75.

Peter, P. (1970). Computation of the degree of filtration stability. 10th ICOLD Congress, Montreal 2, 191.

Pirotton, G. (1965). Essai de compactage par vibration d'enrochements tout-venants. Ponts et chaussées.

Poorooshasb, H. B. \& Forati, J. (1969). Embankment drainage after instantaneous drawdown. Proc. Seventh Int. Conf. Soil Mech. Fdn Engng, México 2, 349.

Pretorius, J. P. G. (1972). Weakness correlation and size effect in rock strength tests. Jnl S. Afr. Inst. Min. Metall. 72, No. 12.

Priest, S. D. \& Hudson, J. A. (1976). Discontinuity spacings in rock. Int. Jnl Rock Mech. Min. Sci. and Geomech. Abstr. 13, 135.

Reinius, E. (1948). The stability of the upstream slope of earth dams. Statens Kommitté for Byggnadsforskning, Meddelanden, No. 12.

Reinius, E. (1961). The stability of the downstream part of earth dams. Bulletin No. 59, Division of Hydraulics, Royal Institute of Technology, Sweden.

Reinius, E. (1973). Some stability properties of a dam having an inclined core. IIth ICOLD Congress, Madrid 3, 17.

Sabarly, F. (1968). Les injections et les drainages de fondation de barrages, en roches peu perméables. Géotechnique 18, No. 2, 229.

Shackel, B. \& Nettleton, A. F. S. (1971). The role of porosimetry in geomechanics. Proc. First AustraliaNew Zealand Conf. Geomech., Melbourne 1, 190.

Sherard, J. L. et al. (1972). Piping in earth dams of dispersive clay. Performance of Earth and Earth-supported Structures 1, Part 1, 589.

Sherard, J. L. et al. (1976). Identification and nature or dispersive soils. Jnl Am. Soc. Civ. Engrs, GT4, 286. 
Sills, G. C. (1975). An assessment, using three field studies, of the theoretical concept of the efficiency of drainage layers in an embankment. Building Res. Estab. Current Paper 9/75.

Silveira, A. (1965). An analysis of the problem of washing through in protective filters. Proc. Sixth Int. Conf. Soil Mech. Fdn Engng, Montreal 2, 551.

Silveira, A. (1966). Considerações sobre a distribuição dos vasios em solos granulares. Proc. Third Brazilian Congr. Soil Mech. Fdn Engng, Belo Horizonte 1, 47.

Silveira, A. (1967). Contribution to the design of drainage trenches for roads. Proc. Fourth Panam. Conf. Soil Mech. Fdn Engng, Caracas 2, 3.

Silveira, A. \& Peixoto Jr, T. L. (1975). On permeability of granular soils. Proc. Fifth Panam. Conf. Soil Mech. Fdn Engng, Buenos Aires 3, 149.

Silveira, A. et al. (1975). On void-size distribution of granular materials. Proc. Fifth Panam. Conf. Soil Mech. Fdn Engng, Buenos Aires 3, 161.

Skempton, A. W. (1961). Horizontal stresses in an over-consolidated Eocene clay. Proc. Fifth Int. Conf. Soil Mech. Fdn Engng, Paris 1, 351.

Skermer, N. A. (1973). Finite element analysis of El Infiernillo Dam. Canad. Geotech. Jnl 10, No. 2, 129.

Snow, D. T. (1968). Rock failure fracture spacings, openings, and porosities. Jnl Am. Soc. Civ. Engrs, SMI, 73.

Sowcrs, G. F. et al. (1957). The residual lateral pressures produced by compacting soils. Proc. Fourth Int. Conf. Soil Mech. Fdn Engng London 2, 243.

Spencer, E. (1967). A method of analysis of the stability of embankments assuming parallel inter-slice forces. Géotechnique 17, No. 1, 11.

Sridharan, A. et al. (1971). Pore size distribution studies. Proc. Am. Soc. Civ. Engrs 97, SM5, 771.

Thanikachalam, V. \& Sakthivadivel, R. (1973). Design of filter thickness based on application of queueing theory. Proc. Eighth Int. Conf. Soil Mech. Fdn Engng, Moscow 4.3, 174.

Thanikachalam, V. \& Sakthivadivel (1974). Grain size criteria for protective filtcrs, an enquiry. Soils and Foundations 14, No. 4, 13.

Tynes, W. O. (1968). Effect of fineness of continuously graded coarse aggregate on properties of concrete. US Waterways Experiment Station, Tech. Report No. 6-819.

US Bureau of Reclamation (1960). Earth manual ( first edition), pp. 322-323.

Vanmarcke, E. H. (1974). Decision analysis in dam safety monitoring. Proc. Engng Fdn Conf. Safety of Small Dams, 127-148.

Vaughan, P. R. (1974). General report: The applications of instrumentation in geotechnical engineering and the interpretation of their results. Proc. Symp. Field Instrumentation, 599.

Walker, L. K. \& Darvall, P. Le P. (1973). Dragdown on coated and uncoated piles. Proc. Eighth Int. Conf. Soil Mech. Fdn Engng, Moscow 2.1, 257.

Wallner, M. (1976). Propagation of sedimentation stable cement pastes in jointed rock. Publications $R$ WTH Univ. Aachen 2.

Waterways Experiment Station, US (1941). Investigation of filter requirements for underdrains. Technical Memorandum No. 183-1.

Wesley, L. D. (1973). Cluster hypothesis and the shear strength of a tropical red clay. Géotechnique 23, No. 1, 109.

Wilson, S. D. \& Squier, R. (1969). Earth and rockfill dams. State-of-the-art report. Proc. Seventh Int. Conf. Soil Mech. Fdn Engng, México State-of-the-art volume, 137.

Windisch, S. J. \& Soulie, M. (1970). Technique for study of granular materials. Proc. Am. Soc. Civ. Engrs 96, SM4, 1113.

Wolski, W. et al. (1970). Protection against piping of dam cores made of Flysh origin cohesive soils. Tenth ICOLD Congress, Montreal 1, 575.

Wright, S. G. et al. (1973). Accuracy of equilibrium slope stability analyses. Proc. Am. Soc. Civ. Engrs 99, SM10, 783.

Yang, J. N. (1975). Approximation to first passage probability. Jnl Engng Mech. Div. Am. Soc. Civ. Engrs 101, EM4, 361.

Zaslavsky, D. \& Kassif, G. (1965). Theoretical formulation of piping mechanism in cohesive soils. Géotechnique 15, No. $3,305$.

Zweck, H. \& Davidenkoff, R. (1957). Étude expérimentale des filtres de granulométrie uniforme. Proc. Fourth Int. Conf. Soil Mech. Fdn. Engng, London 2, 410.

\section{VOTE OF THANKS}

Dr Burland proposed a vote of thanks. In his introduction, Dr Vaughan emphasized Professor de Mello's prodigious energy and capacity for work. The Lecture this evening is a demonstration in itself of these attributes. I am not competent to comment on the more specialized aspects of the presentation. However, it seems clear that many of the ideas we 
have heard this evening are both challenging and controversial and as such will provoke much thought and discussion. This must surely be the measure of the success of a lecture and by that measure the Seventeenth Rankine Lecture will, I am sure, have proved to be outstanding. One of the distinguishing features of Professor de Mello's work is the refreshing and uninhibited manner in which he tackles problems. He refuses to be shackled by conventions, precedents theoretical idealizations and yet his thinking is always based on sound physical principles. He has a wonderful ability to perceive and to present Nature as she is rather than as others would like her to be. In this Lecture, Professor de Mello has concentrated on the design of embankment dams. Yet a particularly noteworthy feature of his Lecture, and one which transcends the specialist aspects of his topic, has been Professor de Mello's approach to, and philosophy of, engineering design. So much of what he has said applies to all aspects of ground engineering and indeed all branches of engineering. His five design principles can surely be applied to other fields of engineering endeavour. For example, Design Principle 1 embraces the requirement that wherever possible a structure should be ductile. Professor de Mello's thinking on the use of statistics and probabilistic methods is both timely and deserving of very careful study. Early in his Lecture Professor de Mello declared his commitment to tackling engineering problems that confront the developing nations. His message seems to me to be entirely relevant to those practising in the more developed countries as well. I suspect that all those designing engineering structures in this country could, with benefit, ask themselves whether their grasp of the 'first order approximations' is sufficient to warrant the time and expense of analysing with full frontal assault their way through problems rather than designing their way round them. I first got to know Victor de Mello and his wife Maria Louisa, who is with us this evening, at the sixth Regional Conference for Africa in 1975. Prior to the conference a small group, including the de Mellos, went on a pre-conference tour. I know I speak for that group when I say that for some weeks afterwards we were living at what can only be described as 'heightened' intensity. Mr Chairman, the Seventeenth Rankine Lecture will be widely read and discussed. Those of us here tonight have had the unique privilege and good fortune of actually having listened to it. I speak for us all when I say that we leave this Lecture theatre with a sense of 'heightened intensity' and a deeper insight into the behaviour of Mother Earth. Mr Chairman, Ladies and Gentlemen, it gives me the utmost pleasure to propose a sincere vote of thanks to Professor Victor de Mello for his outstanding Lecture.

The vote of thanks was accorded with acclamation 